\title{
KASL clinical practice guidelines for liver cirrhosis: Ascites and related complications
}

\author{
The Korean Association for the Study of the Liver (KASL)
}

Keywords: Cirrhosis; Ascites; Guideline

\section{PREAMBLE}

\begin{abstract}
Aims
Ascites is one of the most common complications of liver cirrhosis along with variceal bleeding and hepatic encephalopathy. It is often the first sign of decompensated cirrhosis with portal hypertension. Patients with compensated cirrhosis progress to decompensated cirrhosis at a rate of $5-7 \%$ per year, and about $50 \%$ of the cases develop ascites within 10 years after diagnosis of liver cirrhosis. The 1-year and 2-year survival rates of patients with decompensated cirrhosis complicated with ascites are $60 \%$ and $45 \%$, respectively, which is significantly lower than the 1-year and 2 -year survival rates (95\% and $90 \%$ ) of patients with compensated cirrhosis. ${ }^{1,2}$
\end{abstract}

According to the National Statistical Office, the mortality rate due to liver disease was 13.4 per 100,000 persons in 2015 , the eighth highest cause of death in Korea. It has declined compared to 2005 (mortality rate due to liver disease was 17.2 per 100,000 persons, the sixth highest cause of death cause in Korea). Liver cirrhosis and hepatocellular carcinoma (HCC) are a major cause of death in patients with chronic liver disease. Korean Association for the Study of the Liver (KASL) published guidelines for the management of liver cirrhosis in 2005 which proposed guidelines for the treatment of major complications of liver cirrhosis, including ascites, hepatorenal syndrome, varices and hepatic encephalopathy. In 2011, the guidelines for the management of liver cirrhosis were revised to cover diagnosis of liver cirrhosis, anti-fibrotic treatment of cirrhosis, variceal bleeding, ascites, and hepatic encephalopathy. Six years after the publication of the 2011 guidelines, the need arose to revise the guidelines for liver cirrhosis based on new evidence accumulated. Therefore, KASL revised the

\begin{abstract}
Abbreviations:
ADA, adenosine deaminase; ADQI, Acute Dialysis Quality Initiative; AFB, acidfast bacilli; ALT, alanine aminotransferase; AKI, acute kidney injury; AKIN, Acute Kidney Injury Network; BCAA, branched-chain amino acid; CART, cell-free and concentrated ascites reinfusion therapy; CEA, carcinoembryonic antigen; CKD, chronic kidney disease; $\mathrm{Cl}$, confidence interval; eGFR, estimated glomerular filtration rate; ESBL, extended-spectrum beta-lactamase; GFR, glomerular filtration rate; HCC, hepatocellular carcinoma; $\mathrm{HH}$, hepatic hydrothorax; HR, hazard ratio; HRS, hepatorenal syndrome; ICA, International Club of Ascites; KASL, The Korean Association for the Study of the Liver; KDIGO, Kidney Disease Improving Global Outcomes; LDH, lactate dehydrogenase; LVP, largevolume paracentesis; MARS, molecular adsorbent recirculating system; MDRD, Modification of Diet in Renal Disease; MELD, Model for End-Stage Liver Disease; NSAIDs, non-steroidal anti-inflammatory drugs; NSBBs, Non-selective betablockers; OR, odds ratio; PMN, polymorphonuclear leukocyte; PPIs, proton pump inhibitors; RBCs, red blood cells; SAAG, serum-ascites albumin gradient; SBP, spontaneous bacterial peritonitis; SBPL, spontaneous bacterial pleuritis; $\mathrm{SCr}$, serum creatinine; SIADH, syndrome of inappropriate antidiuretic hormone secretion; SPAG, serum to pleural fluid albumin gradient; TIPS, transjugular intrahepatic portal-systemic shunt
\end{abstract}

Corresponding author: The Korean Association for the Study of the Liver (KASL) (Committee Chair: Yong-Han Paik)

Room A1210 MapoTrapalace, 53 Mapo-daero, Mapo-gu, Seoul 04158 Korea

Tel: +82-2-703-0051, Fax: +82-2-703-0071

E-mail: kasl@kams.or.kr

"KASL Committee for Clinical Practice Guidelines for Liver Cirrhosis: Ascites and Related Complications:

Yong-Han Paik (Committee Chair, Sungkyunkwan University Schoo of Medicine), Yeon Seok Seo (Korea University College of Medicine), Moon Young Kim (Yonsei University Wonju College of Medicine), Jun Yong Park (Yonsei University College of Medicine), Ki Tae Suk (Hallym University College of Medicine), Do Seon Song (College of Medicine, The Catholic University), Dong Hyun Sinn (Sungkyunkwan University School of Medicine), Jeong-Hoon Lee (Seoul National University College of Medicine), Soung Won Jeong (Soonchunhyang University College of Medicine), and Young Kul Jung (Korea University College of Medicine)

Received : Mar. 27, 2018/ Accepted : Apr. 6, 2018 
The Korean Association for the Study of the Liver (KASL) Treatment guideline for ascites and related complications

guidelines for ascites, a major complication of liver cirrhosis. The revisions were based on a systematic approach that reflects evidence-based medicine and expert opinions. This guideline is intended to be used as a practical reference for the treatment of cirrhotic patients with ascites and related complications, and they do not represent an absolute standard of care. The best choice for each patient's care will vary from case to case, and the judgment of the treating physician is important. This guideline may change when medical evidence based on new research findings is accumulated in the future.

\section{Target population}

The guideline targets patients with ascites and related complications (e.g. refractory ascites, spontaneous bacterial peritonitis, hyponatremia, acute kidney injury, hepatorenal syndrome) due to liver cirrhosis. The guideline is intended for clinicians and medical personnels who are in charge of the diagnosis and treatment of patients with liver cirrhosis. This guideline also intended to provide useful clinical information and directions for resident physicians and fellows in training, practitioners, and trainers.

\section{The development, funding, and revision process}

Comprising 10 hepatologists, The Clinical Practice Guideline Committee for Liver Cirrhosis: Ascites and Related Complications ('The Committee') was organized according to the proposal and approval of the KASL Board of Executives. Funding for the revisions was provided by KASL. Each committee member collected and analyzed source data in his or her own field, and the mem- bers then wrote the manuscript together.

\section{Literature review}

The Committee systematically collected and reviewed international and domestic literature published in PubMed, MEDLINE, KoreaMed, and other databases. In addition to published articles, abstracts of important meetings published before August 2017 were evaluated. Key words and key questions were selected using PICO (Patient/Problem, Intervention, Comparison, Outcome) assessments.

\section{Levels of evidence and grades of recommendation}

The evidence and recommendations were graded according to the Grading of Recommendations, Assessment, Development, and Evaluation (GRADE) system, with minor modifications (Table 1). ${ }^{3}$ Levels of evidence were determined based on the possibility of change in a results or clinical outcome after further research. They were described as high (A), moderate (B), or low (C), and were characterized as follows: $A$, the highest level of evidence with the smallest possibility of change in the conclusion; B, a moderate level of potential change; and $C$, the lowest level of evidence with the greatest possibility of change. The strength of a recommendation was also classified according to the GRADE system. Each study was classified as a strong recommendation (1) or a weak recommendation (2), based on the quality of evidence, the balance between the desirable and undesirable effect of an intervention, and socioeconomic aspects (including cost and availability). Each recommendation was ultimately graded as A1, A2, B1, B2,

Table 1. Grading of Recommendations, Assessment, Development, and Evaluation (GRADE)

\begin{tabular}{|c|c|}
\hline & Criteria \\
\hline \multicolumn{2}{|c|}{ Quality of evidence } \\
\hline $\operatorname{High}(A)$ & Further research is very unlikely to change our confidence in the estimate of effect. \\
\hline Moderate (B) & $\begin{array}{l}\text { Further research is likely to have an important impact on our confidence in the estimate of effect and may } \\
\text { change the estimate. }\end{array}$ \\
\hline $\operatorname{Low}(\mathrm{C})$ & $\begin{array}{l}\text { Further research is very likely to have an important impact on our confidence in the estimate of effect and is } \\
\text { likely to change the estimate. Any change of estimate is uncertain. }\end{array}$ \\
\hline \multicolumn{2}{|c|}{ Strength of recommendation } \\
\hline Strong (1) & $\begin{array}{l}\text { Factors influencing the strength of the recommendation included the quality of the evidence, presumed } \\
\text { patient-important outcomes, and cost. }\end{array}$ \\
\hline Weak (2) & $\begin{array}{l}\text { Variability in preference and values, or more uncertainty. Recommendation is made with less certainty, } \\
\text { higher cost, or resource consumption. }\end{array}$ \\
\hline
\end{tabular}

Of the quality levels of evidence, we excluded "very low quality (D)" in our guidelines for convenience. This was originally included in the GRADE system. 
$\mathrm{C} 1$, or $\mathrm{C} 2$, thereby combining the level of evidence $(\mathrm{A}-\mathrm{C})$ and the strength of the recommendation (1 or 2).

\section{List of key questions}

The Committee selected the following key questions as key components to be covered in this guideline.

1. How to diagnose ascites due to liver cirrhosis?

2. How to treat ascites due to liver cirrhosis?

3. How to manage the nutrition of patients with liver cirrhosis and ascites?

4. How to diagnose and treat refractory ascites?

5. How to treat hyponatremia related to liver cirrhosis?

6. How to diagnose spontaneous bacterial peritonitis?

7. How to treat community-acquired spontaneous bacterial peritonitis?

8. How to treat hospital-acquired spontaneous bacterial peritonitis?

9. How to diagnose acute kidney injury and hepatorenal syndrome in patients with liver cirrhosis?

10. How to treat acute kidney injury and hepatorenal syndrome in patients with liver cirrhosis?

11. How to treat hepatic hydrothorax and abdominal hernia?

12. What should be considered when using drugs in patients with liver cirrhosis?

\section{Review of the manuscript and approval process}

Each manuscript written by members was reviewed and approved through meetings of the Committee. The quality of each manuscript and the academic integrity of the contents were evalu- ated based on the standards suggested by AGREE II (Appraisal of Guidelines for Research and Evaluation II). The guidelines were reviewed at a meeting of an external review board composed of seven KASL members. The guideline was further modified following opinions aired at a public hearing and at a symposium open to all KASL members. The final manuscript was approved by the KASL Board of Executives.

\section{Release of the guidelines and a plan for updates}

The revised guideline (The KASL Clinical Practice Guidelines for Liver Cirrhosis: Ascites and Related Complications) was released at a KASL meeting on 23 November 2017. The Korean version of the guideline is available on the KASL website (http://www.kasl. org). Future revisions will be conducted when necessary for the promotion of health in South Korea, following an accumulation of research on the management of ascites and related complications.

\section{ASCITES DUE TO CIRRHOSIS}

\section{Diagnosis}

\section{History}

Approximately $75-85 \%$ of patients presenting with ascites in foreign countries, ${ }^{4-6}$ and $60 \%$ in a Korean single center, ${ }^{7}$ have been reported to have liver cirrhosis as the underlying cause. Ascites is also caused by malignancy, tuberculosis, heart failure, pancreatic disease, and nephrotic syndrome (Table 2). Therefore, the initial diagnosis of ascites needs careful examination for differential diagnosis.

Table 2. Differential diagnosis of ascites

\begin{tabular}{lc}
\hline Classification & Cause of ascites \\
\hline Liver disease & Liver cirrhosis \\
Acute liver failure \\
Budd-Chiari syndrome \\
Non-hepatic cause & Sinusoidal obstruction syndrome \\
& Cancer (peritoneal carcinomatosis, massive liver metastases, etc.) \\
Tuberculous peritonitis \\
Heart failure \\
Pancreatitis \\
Nephrotic syndrome \\
Postoperative lymphatic leak \\
Myxedema \\
Mixed ascites \\
\hline
\end{tabular}


The Korean Association for the Study of the Liver (KASL) Treatment guideline for ascites and related complications

\section{Physical examination}

When there is abdomen swelling, it should lead to percussion of the flanks. One should perform shifting dullness and fluid wave tests. The fluid wave test is inconvenient and performs less well than the shifting dullness test. ${ }^{8}$ Generally $1,500 \mathrm{~mL}$ of fluid must be present before flank dullness is detected. If there is no flank dullness, the patient has less than a 10\% chance of having ascites. ${ }^{8}$ The physical examination for finding ascites in the obese patient is difficult. An abdominal ultrasound can be helpful to confirm ascites. An abdominal ultrasound can detect ascites only when it exist over $100 \mathrm{~mL}{ }^{9}$ Ascites is classified as Grade 1, 2, and 3 according to the amount of ascites. Grade 1 is detected only by imaging techniques, including abdominal sonography. Grade 2 ascites is easily identified by visual inspection and palpation. Grade 3 ascites shows profound distension of the abdomen, as in massive or tense ascites. Patients with heart failure can develop ascites where jugular venous distension is present. Evaluation of blood concentrations of brain natriuretic peptide or pro-brain natriuretic peptide can help discriminate between ascites from heart failure and ascites from cirrhosis. ${ }^{10}$

\section{Abdominal paracentesis}

Abdominal paracentesis with ascitic fluid analysis is the most rapid and efficient test to diagnose ascites. ${ }^{11,12}$ It can ensure the cause of ascites ${ }^{4}$ and the infection. ${ }^{12} \mathrm{~A}$ diagnostic paracentesis should be performed 1) in all patients with new-onset Grade 2 or 3 ascites, 2) in all patients hospitalized for worsening ascites, and 3) with any complication of cirrhosis, including fever, abdominal pain, gastrointestinal bleeding, hepatic encephalopathy, hypotension, or renal insufficiency. ${ }^{13}$ Suitable sites for paracentesis include the left or right lower quadrant areas. The left lower quadrant is preferred because of the greater depth of ascites and the thinner abdominal wall. ${ }^{14}$ Severe hemorrhage occurs in $0.2-2.2 \%$ of puncures, ${ }^{15-17}$ and death is rare. ${ }^{15-21}$ In one study, the death rate was $0.02 \%$ among 4,729 prodedures. ${ }^{17}$ Hemorrhage following paracentesis can occur from the direct puncture of a superficial abdominal wall vein (such as the superficial epigastric vein), of mesenteric varices, or of intraperitoneal collateral vessels (including the paraumbilical vein). ${ }^{15,19,22}$ Bleeding can also appear from a direct puncture of the inferior epigastric artery or the deep circumflex iliac artery. ${ }^{23,24}$ Although most reports detected symptoms during the first 6 to $24 \mathrm{~h}$ after paracentesis, delayed symptoms up to 1 week after the procedure have also been described. ${ }^{15,25}$ Most bleeding can be handled by medical treatment, such as fluid resuscitation, transfusion, and correction of coagulation disorders.
However, transcatheter coil embolization ${ }^{23}$ or laparoscopy with vessel ligature ${ }^{25}$ should be considered when hemodynamic instability persists despite medical treatment. Alternatively, a transjugular intrahepatic portal-systemic shunt (TIPS) ${ }^{21}$ or liver transplantation $^{15}$ can be considered in cases of severe bleeding.

When there is clinically evident hyperfibrinolysis or disseminated intravascular coagulation, paracentesis should be prohibited. Careful attention is needed for patients with severe liver dysfunction and severe renal dysfunction, as risk of complication is higher. ${ }^{17}$ Pregnancy, severe intestinal distension, and a history of extensive abdominal surgery are relative contraindications for paracentesis; in these cases, abdominal sonography can be helpful. ${ }^{26}$ The routine prophylactic use of fresh frozen plasma or platelets before paracentesis is not generally recommended. ${ }^{27-29}$ However, patients with severe coagulopathy require special precautions for bleeding, and some physicians prefer to transfuse blood products (fresh frozen plasma and/or platelets) before paracentesis. Further study is needed to see whether these prophylactic managements are helpful.

\section{Ascitic fluid analysis and differential diagnosis}

Once ascitic fluid has been extracted, its gross appearance should be examined. Turbid fluid can result from the presence of infection or tumor cells. White, milky fluid indicates a triglyceride level $>200 \mathrm{mg} / \mathrm{dL}$ (and often $>1,000 \mathrm{mg} / \mathrm{dL}$ ), which is the hallmark of chylous ascites. Chylous ascites results from lymphatic disruption that may occur with trauma, cirrhosis, tumor, tuberculosis, or certain congenital abnormalities. Dark brown fluid can reflect a high bilirubin concentration and indicates biliary tract disruption. Black fluid may indicate the presence of pancreatic necrosis or metastatic melanoma. In uncomplicated ascites due to cirrhosis, screening tests (e.g. cell count and differential, albumin, and total protein concentration) are performed on the initial specimen (Table 3). The serum albumin level should be measured simultaneously to permit calculation of the serum-ascites albumin gradient (SAAG). Calculating the SAAG involves measuring the serum albumin concentration and the ascitic fluid specimens obtained on the same day, and subtracting the ascitic fluid value from the serum value. If the SAAG is greater than or equal to 1.1 $\mathrm{g} / \mathrm{dL}$, the patient has portal hypertension, with approximately 97\% accuracy. ${ }^{4}$ The SAAG is useful for distinguishing ascites caused by portal hypertension from nonportal hypertensive ascites. Possible causes of SAAG values $\geq 1.1 \mathrm{~g} / \mathrm{dL}$ include liver cirrhosis, cardiac ascites, hepatic vein thrombosis (Budd-Chiari syndrome), sinusoidal obstruction syndrome (veno-occlusive disease), 
or massive liver metastases. A SAAG value $<1.1 \mathrm{~g} / \mathrm{dL}$ indicates that the ascites is not related to portal hypertension, and possible causes are tuberculous peritonitis, peritoneal carcinomatosis, or pancreatic ascites (Fig. 1).

Patients undergoing serial therapeutic paracentesis are typically tested only for cell count and differential. ${ }^{30,31}$ Repeating tests of total protein and SAAG on fluid removed therapeutically is usually not needed. If ascitic fluid infection is suspected (fever, abdominal pain, or unexplained encephalopathy, acidosis, azotemia, hypo- tension, or hypothermia), bacterial culture of the fluid in aerobic and anaerobic blood culture bottles inoculated at the bedside should be performed. Additional testing may be performed in each clinical situation (Table 3). When cancer is suspected, ascitic fluid cytology is performed. The ascitic fluid cytology is positive only in the setting of peritoneal carcinomatosis. The sensitivity of cytology in detecting peritoneal carcinomatosis is $96.7 \%$ if three samples (from different paracentesis procedures) are sent and processed promptly. ${ }^{32}$ Carcinoembryonic antigen (CEA) of the as-

Table 3. Ascitic fluid analysis

\begin{tabular}{lcc}
\hline & Analysis & Diagnosis \\
\hline Routine & Cell count and differential & Albumin \\
Total protein & Gram stain & Ascites differential diagnosis, \\
Optional & Spontaneous bacterial peritonitis \\
Culture in blood culture bottle & Bacterial infection \\
Acid-fast bacilli smear and culture & Malignant ascites \\
Adenosine deaminase & Tuberculous peritonitis \\
Lactate dehydrogenase & Glucose & Secondary bacterial peritonitis \\
Carcinoembryonic antigen & Plkaline phosphatase \\
Amylase & Pancreatic ascites \\
Triglyceride & Chylous ascites \\
Bilirubin & Biliary tract perforation
\end{tabular}

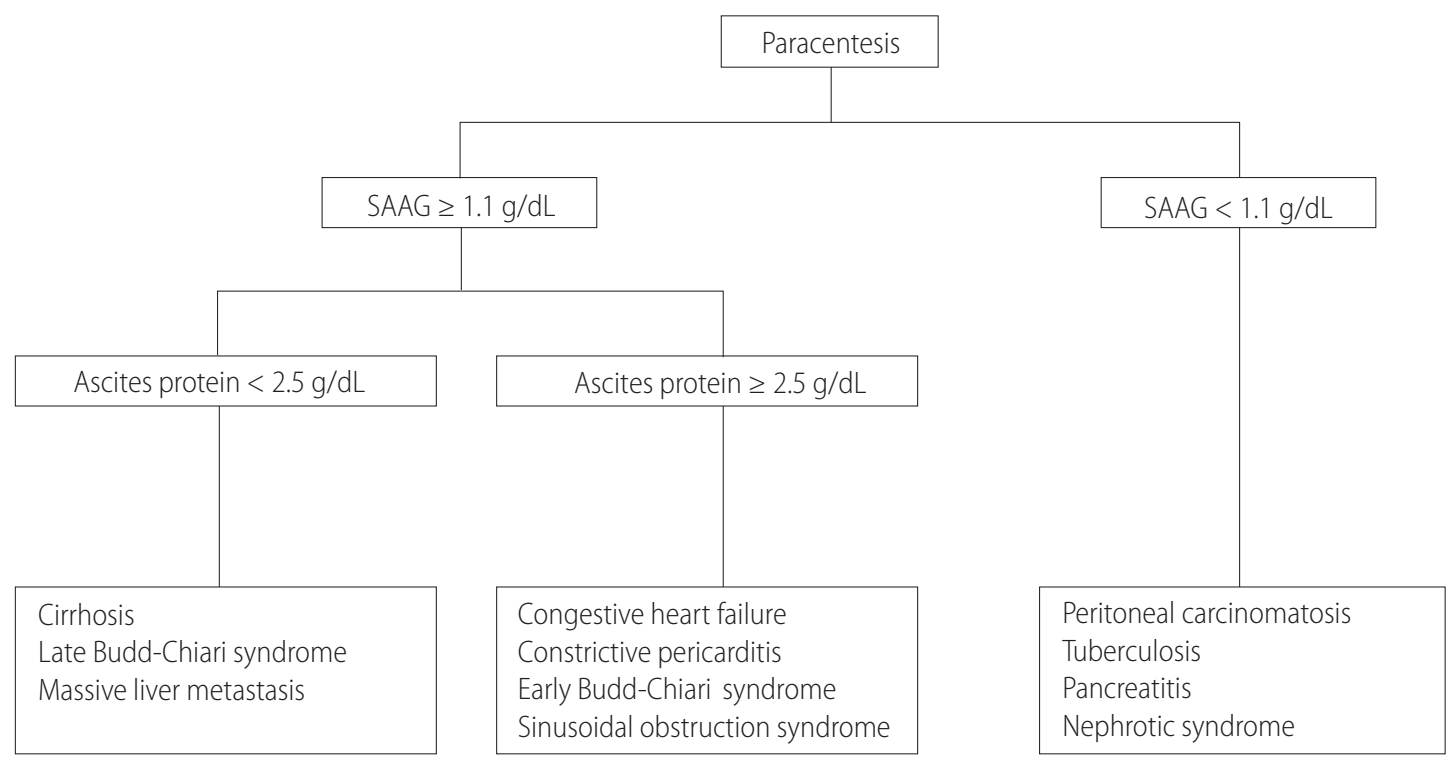

Figure 1. Algorithm to differentiate the cause of ascites. SAAG, serum-ascites albumin gradient. 
The Korean Association for the Study of the Liver (KASL) Treatment guideline for ascites and related complications

citic fluid does not seem to be sensitive enough to diagnose malignancy-related ascites. However, due to its high specificity, high levels of CEA are more likely to be malignancy-related ascites. ${ }^{33}$ Tuberculous peritonitis is typically associated with ascitic fluid lymphocytosis but can be difficult to diagnose by paracentesis. When tuberculous peritonitis is suspected, an acid-fast bacilli (AFB) smear, culture, and adenosine deaminase (ADA) assay can be performed. The sensitivity of a smear of ascitic fluid for mycobacteria ranges from $0 \%$ to $86 \%,{ }^{34-36}$ and the sensitivity of a fluid culture for mycobacteria ranges from $20 \%{ }^{37}$ to $57-83 \% .{ }^{35,38,39}$ In patients with tuberculous peritonitis without cirrhosis, the ADA assay shows a sensitivity of $100 \%$ and a specificity of $96.6-100 \%$ when the ADA value is higher than 32-40 U/L. ${ }^{40-43}$ However, tuberculous peritonitis with cirrhotic ascites yields low total protein in the ascites fluid, and the ADA assay shows low sensitivity. ${ }^{44}$ Therefore, patients with liver cirrhosis should carefully rule out a diagnosis of tuberculous peritonitis when they have a low ADA value. In one Korean study of patients with liver cirrhosis, the ADA assay showed a sensitivity of $91.7 \%$, a specificity of $92 \%$, and an accuracy of $91.9 \%$ when an ADA cut-off value of $32 \mathrm{U} / \mathrm{L}$ was used. ${ }^{45} \mathrm{~A}$ recent study of patients with tuberculous peritonitis with cirrhotic ascites also showed a sensitivity of $100 \%$ and a specificity of $93.3 \%$ when an ADA cut-off value of $27 \mathrm{U} / \mathrm{L}$ was used. ${ }^{46}$ These studies indicate that ADA can be useful to diagnose tuberculous peritonitis with cirrhotic ascites. Patients at high risk for tuberculous peritonitis (e.g. recent immigration from an endemic area or acquired immunodeficiency syndrome) should have testing for mycobacteria on the first ascitic fluid specimen ${ }^{47}$ Polymerase chain reaction testing for mycobacteria or laparoscopy with biopsy and mycobacterial culture of tubercles are the most rapid and accurate methods of diagnosing tuberculous peritonitis. When secondary peritonitis resulting from a perforated hollow viscus is suspected, ascitic glucose and lactate dehydrogenase (LDH) levels can be measured. Secondary peritonitis is suggested by an ascitic glucose level $<50 \mathrm{mg} / \mathrm{dL}$, or an ascitic LDH level higher than the serum LDH level. ${ }^{48}$ An elevation of CEA ( $>5 \mathrm{ng} /$ $\mathrm{mL}$ ) or alkaline phosphatase ( $>240 \mathrm{U} / \mathrm{L}$ ) can also be helpful for the diagnosis of secondary peritonitis resulting from a perforated hollow viscus ${ }^{49}$ When pancreatic ascites is suspected, the ascitic amylase level should be measured, which is typically $>1,000 \mathrm{mg} /$ $\mathrm{dL}$. Rarely, trauma or iatrogenic origin can cause urinary ascites by injury of the bladder or ureter. Elevated levels of urea and creatinine in the ascites fluid can be clues for diagnosis. ${ }^{50}$ When the cause of ascites remains uncertain, laparotomy or laparoscopy with peritoneal biopsy for histology and culture remains the gold standard. Approximately $5 \%$ of patients with ascites can have two or more causes of ascites formation, including liver cirrhosis, peritoneal carcinomatosis or tuberculous peritonitis (Table 2). ${ }^{4}$ In case of obvious cause for ascites, some cases are finally found to have multiple causes of ascites composition (e.g. heart failure, diabetic nephropathy, and cirrhosis). ${ }^{51}$ In this setting, the sum of predisposing causes makes progress to sodium and water retention, even though each factors might not be enough to cause fluid retention. Patients with ascites (or pleural fluid of any cause) have an elevated serum CA125 level; when ascites is controlled, the CA125 level decreases rapidly. ${ }^{52,53}$ CA125 levels are elevated when mesothelial cells are under pressure from the presence of fluid, making this test very nonspecific. CA125 levels is not helpful in the differential diagnosis of ascites. It is not recommended in patients with any type of ascites.

\section{[Recommendations]}

1. A diagnostic paracentesis should be performed in all patients with new onset Grade 2 or 3 ascites, in all patients hospitalized for worsening of ascites, and in all patients with any complication of cirrhosis (including fever, abdominal pain, gastrointestinal bleeding, hepatic encephalopathy, hypotension, or renal insufficiency) (A1).

2. The initial laboratory investigation of ascites fluid should include an ascitic fluid cell count and differential, ascitic fluid total protein, and albumin. Calcuation of serum-ascites albumin gradient should be performed for differential diagnosis of ascites (A1).

3. If ascitic fluid infection is suspected, bacterial culture of the fluid in aerobic and anaerobic blood culture bottles inoculated at the bedside should be performed (A1).

\section{Treatment}

\section{First-line treatment}

Treating underlying disease: The basic treatment for ascites is treatment of the underlying disease. Cirrhotic ascites related to alcohol use, virus hepatitis, or autoimmune liver disease can be controlled by treating the underlying cause of liver disease (Table 4) ${ }^{54}$ Alcoholic cirrhosis is a major cause of ascites. ${ }^{7}$ For them, abstinence improves liver fibrosis, lowers portal pressure, and is effective in controlling ascites..$^{55}$ Abstinence can lead to the elimination of ascites, increase the response to diuretics, and ultimately, the survival of alcoholic cirrhosis patients with ascites.$^{56}$ In a study of patients with alcoholic liver cirrhosis of Child-Pugh class C, the three-year survival rate was approximately $75 \%$ for patients who 
stopped drinking alcohol, but the mortality rate was significantly higher for patients who continued alcohol use. ${ }^{56}$ Baclofen acts on GABA receptors and reduce alcohol craving. In a study of alcoholic liver cirrhosis, baclofen use for 5.8 months safely improved bilirubin levels and Model for End-Stage Liver Disease (MELD) scores. ${ }^{57}$ In a study of patients with alcoholic liver cirrhosis, 12 weeks of baclofen administration was effective in reducing alcohol craving without adverse effects. ${ }^{58}$ In patients with hepatitis B virus-related liver cirrhosis, oral antiviral agents improved liver function and reduced the complications of liver cirrhosis, including ascites ${ }^{54,59-62}$ In a study of 267 patients with hepatitis $C$ virus-related cirrhosis, 12 weeks of treatment with sofosbuvir and velpatasvir improved the MELD score in 51\% of patients and improved the Child-Pugh score in $47 \%$ of patients. ${ }^{63}$ In patients with hepatitis $C$ virus-related cirrhosis and portal hypertension, six patients with pre-treatment ascites had controlled ascites after treatment of sofosbuvir and ribavirin for 24 weeks. ${ }^{64}$

Nutritional management and education: Most cirrhotic patients with ascites are malnourished. ${ }^{65}$ Depending on the state of the patient, the following carbohydrate, protein, and caloric intakes are recommended: 2-3 g/kg/day carbohydrate, $1.2-1.5 \mathrm{~g} /$ $\mathrm{kg} /$ day protein, and $35-40 \mathrm{kcal} / \mathrm{kg} /$ day caloric intake. ${ }^{66,67}$ In the presence of hepatic encephalopathy, administration of a branched-chain amino acid (BCAA) preparation may be considered. ${ }^{66}$ If three meals per day do not provide an adequate nutritional intake, a smaller and frequent meals are recommended. ${ }^{68-70}$ A late-evening snack of $200 \mathrm{kcal}$ improves the nutritional status in patients with cirrhosis and intractable ascites. ${ }^{71-73}$ If the patient is actively ill or in a critical state, higher protein $(1.5 \mathrm{~g} / \mathrm{kg} / \mathrm{day})$ and caloric intakes (40 kcal/kg/day) can be considered in conjunction with medical treatment.

While long-term oral or enteral nutrition is thought to be helpful for patients with alcoholic liver cirrhosis, additional studies are required to see the impact of these management. Most studies regarding this issue are limited by small sample sizes and/or insufficient treatment periods. ${ }^{74}$ However adequate nutritional therapy reduces complications of alcoholic liver cirrhosis and is not harmful. Currently there are no clear guidelines regarding the supplementation of vitamins or minerals in patients with liver cirrhosis and ascites. However, adequate amounts of vitamin A, thiamine, vitamin B12, folic acid, pyridoxine, vitamin $D$, and zinc can be considered for supplementation in case of nutritional deficiency. ${ }^{66,75}$ Zinc is involved in albumin and BCAA metabolism, and zinc supplements improve ascites and encephalopathy. ${ }^{76,77}$ It is important to educate and counsel patients, caregivers, and medical staff about salt intake, diuretics use, and nutrition in the treatment of patients with cirrhosis and ascites. In a study of 77 patients with hepatocellular carcinoma and ascites, active nutritional education improved the prognosis of the patients. .1178 $^{1,78}$

Sodium intake restriction: The mechanisms responsible for ascites formation in liver cirrhosis include renal functional abnormalities that favor sodium and water retention. The mainstays of treatment include dietary sodium restriction and natriuresis by using oral diuretics. ${ }^{79} \mathrm{~A}$ low-salt diet is considered effective for controlling ascites and shortening hospitalization. Less than $5 \mathrm{~g} /$ day of salt intake (sodium: $2 \mathrm{~g} / \mathrm{day}, 88 \mathrm{mmol} /$ day) is recommended. Greater dietary sodium restriction is not recommended because it may worsen the malnutrition that is usually present in these patients. ${ }^{80}$ Patients who do not follow a low-salt diet can control ascites by increasing their diuretic dose while allowing an appropriate amount of salt. Body water is passively released by excretion of sodium in the kidney, hence, fluid restriction is not usually necessary for patients with cirrhosis and ascites.

Table 4. Grading of ascites and suggested treatment

\begin{tabular}{lcc}
\hline & Grade 1 & Grade 2 \\
\hline Sodium intake restriction & Grade 3 \\
Diuretics & Treating underlying disease \\
Paracentesis & Nutritional treatment and education \\
First-line treatment & Discontinue NSAIDs, ACE inhibitors, or angiotensin receptor blockers \\
\end{tabular}

Grade 1 (mild). Ascites is only detectable by an examination such as ultrasound. Grade 2 (moderate). Ascites causing moderate symmetrical distension of the abdomen. Grade 3 (large). Ascites causing marked abdominal distension. ' $\mathbf{O}$ ' indicate recommended treatment.

NSAIDs, non-steroidal anti-inflammatory drugs; ACE, angiotensin converting enzyme. 
The Korean Association for the Study of the Liver (KASL) Treatment guideline for ascites and related complications

Admission and bed rest: Theoretically, renin-angiotensionaldosteron and sympathetic neverous system activity increase and glomerular filtration and sodium excretion reduce at the time of standing. However, there are no trials to support best rests, and excessive best rest may not only be impractical but may also cause problems such as muscle atrophy. ${ }^{81}$ Patients with ascites can be managed in outpatient basis, but hospitalization is recommended in cases complicated by upper gastrointestinal bleeding, hepatic encephalopathy, bacterial infection, hypotension, and liver cancer.

\section{Medications}

Diuretics: A low-salt diet alone is often unsuccessful in controlling ascites in patients with cirrhosis. For quicker recovery of symptom and sodium balance, diuretics are used in case of ascites Grade 2 or $3{ }^{82}$ Oral administration of diuretics is standard, and intravenous use is not recommended because it can cause kidney damage due to sudden body fluid loss.

Secondary hyperaldosteronism in patients with liver cirrhosis induces reabsorption of sodium and water in the distal renal tubule and collecting tubule, causing hypokalemia. Aldosterone antagonists inhibit this mechanism, and hence are commonly used for controlling ascites in patients with liver cirrhosis. Spironolactone has a long half-life and a slow onset of action. It requires three to four days to achieve a stable concentration. Spironolactone is initiated at a dose of 50-100 mg/day, with a maximum dose of 400 $\mathrm{mg} /$ day. Side effects include hyperkalemia, gynecomastia, mastalgia, hyposexuality, and erectile dysfunction. ${ }^{83}$ Amiloride has less diuretic effect than spironolactone, but has less anti-androgen effect. Amiloride (10-40 mg/day, 1/10 dose of spironolactone) can be substituted for spironolactone in patients with tender gynecomastia. $^{84}$

Loop diuretics act on the Na-K-2Cl receptors in the thick ascending limb of Henle's loop. Furosemide, a representative loop diuretic, has rapid onset of action. Hypokalemia may occur as a side effect, but hyperkalemia caused by aldosterone antagonists can be corrected. The starting dose is $20-40 \mathrm{mg} /$ day, with a maximum dose of $160 \mathrm{mg} /$ day. Torasemide is characterized by a longer half-life and longer duration of action than furosemide, and is used at a quarter of the dose of furosemide. ${ }^{85}$

Aldosterone antagonist is the mainstay of diuretic treatment. Loop diuretics can be used as a combination therapy with aldosterone antagonist, sequentially or initially. ${ }^{86}$ Monotherapy with loop diuretics is not recommended. For sequential use, spironolactone monotherapy can be started and furosemide is added in case of insufficient response to spironolactone monotherapy, or in case of hyperkalemia related to spironolactone monotherapy. ${ }^{86}$ Initial combination therapy of aldosterone antagonist and loop diuretics can also be considered, using a ratio of 100:40 of spironolactone and furosemide that can maintain adequate serum potassium levels. Combination therapy yielded a faster control of ascites with lower risk of developing hyperkalemia compared to aldosterone monotherapy in case of recurrent ascites. ${ }^{87}$

Diuretics should be used as small dose as possible when the ascites is controlled to prevent complications. In cases of hepatic encephalopathy, hyponatremia below $120 \mathrm{mmol} / \mathrm{L}$ (despite water restriction), acute kidney injury (AKI), or lack of response in weight with a low-salt diet ( $<5 \mathrm{~g} /$ day), diuretics should be stopped and the patient's status should be reevaluated. ${ }^{88}$ When using diuretics, changes in body weight, vital signs, serum creatinine $(\mathrm{s} C \mathrm{r})$, sodium, and potassium should be periodically monitored. If the serum sodium level decreases below $125 \mathrm{mmol} / \mathrm{L}$, diuretics can be carefully reduced or discontinued, and fluid restriction can be considered. ${ }^{80}$ Loop diuretics should be reduced or stopped in case of hypokalemia. Aldosterone antagonist should be reduced or stopped in case of hyperkalemia.

Weight control: There is no limit to weight loss per day when peripheral edema is present, however, the patient's condition should be carefully considered to determine amount of weight loss per day. For patients without edema, a maximum weight loss of $0.5 \mathrm{~kg} /$ day is recommended. ${ }^{13,89}$ Daily urine sodium excretion can be measured to evaluate the resonse of the diuretics and low salt diet. ${ }^{11,55}$ Currently recommended low salt diet ( $5 \mathrm{~g} /$ day) contains sodium $88 \mathrm{mmol} /$ day. About $10 \mathrm{mmol} /$ day of sodium is excreted in non-urinary body fluids such as sweat. Therefore, the excretion of urine sodium should be equal to $78 \mathrm{mmol} /$ day to maintain sodium balance in patients taking low salt diet. For patient not responding to low salt diet and diuretics, it can be considered that low salt intake was not followed by the patient (sodium intake was more than $88 \mathrm{mmol} /$ day) if urinary sodium excretion is over $78 \mathrm{mmol} /$ day. If urinary sodium excretion is under $78 \mathrm{mmol} /$ day, sodium excretion is inadequate and increase in diuretics dose can be considered. Collecting urine and measuring 24 hour sodium is cumbersome to measure it every day, and can be replace with a random urine sodium/potassium ratio (spot urine $\mathrm{Na} / \mathrm{K}$ ratio). ${ }^{90} \mathrm{~A}$ spot urine $\mathrm{Na} / \mathrm{K}$ ratio of more than 1 represents a sodium excretion rate of more than $78 \mathrm{mmol} / \mathrm{day}$, with $90-95 \%$ confidence. ${ }^{91} \mathrm{~A}$ spot urine $\mathrm{Na} / \mathrm{K}$ ratio can be tested regardless of time, as there is no difference in morning or afternoon test results. ${ }^{92}$ 
Branched-chain amino acid supplementation: Long-term oral BCAA supplementation improves nitrogen balance, hepatic encephalopathy, and liver enzyme profiles in patients with hypoalbuminemia. ${ }^{93,94}$ A daily supply of $34 \mathrm{~g}$ of protein, including $B C A A$, reduced the number of hospitalizations due to infection, gastrointestinal bleeding, ascites, or hepatic encephalopathy in patients with symptomatic alcoholic cirrhosis. ${ }^{95}$ Treatment with BCAA in 204 patients with decompensated cirrhosis for 24 weeks resulted in an increase in albumin and a decrease in ascites and edema. ${ }^{96}$ In a randomized comparative study, more than one year of treatment with BCAA significantly reduced the incidence of ascites. ${ }^{97} \mathrm{~A}$ different study demonstrated that administration of BCAA to 21 patients with liver cirrhosis improved albumin levels and increased muscle mass. ${ }^{98}$ In another study of patients with liver cirrhosis, high-protein $(1.2 \mathrm{~g} / \mathrm{kg}$ ) and high-fiber (30 g fiber) diets with a BCAA preparation increased muscle mass and prevented hepatic coma. ${ }^{99}$ In patients with hepatocellular carcinoma (HCC) who underwent liver resection, the use of BCAA was effective in preventing ascites and pleural effusion. ${ }^{100}$ In related studies conducted in patients with liver cirrhosis, long-term BCAA therapy improved bilirubin levels, Child-Pugh scores, albumin levels, and survival rates. ${ }^{101,102}$

Albumin: Albumin carries loop diuretics to the kidneys. ${ }^{103} \mathrm{Ad}-$ ministration of albumin increased the response to diuretics and reduced hospitalization days. ${ }^{104}$ In a meta-analysis, administration of albumin significantly reduced side effects from large-volume paracentesis (LVP) and reduced mortality. ${ }^{105}$ In a randomized controlled trial of patients with spontaneous bacterial peritonitis, administration of albumin reduced the incidence of hepatorenal syndrome ${ }^{106}$ In a randomized clinical trial in patients with ascites, the survival rate of patients treated with albumin ( $25 \mathrm{~g} /$ week for one year and then bi-weekly albumin administration) was higher than that of the diuretic alone group. ${ }^{107}$ In a recent report by an Italian group, the administration of 6-8 $\mathrm{g}$ of albumin per liter of paracentesis was recommended for the prevention of adverse effects after large-volume paracentesis (more than $5 \mathrm{~L}$ ). To prevent renal damage after treatment of spontaneous bacterial peritonitis, high-risk patients (more than $4 \mathrm{mg} / \mathrm{dL}$ of bilirubin or more than $1 \mathrm{mg} / \mathrm{dL}$ of $\mathrm{s}(\mathrm{r}$ ) were advised to receive $1.5 \mathrm{~g} / \mathrm{kg}$ albumin at diagnosis, and 1 $\mathrm{g} / \mathrm{kg}$ albumin at 3 days. ${ }^{108}$

Therapeutic paracentesis: Therapeutic paracentesis refers to draining a large amount of ascites for therapeutic purposes in patients with abdominal wall distension. ${ }^{109}$ LVP is safe when $8 \mathrm{~g}$ of albumin per 1 liter of ascites is administered. Therapeutic paracentesis is an effective treatment for patients with refractory ascites. It is faster than the use of diuretics alone, and shortens the length of the hospital stay. ${ }^{110}$

\section{[Recommendations]}

1. Treatment of underlying disease is important in patients with cirrhotic ascites (A1).

2. Supplementation of protein (1.2-1.5 g/ kg/day) is recommended in patients with cirrhotic ascites (B1).

3. In patients with cirrhotic ascites, the recommended intake of salt is $5 \mathrm{~g} /$ day or less (sodium $2 \mathrm{~g} /$ day, $88 \mathrm{mmol} /$ day). Fluid restriction is not necessary if the serum sodium concentration is in the normal range (B1).

4. In the case of peripheral edema, there is no limitation on weight loss/day, but weight loss/day should be decided carefully considering the condition of the patient. In the absence of peripheral edema, weight loss of $0.5 \mathrm{~kg} /$ day is recommended (A1).

5. The primary diuretic drug used for patients with cirrhotic ascites is an aldosterone antagonist. Spironolactone is recommended at a starting dosage of 50-100 mg/day, increasing to $400 \mathrm{mg} /$ day (A1). Furosemide, a loop diuretic, can be used in combination to increase the diuretic effect and maintain normal serum potassium levels. Furosemide is recommended at a starting dosage of 20-40 mg/day, increasing to $160 \mathrm{mg} /$ day (A1).

6. When hypokalemia occurs, the loop diuretic should be reduced or stopped. When hyperkalemia develops, the aldosterone antagonist should be reduced or stopped (B1).

7. In cases of severe hyponatremia, acute kidney injury, overt hepatic encephalopathy, or severe muscle spasm, diuretics dose should be reduced or stopped (B1).

8. In the case of therapeutic large-volume paracentesis, 6-8 $\mathrm{g}$ of albumin infusion per liter of ascites drained is recommended (A1).

\section{REFRACTORY ASCITES}

\section{Definition and diagnosis of refractory ascites}

Refractory ascites is defined as fluid overload which 1) fails to respond to a restriction of salt intake and the maximum dose of diuretic treatment (spironolactone at $400 \mathrm{mg} /$ day and furosemide at $160 \mathrm{mg} /$ day), or 2) reappears rapidly after therapeutic paracentesis. ${ }^{111}$ Refractory ascites is classified into diuretic-resistant and diuretic-intractable forms (Table 5). ${ }^{112}$

\section{Management of refractory ascites}

\section{Large-volume paracentesis}

Serial LVP is an effective management strategy for refractory 
The Korean Association for the Study of the Liver (KASL)

Table 5. Definition and diagnostic criteria for refractory ascites in cirrhosis ${ }^{112}$

\begin{tabular}{|c|c|}
\hline & Definition \\
\hline Diuretic-resistant ascites & $\begin{array}{l}\text { Ascites that cannot be mobilized or the early recurrence of which cannot be prevented because of a lack of } \\
\text { response to sodium restriction and diuretic treatment }\end{array}$ \\
\hline Diuretic-intractable ascites & $\begin{array}{l}\text { Ascites that cannot be mobilized or the early recurrence of which cannot be prevented because of the } \\
\text { development of diuretic-induced complications that preclude the use of an effective diuretic dosage }\end{array}$ \\
\hline \multicolumn{2}{|l|}{ Requisites } \\
\hline Treatment duration & $\begin{array}{l}\text { Intensive diuretic therapy (spironolactone } 400 \mathrm{mg} / \text { day and furosemide } 160 \mathrm{mg} / \text { day) for at least } 1 \text { week and } \\
\text { on a salt-restricted diet of less than } 5 \mathrm{~g} / \text { day }\end{array}$ \\
\hline Response of therapy & Mean weight loss of $<800 \mathrm{~g}$ over 4 days and urinary sodium output less than the sodium intake \\
\hline Early ascites recurrence & Recurrence of grade $2-3$ ascites within 4 weeks of initial mobilization \\
\hline Diuretic-induced complications & $\begin{array}{l}\text { Hepatic encephalopathy: development of encephalopathy in the absence of any other precipitating factor } \\
\text { Renal impairment: }>0.3 \mathrm{mg} / \mathrm{dL} \text { increase of } \mathrm{s} C \mathrm{r} \text { within } 48 \text { hours of baseline or } 1.5 \text {-fold increase within } 1 \text { week } \\
\text { Hyponatremia: decrease of serum sodium by }>10 \mathrm{mEq} / \mathrm{L} \text { to serum sodium of }<125 \mathrm{mEq} / \mathrm{L} \\
\text { Hypo- or hyperkalemia: change in serum potassium to }<3 \mathrm{mmol} / \mathrm{L} \text { or }>6 \mathrm{mmol} / \mathrm{L}\end{array}$ \\
\hline
\end{tabular}

sCr, serum creatinine.

ascites. LVP is not a first-line option for all patients with ascites. It is performed on selected patients who have difficulty eating or breathing due to abdominal distension. After LVP, maintenance therapy should be followed. Compared with diuretic treatment, LVP with intravenous albumin replacement shortens the length of the hospital stay and reduces the risk of hyponatremia, AKI, and hepatic encephalopathy. However, repeated LVP increases the risk of infection and malnutrition related to protein loss. ${ }^{113}$ In order to reduce the need for LVP, a salt-restricted diet is recommended.

When diuretic-resistant ascites develops, diuretics treatment is generally discontinued. The European Association for the Study of the Liver recommends discontinuing diuretics when urinary sodium excretion is $<30 \mathrm{mmol} /$ day. $^{13}$ As diuretic-resistant ascites is controlled by paracentesis thereafter, the interval and amount of paracentesis reflects a patient's degree of compliance to a lowsalt diet. In Korea, the mean daily sodium intake is 200-300 $\mathrm{mmol}$. However, sodium intake can be reduced to $88 \mathrm{mmol} /$ day or less if a patient maintains a low-salt (up to $5 \mathrm{~g} /$ day) diet. ${ }^{114}$ In general, patients with refractory ascites excrete less than $20 \mathrm{mmol} /$ day of sodium in the urine. About $10 \mathrm{mmol} /$ day is additionally excreted by insensible loss with body fluids such as sweat. Thus, even if a patient maintains a low-salt diet, more than $60 \mathrm{mmol}$ sodium per day remains in the body. If more than $10 \mathrm{~L}$ of paracentesis is needed during a two-week period, the patient is clearly not complying with a low-salt diet.

LVP may shorten the survival of patients due to post-paracentesis circulatory dysfunction. ${ }^{115}$ For LVP of more than $5 \mathrm{~L}$, infusion of 6-8 $\mathrm{g}$ of intravenous albumin per liter of drained ascites is recommended. Although the incidence of post-paracentesis circulatory dysfunction is relatively low after drainage of $<5 \mathrm{~L}$ of ascites, colloid replacement (mainly intravenous albumin infusion) can be considered. $^{13,116}$ Midodrine ${ }^{117}$ or terlipressin ${ }^{118}$ can be also used to prevent circulatory dysfunction after LVP.

\section{Medical treatment}

In patients with refractory ascites, non-selective beta-blockers (NSBBs) may lower blood pressure and increase the frequency of paracentesis-induced circulatory dysfunction, which may exacerbate renal function. It has been shown that NSBBs shorten the survival of patients with refractory ascites. ${ }^{119}$ Thus, the risks and benefits of NSBBs should be carefully weighed in patients with refractory ascites, and consideration must be given to discontinuing NSBBs in patients who are already using them. ${ }^{120}$ A NSBBs-induced decrease in the mean arterial pressure is a poor prognostic factor in the decompensated cirrhosis of patients with ascites. ${ }^{121}$ Angiotensin converting enzyme inhibitors and angiotensin receptor blockers are not recommended in these patients for the same reason. ${ }^{13}$

In addition to standard diuretic treatment, oral midodrine (7.5 $\mathrm{mg}$ three times daily) or clonidine ( $0.1 \mathrm{mg}$ twice daily) can be beneficial in controlling refractory ascites. ${ }^{122}$ In particular, additional midodrine on standard diuretic treatment has been shown to increase urine volume, urine sodium, mean arterial pressure, and survival in patients with refractory ascites. ${ }^{123}$ Additional use of clonidine has yielded diverse responses associated with the a2adrenoreceptor polymorphism. ${ }^{124}$ Vaptan, a selective V2 receptor blocker, was not more effective in controlling refractory ascites than diuretics treatment; rather, it increased the risk of mortality when used in combination with diuretics. ${ }^{125}$ 
In patients with a poor response to medical treatment, including those discontinuing NSBBs and additional midodrine or clonidine treatment, other options might be applied. These include serial LVP, liver transplantation, TIPS, and peritoneovenous shunt, and other experimental options.

\section{Transjugular intrahepatic portosystemic shunt}

In patients with refractory ascites, TIPS can reduce the risk of ascites recurrence and improve the survival rate compared with serial LVP. ${ }^{126}$ However, TIPS is an expensive and invasive procedure. Moreover, hepatic encephalopathy occurs in 30-50\% of patients who receive TIPS. There is no significant difference in the hepatic encephalopathy incidence between TIPS and serial LVP. ${ }^{127}$ However, encephalopathy is more severe in patients with TIPS patients. ${ }^{128}$ This could worsen the quality of life and should be acknowledged. ${ }^{129}$ It takes time to eliminate ascites after TIPS, and most patients require maintenance of diuretics and salt restriction. Since diuretic resistance may be improved by TIPS, titrating the diuretic dose may be required.

Polytetrafluoroethylene-covered stents reduce the rate of stent obstruction. In a recent study, a polytetrafluoroethylene-covered stent with a $10 \mathrm{~mm}$-diameter was more effective in controlling refractory ascites (without increasing the encephalopathy risk) than a stent with a diameter of $8 \mathrm{~mm} .{ }^{130}$ Patients received TIPS have a lower risk of liver transplantation than patients who received serial LVP during the first year of follow-up. ${ }^{131,132}$ Those who undergo TIPS before liver transplantation show a lower mortality rate than those who do not receive TIPS (adjusted hazard ratio [HR], 0.95; $95 \%$ confidence interval $[\mathrm{Cl}], 0.90-0.99) .{ }^{133}$ A retrospective study has suggested that surgical shunts are more effective for refractory ascites than TIPS, ${ }^{134}$ but prospective comparison studies are needed. Cirrhotic patients usually have a high left-ventricular ejection fraction of $>70-75 \%$ due to pathophysiological changes. TIPS can induce diastolic heart failure in patients with diastolic dysfunction and an ejection fraction of $50-60 \%$, which may consequently shorten the expected residual survival. ${ }^{135,136}$ In patients with renal impairment, and especially in patients on dialysis, the effect of TIPS may be attenuated. ${ }^{137}$

\section{Liver transplantation}

Patients with refractory ascites often require liver transplantation because $21 \%$ of patients die within six months, and the median survival is less than one year. ${ }^{138,139}$ Patients with refractory ascites tend to have a poor prognosis, even if the MELD score is relatively low (below 18). Hyponatremia, which is common in pa- tients with refractory ascites, is also associated with a poor prognosis. ${ }^{140}$ For these reasons, additional prognosis prediction models (e.g. MELD-Na) have been introduced. ${ }^{141}$

\section{Other experimental options}

In a retrospective study, administration of albumin (50 g per week) reduced the body weight of patients with refractory ascites who did not meet the indications for TIPS, but further prospective studies are warranted. ${ }^{142} \mathrm{~A}$ randomized pilot study showed that patients who used clonidine along with spironolactone had shorter hospital stays than patients who underwent serial LVP with intravenous albumin infusion. ${ }^{143}$

Although peritoneovenous shunt has been performed for refractory ascites since the 1970s, it causes many procedure-related complications and offers no benefit over medical treatment in terms of survival. ${ }^{144}$ Therefore, peritoneovenous shunt should be considered only for patients who are not candidates for liver transplantation, and who have poor access to serial LVP. It can be also applied to patients with abdominal wounds, which limit serial LVP. A medical device that drains ascites into the urinary bladder has been developed, and recent clinical trials demonstrated that the device improved the quality of life for patients by reducing the requirement for serial LVP. However, side effects, such as AK were also reported. ${ }^{145}$ Indwelling catheters and ports may be useful in malignant ascites, but their safety and efficacy have not been clearly demonstrated in cirrhosis-induced ascites.

Cell-free and concentrated ascites reinfusion therapy (CART) during LVP may be considered in Asian patients who have low body mass. During CART, concentrated ascites fluid is reinfused after the removal of cells. CART appears to be as effective as albumin infusion and may reduce the albumin consumption. ${ }^{146,147}$

\section{[Recommendations]}

1. Liver transplantation is recommended in patients with refractory ascites (A1).

2. Patients with refractory ascites should maintain a low-salt diet and control their ascites with serial large-volume paracentesis (A1).

3. For large-volume paracentesis in patients with refractory ascites, 6-8 $\mathrm{g}$ of albumin infusion per liter of ascites drain is recommended $(\mathrm{A} 1)$

4. A transjugular intrahepatic portosystemic shunt can be performed for the management of refractory ascites (A2).

5. Beta-blockers should be used with caution, and careful monitoring of blood pressure and renal function is required for patients with refractory ascites (B1) 
The Korean Association for the Study of the Liver (KASL) Treatment guideline for ascites and related complications

\section{HYPONATREMIA}

Hyponatremia is a commonly observed complication related to hypoalbuminemia and portal hypertension in patients with advanced liver cirrhosis. Generally, hyponatremia is defined as a serum sodium concentration less than $135 \mathrm{mmol} / \mathrm{L}$. Hyponatremia in patients with liver cirrhosis is mostly dilutional hyponatremia, and is defined at a serum sodium concentration below $130 \mathrm{mmol} / \mathrm{L}^{13,81,148,149}$ This is because the risk of complications increases significantly in patients with hyponatremia below $130 \mathrm{mmol} / \mathrm{L}$ and liver cirrhosis accompanied by ascites. Complications include spontaneous bacterial peritonitis (odd ratio [OR], 3.40; 95\% Cl, 2.35-4.92), hepatorenal syndrome (OR, 3.45; 95\% Cl, 2.04-5.82), and hepatic encephalopathy $(\mathrm{OR}, 2.36 ; 95 \% \mathrm{Cl}, 1.41-3.93)$. More evidence is needed to establish the starting point of treatment for hyponatremia. ${ }^{150}$

\section{Pathophysiology}

Hyponatremia in liver cirrhosis is caused by systemic vasodilatation due to a deterioration of portal hypertension, and by a decreased effective plasma volume. ${ }^{151}$ This causes a decrease in systemic vascular resistance, a decrease in mean arterial blood pressure, and an increase in cardiac output. Ultimately, it induces hyperdynamic circulation. ${ }^{150,152}$ In particular, nitric oxide, glucagon, vasoactive intestinal peptide, substance $P$, platelet activating factors, prostaglandins, and prostacyclins accumulate and contribute to splanchnic arterial vasodilation. ${ }^{153-155}$

Systemic vasodilation and decreased effective plasma volume stimulate the body to maintain effective plasma volume through the renin-angiotensin-aldosterone system. This results in excessive reabsorption of sodium and water. Eventually, lower extremity edema and ascites are clinically observed. ${ }^{156}$ Hyponatremia is particularly severe in patients with decompensated liver cirrhosis because the regulation of antidiuretic hormone in accordance with body water is inadequate. ${ }^{157}$ Increased arterial natriuretic peptide, decreased prostaglandin E2, and decreased degradation of antidiuretic hormone also aggravate hyponatremia. ${ }^{156}$

\section{Treatment of hyponatremia}

\section{Treatment according to the cause of hyponatremia}

The first step in the treatment of hyponatremia is to distinguish the type of hyponatremia. Fluid resuscitation is needed for hypovolemic hyponatremia. In patients with liver cirrhosis, hypovolemic hyponatremia caused by excessive diuretic use is common. With- drawal of diuretics or correction of other possible cause of dehydration should be considered. In these patients, hypertonic sodium chloride administration can be considered. However, this requires attention because an excessive correction of the serum sodium concentration can cause many side effects or complications. In particular, a correction of more than $9 \mathrm{mmol} / \mathrm{L}$ within 24 hours is associated with central pontine myelinolysis or seizures. Frequent monitoring is necessary when correcting the serum sodium concentration. ${ }^{158}$

In cases of hypervolemic hyponatremia, discontinuation of intravenous fluid therapy and free water restriction should be considered. If the serum sodium concentration is below $120-125 \mathrm{mmol} / \mathrm{L}$ and neurologic symptoms are present, fluid restriction (1-1.5 L/ day) should be considered. The effect of restricting fluid intake on the serum sodium concentration is unclear, and prospective studies are lacking. However, an indirect analysis of patients who underwent fluid restriction as a control group in clinical trials showed that, at least, fluid restriction could prevent deterioration of serum sodium level below a certain level. ${ }^{159,160}$ Plasma expander such as albumin infusion has been tried, and was reported to be effective in hyponatremia. However, the number of patients was very small. ${ }^{161}$ The administration of hypertonic sodium chloride allows a temporary elevation in the serum sodium concentration and symptom relief after administration, but this treatment requires close attention because edema and ascites can be worsened.

\section{Vaptan}

In terms of the pathophysiology of hypervolemic hyponatremia, an ideal therapy should encourage the excretion of solute-free water to prevent losing electrolytes through urination. The recently developed vaptan drugs selectively inhibit the V2 receptor of vasopressin, an antidiuretic hormone of the prinical cell in the collecting duct of the urinary tract. Vaptans selectively suppress water reabsorption, thereby enhancing urinary excretion. Without vaptans, systemic vasodilation and decreased effective plasma volume increase vasopressin and water reabsorption in patients with hypervolemic hyponatremia. In particular, vaptans are effective in patients with the syndrome of inappropriate antidiuretic hormone secretion (SIADH), heart failure, and liver cirrhosis. Clinical studies have shown that vaptans can enhance urinary excretion without affecting renal function, urinary sodium excretion, cardiovascular function, or the renin-angiotensin-aldosterone system. Several vaptans are currently available in clinical practice, and can be used intravenously (conivaptan) or orally (lixivaptan, 
satavaptan, and tolvaptan).

Conivaptan is a dual arginine vasopressin antagonist with affinity for the human V1A and V2 receptors. ${ }^{162-164}$ It is an intravenous drug approved by the Food and Drug Administration since 2005 for the treatment of euvolemic and hypervolemic hyponatremia. ${ }^{165}$ It binds to human plasma proteins when administered by injection. It is metabolized by CYP3A (an intrahepatic enzyme), and $83 \%$ of the metabolites are excreted through the stool. ${ }^{166}$ It is used for short periods of 2-4 days for the improvement of euvolemic or hypervolemic hyponatremia. Frequent adverse events reported in clinical studies included phlebitis and hypersensitivity at the injection site, observed in $70 \%$ of patients. In addition, minor headache, thirst, constipation, and nausea were reported. ${ }^{165}$ Serious adverse events, including excessive hypotension and a rapid increase in the serum sodium concentration, occurred in $10 \%$ of patients. ${ }^{167}$ Hypokalemia occurred in $20 \%$ of patients. Arrhythmia and rhabdomyolysis due to hypokalemia occurred in some patients with heart failure. ${ }^{165}$ Adverse effects such as deterioration of liver function or hepatic failure have not been reported, but $50 \%$ of the dose is recommended in patients with uncompensated liver cirrhosis because metabolism of the drug is approximately $60 \%$ slower. $^{168}$

Lixivaptan is a very potent oral drug that functions as a nonpeptide V2 receptor antagonist. In 60 patients with liver cirrhosis accompanied by hyponatremia, serum sodium levels were normalized in $27 \%$ and $50 \%$ of patients dosed with $100 \mathrm{mg}$ and $200 \mathrm{mg}$ of lixivaptan, respectively. ${ }^{159}$ However, both treatment groups had side effects including severe dehydration and hypotension. In a placebo-controlled study performed with three different doses $(25,125,250 \mathrm{mg})$ in patients with liver cirrhosis accompanied by ascites, there was a dose-dependent increase in urine volume, reduction in body weight, and rise in the serum sodium concentration. However, 12 of 32 clinical study participants dropped out owing to dehydration, thirst, and hypotension caused by an excessive increase in urine volume during the study period (8 days). The drugs were discontinued because of the rapid increase in the serum sodium concentration. ${ }^{160}$ As side effects were frequent and severe in patients with liver cirrhosis, trials have since been conducted mainly on patients with heart failure.

There was improvement of hyponatremia in patients with SIADH who were treated with 25-50 mg/day of satavaptan for approximately 12 months, suggesting the possibility of long-term hyponatremia correction. ${ }^{169}$ When satavaptan was administered at 5-25 mg/day for 14 days, there was improvement in hyponatremia (average 4.5-6.6 mmol/L increase in the serum sodium concentra- tion, compared with levels before medication) and ascites (average 1.5-1.6 kg body weight reduction) in patients with liver cirrhosis, relative to a placebo group. Satavaptan reduced the recurrence of ascites and increased the diuretic effect, regardless of hyponatremia. ${ }^{170,171}$ In a large-scale, phase III study comparing satavaptan with placebo in 1,200 patients with liver cirrhosis accompanied by ascites, hyponatremia was improved in only eight days with 5-10 mg/day $(O R, 2.91 ; 95 \% ~ C l, 1.46-5.78)$. Furthermore, no significant differences in complications or survival rates were observed (compared to a placebo group) when satavaptan was used for 52 weeks. In one subgroup analysis of patients with reduced baseline liver function, there were increased side effects and higher mortality rates due to complications (HR, 1.47; 95\% $\mathrm{Cl}, 1.01-2.15)$. Therefore, caution is needed when administering satavaptan for long-term periods. ${ }^{125}$

Tolvaptan, an oral medication, significantly improved weight gain and hyponatremia (compared with a placebo group) in a study of patients with congestive heart failure. ${ }^{172}$ When 120 patients with liver cirrhosis received $15-60 \mathrm{mg}$ of tolvaptan for 30 days, there was a significant improvement in the serum sodium concentration by the fourth day of treatment. This was well maintained until the 30th day (the end-point of treatment), and gradually dropped to the level of the control group after termination of treatment. There were no serious side effects, although dry mouth and thirst were reported. ${ }^{173}$ As an extension of the above study, 111 patients who received more than $15 \mathrm{mg}$ of tolvaptan for more than two years in order to verify its long-term stability and efficacy. Among them, six patients dropped out owing to thirst, fatigue, or polyuria. There were no significant side effects over the longterm period except in one patient, who stopped medication because of hypernatremia. ${ }^{174}$ However, $4.4 \%$ of the tolvaptan treatment group (vs. 1.0\% of the placebo group) had elevated alanine aminotransferase (ALT) levels. In fact, their ALT levels were more than three times the normal upper limit defined in a phase III study of tolvaptan in patients with autosomal dominant polycystic kidney disease. Therefore, the U.S. Food and Drug Administration has limited tolvaptan treatment in patients with liver cirrhosis or impaired liver function. The European Medicines Agency approved the use of tolvaptan in 2015 , but has recommended monthly liver function tests in patients with autosomal dominant polycystic kidney disease. ${ }^{174-178}$ In China and Japan, low doses of tolvaptan (7.5$15 \mathrm{mg} /$ day) have been approved to control ascites, with a warning that liver dysfunction may occur. ${ }^{179}$ 
The Korean Association for the Study of the Liver (KASL) Treatment guideline for ascites and related complications

\section{Prognosis of hyponatremia}

Hyponatremia is associated with mortality in patients with liver cirrhosis and ascites. The risk of refractory ascites increases and frequent therapeutic paracentesis is required when the serum sodium concentration drops below $135 \mathrm{mmol} / \mathrm{L}$. ${ }^{150,180}$ In cases where the serum sodium concentration drops below $130 \mathrm{mmol} / \mathrm{L}$, quality of life markedly decreases due to dietary regulations for ascites control and diminished cognitive function. ${ }^{181,182}$ Patients with hyponatremia are frequently exposed to spontaneous bacterial peritonitis, higher risk of hepatorenal syndrome and death, showing poorer prognosis. ${ }^{182}$ The MELD-Na score, which adds the sodium level to the calculation of MELD score, is used to determine the prognosis of end-stage cirrhosis. The prognosis is poorer when accompanied by hyponatremia. MELD-Na score is used to prioritize liver transplant candidate in the United States. ${ }^{183}$ Hyponatremia is also known to affect the overall survival after transplantation, and serious neurological complications can occur if hyponatremia is corrected rapidly after transplantation. ${ }^{184}$

\section{[Recommendations]}

1. When the serum sodium concentration decreases to less than $130 \mathrm{mmol} / \mathrm{L}$ in patients with liver cirrhosis and ascites, most are dilutional hyponatremia. Hyponatremia requires special attention as it is associated with a poor prognosis and multiple complications (A1).

2. Fluid intake can be restricted to $1.0-1.5 \mathrm{~L} /$ day in cases of dilutional hyponatremia when the serum sodium concentration falls below 120-125 mmol/L (B1).

Administration of a plasma expander, such as albumin, may be considered for the treatment of hyponatremia (B2).

\section{SPONTANEOUS BACTERIAL PERITONITIS}

\section{Definition and diagnostic criteria}

\section{Definition}

Spontaneous bacterial peritonitis (SBP) is bacterial infection of ascites, without an evident intra-abdominal, surgically treatable source of infection. SBP occurs in $20-30 \%$ of patients with cirrhotic ascites, ${ }^{12,185}$ and its mortality rate is approximately $20 \%{ }^{186}$

\section{Diagnosis}

An abdominal paracentesis should be performed and ascites fluid should be analyzed in patients with signs of peritonitis (abdominal pain, vomiting, ileus, etc.) or other signs of infection. This also applies to patients with unexplained worsening liver and/or kidney function, or hepatic encephalopathy. ${ }^{13}$ SBP can be diagnosed when the ascitic polymorphonuclear leukocyte (PMN) count $\geq 250 / \mathrm{mm}^{3}$, without an evident intra-abdominal infection. If there are red blood cells (RBCs) in the ascites, the PMN count is adjusted by subtracting 1 PMN per $250 \mathrm{RBCs} / \mathrm{mm}^{3}{ }^{187}$ Ascitic fluid for culture should be taken before empirical antibiotics administration. Inoculation of ascitic fluid into blood culture bottles at the bedside is recommended because of the higher growth rate observed (approximately $80 \%$ ) compared to conventional culture methods (approximately $50 \%$ ). ${ }^{188}$ Approximately $40 \%$ of patients who have an ascitic PMN count $\geq 250 / \mathrm{mm}^{3}$ are culture-negative (even with the appropriate culture tests), a condition known as culture-negative neutrocytic ascites. ${ }^{187}$ Because these patients show a clinical course similar to patients with culture-positive ascitic fluid, empirical antibiotic therapy is recommended. ${ }^{189}$ In some patients, a single strain of bacteria is cultured in the ascitic fluid, but the ascitic PMN count $<250 / \mathrm{mm}^{3}$ (a condition known as monomicrobial nonneutrocytic bacterascites). These results indicate the colonization of bacteria in the ascites, and asymptomatic patients need no treatment because most of them resolve the colonization without antibiotics. ${ }^{190,191}$ In one prospective study, many patients with signs or symptoms of infection, but an ascitic PMN count $<250 / \mathrm{mm}^{3}$, progressed to SBP. ${ }^{191}$ Patients with signs or symptoms of infection (such as fever or abdominal pain), including patients with unexplained complications (such as renal impairment or hepatic encephalopathy), should therefore receive empirical antibiotics while awaiting the results of culture, even if the ascitic PMN count $<250 / \mathrm{mm}^{3}$. It may be possible to diagnose SBP more quickly using the reagent strip test. However, this test is not recommended due to its low sensitivity and high false-negative rate. ${ }^{192-194}$

\section{Secondary bacterial peritonitis}

Approximately $5 \%$ of patients develop secondary bacterial peritonitis caused by intestinal perforation or abscess. ${ }^{195}$ Secondary bacterial peritonitis has a high mortality rate (50-80\%), ${ }^{48,196}$ and surgical treatment should be considered. However, it is important to differentiate between secondary bacterial peritonitis and spontaneous bacterial peritonitis because unnecessary laparotomy in cirrhotic patients increases the mortality rate. ${ }^{197}$ Secondary bacterial peritonitis may be suspected in the following cases: 1) the PMN count increases to $>1,000 / \mathrm{mm}^{3} ; 2$ 2) multiple organisms are seen by Gram stain or in culture using the ascitic fluid; 3 ) the ascitic total protein concentration $\geq 1 \mathrm{~g} / \mathrm{dL} ; 4)$ the $L D H$ level in the ascites fluid is above the normal upper limit of LDH in the serum; 
5) the ascitic glucose concentration $\leq 50 \mathrm{mg} / \mathrm{dL}$; and 6) the ascitic PMN count does not drop after 48 hours of antibiotic treatment. ${ }^{48}$ Elevated levels of ascitic fluid CEA ( $>5 \mathrm{ng} / \mathrm{mL}$ ) or alkaline phosphatase ( $>240 \mathrm{U} / \mathrm{L})$ are helpful in the diagnosis of secondary bacterial peritonitis caused by intestinal perforation. ${ }^{49}$ Clinical manifestations, course of treatment, ascitic glucose levels, and LDH levels may be helpful, however appropriate imaging techniques (such as abdominal computed tomography) are necessary if secondary peritonitis is suspected.

\section{[Recommendations]}

1. If spontaneous bacterial peritonitis is suspected and the polymorphonuclear leukocyte count is greater than $250 / \mathrm{mm}^{3}$, the patient should be diagnosed as spontaneous bacterial peritonitis (regardless of the ascitic fluid culture result) and empirical antibiotic therapy should be started (A1).

2. Even if the polymorphonuclear leukocyte count is less than 250/ $\mathrm{mm}^{3}$, when symptoms or signs of infection are present (e.g. body temperature $>37.8^{\circ} \mathrm{C}$, abdominal pain or tenderness), empirical antibiotic administration is recommended until culture results become available (B1).

3. If secondary bacterial peritonitis is suspected, imaging tests such as abdominal computed tomography should be performed (A1). Tests for ascitic total protein, lactate dehydrogenase, glucose, Gram stain, carcinoembryonic antigen, and alkaline phosphatase help differentiate secondary bacterial peritonitis from spontaneous bacterial peritonitis (B1).

\section{Treatment}

\section{Community-acquired spontaneous bacterial peritonitis}

Patients who are suspected of ascitic fluid infection should begin empirical antibiotic therapy before culture and antibiotic susceptibility test results are avialable. The most commonly identified bacteria in culture are Escherichia coli, Klebsiella pneumoniae, and Streptococcus (Table 6). ${ }^{198-202}$ Third-generation cephalosporin antibiotics are recommended as they are effective for most causative bacterial pathogens, including these strains. Cefotaxime is the most studied third-generation cephalosporins. Intravenous cefotaxime treatment in patients with SBP delivers a high concentration of drug to the ascites, ${ }^{203}$ and yields a high resolution rate of $69-98 \% .{ }^{203-207}$ In one study, a 5-day treatment group and a 10 day treatment group showed similar therapeutic effects. ${ }^{203}$ Intravenous ceftriaxone treatment showed a $73-100 \%$ resolution rate, similar to cefotaxime treatment (Table 7) ${ }^{206,208-210}$ Therefore, in patients suspected of SBP, cefotaxime at a dose of $2 \mathrm{~g}$ every 6-8 hours, or ceftriaxone at a dose of $1 \mathrm{~g}$ every 12-24 hours, are recommended by intravenous injection. The standard treatment duration is 5 to 10 days. However, the treatment duration should vary according to the symptoms and/or results of antimicrobial susceptibility testing. Similarly, antibiotics should be replaced in accordance with the susceptibility results of bacteria cultured from ascites or blood.

Treatment with amoxicillin-clavulanic acid shows similar SBP resolution rates to cefotaxime, and treatment with ciprofloxacin

Table 6. Bacteria causing spontaneous bacterial peritonitis in Korea

\begin{tabular}{lcc}
\hline Reference & Gram (-) & Gram (+) \\
\hline Park et al. ${ }^{198}$ & E.coli (35.8\%) & Streptococcus species (15.2\%) \\
& Klebsiella species (15.5\%) & Staphylococcus species (4.6\%) \\
Enterococcus species (3.3\%)
\end{tabular}

E.coli, Escherichia coli. 
The Korean Association for the Study of the Liver (KASL)

Table 7. Antibiotic therapy in patients with spontaneous bacterial peritonitis

\begin{tabular}{|c|c|c|c|c|c|c|}
\hline Reference & Treatment & $\mathbf{N}$ & Resolution (\%) & $P$-value & Mortality (\%) & $P$-value \\
\hline Felisart et al. ${ }^{204}$ & $\begin{array}{l}\text { Tobramycin } 1.75 \mathrm{mg} / \mathrm{kg} / 8 \mathrm{hr} \text { IV } \\
\text { + ampicillin } 2 \mathrm{~g} / 4 \mathrm{hr} \text { IV } \\
\text { Cefotaxime } 2 \mathrm{~g} / 4 \mathrm{hr} \text { IV }\end{array}$ & 73 & $\begin{array}{l}56 \\
85\end{array}$ & $<0.02$ & $\begin{array}{l}31 \\
19\end{array}$ & NS \\
\hline Runyon et al. ${ }^{203}$ & $\begin{array}{l}\text { Cefotaxime } 2 \mathrm{~g} / 8 \mathrm{hr} \text { IV for } 5 \text { days } \\
\text { Cefotaxime } 2 \mathrm{~g} / 8 \mathrm{hr} \text { IV for } 10 \text { days }\end{array}$ & 100 & $\begin{array}{l}93 \\
91\end{array}$ & NS & $\begin{array}{l}32.6 \\
42.5\end{array}$ & NS \\
\hline Ricart et al. ${ }^{205}$ & $\begin{array}{l}\text { Amoxicillin/clavulanic acid } 1 \mathrm{~g} / 0.2 \mathrm{~g} / 8 \mathrm{hr} \text { IV, } \\
500 \mathrm{mg}-125 \mathrm{mg} / 8 \mathrm{hr} \mathrm{PO} \\
\text { Cefotaxime } 1 \mathrm{~g} / 6 \mathrm{hr}\end{array}$ & 96 & $\begin{array}{l}87.5 \\
83.3\end{array}$ & NS & $\begin{array}{l}12.5 \\
20.8\end{array}$ & NS \\
\hline Tuncer et al. ${ }^{206}$ & $\begin{array}{l}\text { Ciprofloxacin } 500 \mathrm{mg} / 12 \mathrm{hr} \text { for } 5 \text { days } \\
\text { Cefotaxime } 2 \mathrm{~g} / 8 \mathrm{hr} \text { IV for } 5 \text { days } \\
\text { Ceftriaxone } 2 \mathrm{~g} / 24 \mathrm{hr} \text { IV for } 5 \text { days }\end{array}$ & 53 & $\begin{array}{c}80 \\
76.4 \\
82.3\end{array}$ & NS & $\begin{array}{l}13.3 \\
11.7 \\
17.6\end{array}$ & NS \\
\hline Sort et al. ${ }^{106}$ & $\begin{array}{l}\text { Cefotaxime } 2 \mathrm{~g} / 6 \mathrm{hr} \text { IV } \\
\text { Cefotaxime } 2 \mathrm{~g} / 6 \mathrm{hr} \text { IV + Albumin IV }\end{array}$ & 126 & $\begin{array}{l}94 \\
98\end{array}$ & NS & $\begin{array}{l}29 \\
10\end{array}$ & 0.01 \\
\hline $\begin{array}{l}\text { Gómez-Jiménez et } \\
\text { al. }^{209}\end{array}$ & $\begin{array}{l}\text { Cefonicid } 2 \mathrm{~g} / 12 \mathrm{hr} \\
\text { Ceftriaxone } 2 \mathrm{~g} / 24 \mathrm{hr}\end{array}$ & 60 & $\begin{array}{c}94 \\
100\end{array}$ & NS & $\begin{array}{l}30 \\
37\end{array}$ & NS \\
\hline Yim et al. ${ }^{207}$ & $\begin{array}{l}\text { Cefotaxime } 2 \mathrm{~g} / 8 \mathrm{hr} \text { IV for } 5 \text { days } \\
\text { Ceftriaxone } 2 \mathrm{~g} / 24 \mathrm{hr} \text { IV for } 5 \text { days } \\
\text { Ciprofloxacin } 400 \mathrm{mg} \text { PO for } 5 \text { days }\end{array}$ & 261 & $\begin{array}{l}69.1 \\
76.2 \\
76.1\end{array}$ & NS & $\begin{array}{l}15 \\
18 \\
15\end{array}$ & NS \\
\hline
\end{tabular}

NS, not significant.

shows similar survival rates to cefotaxime. ${ }^{205,211}$ Oral treatment with ofloxacin shows similar therapeutic efficacy to cefotaxime in patients without complications (such as gastrointestinal bleeding, renal dysfunction, hepatic encephalopathy, ileus, and shock). ${ }^{212}$ However, caution is needed because causative oraganims isolated in community-acquired SBP is increasingly resistant to quinolone. ${ }^{198}$ Recently, a university hospital in Korea reported that E.coli resistance to quinolone was as high as $31.7 \%{ }^{213}$ The risk of quinolone resistance is increased in patients who have previously recovered from SBP and in those who have been exposed to quinolone. ${ }^{213-218}$ In patients with these risk factors, the choice of antibiotics should be made taking into account the possibility of infection by quinolone-resistant strains.

\section{Hospital-acquired spontaneous bacterial peritonitis}

Hospital-acquired SBP is defined as occurring after more than 48-72 hours of hospitalization. ${ }^{219,220}$ Hospital-acquired SBP is at risk of treatment failure when third-generation cephalosporins, the first choice of empirical treatment for community-acquired SBP, are used. 200,214,215,220,221 According to various Korean studies, extended-spectrum beta-lactamase (ESBL)-producing bacterial strains account for $5-30 \%$ of all SBP cases. ${ }^{200,215-217}$ More specifically, ESBL-producing bacteria account for $13-20 \%$ of communityacquired SBP cases, but 46-66\% of hospital-acquired SBP cases. ${ }^{215,217}$ The frequency of ESBL-producing bacteria has also been increasing within the same hospital. ${ }^{198,216,217}$ Cases of SBP caused by multidrug-resistant gram-positive bacteria (such as Enterococcus or methicillin-resistant Staphylococcus aureus) have also increased (Table 8). ${ }^{199,200}$ Hospital-acquired SBP has a higher mortality rate than community-acquired SBP, due to increased resistance to third-generation cephalosporins, infection by Gram positive bacteria and multidrug-resistant strains. ${ }^{200,216}$ In a randomized, controlled study of patients with hospital-acquired SBP, meropenem-daptomycin treatment was more effective than ceftazidime. ${ }^{219}$ An empirical selection of antibiotics should be based on the severity of the infection, the risk factors for multidrug-resistant infection, and local epidemiology. ${ }^{222,223}$ Risk factors for multidrugresistant bacterial infection include hospital-acquired infection, long-term use of prophylactic antibiotics, recent use of beta-lactam antibiotics, and recent history of hospitalization. ${ }^{220,224}$ Carbapenem treatment (with or without glycopeptides) is often considered in patients with severe infection or with risk factors for multidrug-resistant bacterial infection. With this treatment, it is necessary to re-evaluate and consider de-escalation after 48-72 hours in order to reduce the chance of developing antibiotics resistance. ${ }^{222}$ As a general rule, it is necessary to select empirical antibiotics based on local epidemiology by regularly monitoring of commonly isolated organism and their resistance profiles at each institution. 


\section{Follow-up paracentesis}

Because most SBP shows a good response to empirical antibiotics, routine follow-up paracentesis to evaluate the treatment response is not needed in patients with SBP. Follow-up paracentesis can be helpful if there are no symptom improvements after treatment, or if secondary bacterial peritonitis is suspected. If the PMN count in the ascitic fluid does not decrease by more than $25 \%$ after 2 days of empirical antibiotics, ${ }^{187}$ this should be considered as treatment failure. For these patients, drugs targeting bacteria that cannot be treated with cephalosporins such as ESBL-producing bacteria, MRSA, enterococcus, and pseudomonas should be considered.

\section{Other treatments}

Albumin: Approximately 30-40\% of patients with SBP develop renal dysfunction, ${ }^{225,226}$ and when renal dysfunction develops, the risk of mortality is very high. ${ }^{227}$ In patients with SBP, cefotaxime treatment with albumin infusion $(1.5 \mathrm{~g} / \mathrm{kg}$ at the time of diagnosis and $1.0 \mathrm{~g} / \mathrm{kg}$ at 3 days) decreased the incidence of hepatorenal syndrome (HRS) (10\% vs. $33 \%)$ and mortality (10\% vs. $29 \%)$ compared to cefotaxime alone. ${ }^{106}$ The incidence of HRS is low $(<8 \%)$ in patients with serum bilirubin $<4 \mathrm{mg} / \mathrm{dL}$ and $\mathrm{s} C \mathrm{r}<1.0$ $\mathrm{mg} / \mathrm{dL}$ on diagnosis of SBP. ${ }^{106}$ On the other hand, patients with serum bilirubin $>4 \mathrm{mg} / \mathrm{dL}$ or sCr $>1.0 \mathrm{mg} / \mathrm{dL}$ are at high risk (58\%)

Table 8. Spontaneous bacterial peritonitis caused by antibiotic-resistant bacteria in Korea

\begin{tabular}{|c|c|c|c|}
\hline Reference & Acquisition site & Antibiotic-resistant bacteria & Rate \\
\hline \multirow[t]{4}{*}{ Kim et al. ${ }^{+199}$} & Community+Nosocomial & Methicillin-resistant Staphylococcus aureus & $6 / 77(7.8 \%)$ \\
\hline & & Vancomycin-resistant Enterococcus & $2 / 77(2.6 \%)$ \\
\hline & & ESBL-producing E.coli & $4 / 77(5.2 \%)$ \\
\hline & & ESBL-producing Klebsiella species & 6/77 (7.8\%) \\
\hline \multirow[t]{6}{*}{ Song et al. ${ }^{+215}$} & Community & Cefotaxime-resistant E.coli & $6 / 44(13.6 \%)$ \\
\hline & & ESBL-producing E.coli & 6/44 (13.6\%) \\
\hline & & Ciprofloxacin-resistant E.coli & $6 / 44(13.6 \%)$ \\
\hline & Nosocomial & Cefotaxime-resistant E.coli & $14 / 18(77.7 \%)$ \\
\hline & & ESBL-producing E.coli & $12 / 18(66.7 \%)$ \\
\hline & & Ciprofloxacin-resistant E.coli & $8 / 18(44.4 \%)$ \\
\hline \multirow[t]{3}{*}{ Cheong et al. ${ }^{\dagger 200}$} & Community+Nosocomial & 3rd generation cephalosporin-resistant GNB & 25/182 (13.7\%) \\
\hline & & Quinolone-resistant GNB & $36 / 182(19.8 \%)$ \\
\hline & & ESBL-producing GNB & $11 / 182(6.0 \%)$ \\
\hline \multirow[t]{3}{*}{ Kim et al. ${ }^{* 213}$} & Community & Fluoroquinolone-resistant E.coli & $26 / 82(31.7 \%)$ \\
\hline & & 3rd generation cephalosporin-resistant E.coli & $6 / 82(7.3 \%)$ \\
\hline & & ESBL-producing E.coli & $5 / 82(6.1 \%)$ \\
\hline Song et al. ${ }^{\ddagger 216}$ & Community+Nosocomial & ESBL-producing E.coli and Klebsiella species & $26 / 78(33.3 \%)$ \\
\hline Kim et al. ${ }^{\ddagger 217}$ & Community+Nosocomial & ESBL-producing E.coli and Klebsiella pneumoniae & $52 / 241(21.6 \%)$ \\
\hline \multirow[t]{8}{*}{ Park et al. ${ }^{\ddagger 218}$} & Community+Nosocomial & ESBL-producing E.coli & \\
\hline & & In 1995 & 0/17 (0\%) \\
\hline & & In 1998 & $7 / 43(16 \%)$ \\
\hline & & $\ln 1999$ & 18/55 (33\%) \\
\hline & & ESBL-producing Klebsiella pneumoniae & \\
\hline & & In 1995 & $3 / 5(60 \%)$ \\
\hline & & In 1998 & $2 / 20(10 \%)$ \\
\hline & & $\ln 1999$ & $3 / 12(25 \%)$ \\
\hline
\end{tabular}

ESBL, extended-spectrum beta-lactamase; E. coli, Escherichia coli; GNB, gram-negative bacilli.

"Studies only on spontaneous bacterial peritonitis by $E$. coli.

${ }^{\dagger}$ Studies on whole spontaneous bacterial peritonitis.

${ }^{\ddagger}$ Studies only on spontaneous bacterial peritonitis by E. coli and Klebsiella. 
The Korean Association for the Study of the Liver (KASL) Treatment guideline for ascites and related complications

for renal dysfunction, and albumin treatment is helpful in these patients. ${ }^{228}$ Recently, there was a report that low doses of albu$\min (1.0 \mathrm{~g} / \mathrm{kg}$ at the time of diagnosis and $0.5 \mathrm{~g} / \mathrm{kg}$ at 3 days) are effective in preventing renal dysfunction, but further studies are needed. ${ }^{229}$

Non-selective beta-blockers and diuretics: Non-selective beta-blockers (NSBBs) are known to inhibit the development of SBP by reducing intestinal transit time, inhibiting intestinal bacterial overgrowth, and reducing intestinal bacterial translocation. ${ }^{230}$ A meta-analysis of patients using NSBBs for the prevention of variceal bleeding showed that NSBBs reduced the incidence of SBP by $12.1 \%(\mathrm{OR}, 0.428 ; 95 \% \mathrm{Cl}, 0.26-0.70) .{ }^{231} \mathrm{~A}$ retrospective study showed that the use of NSBBs in patients with SBP reduced the risk of transplant-free survival $(H R, 1.58 ; P=0.014)$ by increasing the risk of HRS and AKI. ${ }^{232}$ Another study showed that high-dose NSBBs decreased survival (adjusted HR, 1.30; $P=0.059$ ), while low-dose NSBBs increased survival (adjusted HR, 0.34; $P=0.03$ ). ${ }^{233}$ Therefore, the role of NSBBs in patients with SBP is still unclear, and clinicians should discontinue or adjust the dose considering the benefits and risks of its use.

The use of diuretics in cirrhotic patients with ascites increases total protein and complement levels in the ascitic fluid. Diuretics also increase opsonic activity in the ascites, thus inhibiting the development of SBP. ${ }^{234}$ In one study of patients with SBP, those with a response to diuretics showed elevated total protein and opsonic activity in ascites. ${ }^{235}$ However, AKI is common in patients with SBP. Therefore, renal function monitoring is needed, and the dose of diuretics should be reduced or discontinued according to changes in renal function.

\section{Prophylaxis}

\section{Primary prophylaxis}

Bacterial infections, including SBP, occur in $35-66 \%$ of liver cirrhosis patients with gastrointestinal bleeding within 1-2 weeks of admission. ${ }^{236}$ In these patients, infection increases treatment failure, re-bleeding, and mortality. ${ }^{27,238} \mathrm{~A}$ meta-analysis of previous studies showed that prophylactic antibiotic therapy in patients with liver cirrhosis with gastrointestinal bleeding reduced severe bacterial infections, re-bleeding, and mortality. ${ }^{236,239}$ Administration of oral norfloxacin (400 mg twice for 1 week) is effective in preventing infection in patients with liver cirrhosis accompanied by gastrointestinal bleeding. ${ }^{240}$ However, in patients with gastrointestinal bleeding accompanied by severe hepatic dysfunction (two or more factors: ascites, severe malnutrition, bilirubin $>3$ $\mathrm{mg} / \mathrm{dL}$, or hepatic encephalopathy), prophylaxis with ceftriaxone (1 $\mathrm{g} /$ day for 1 week) was more effective than oral norfloxacin. ${ }^{241}$

Among patients with ascites, those with low protein concentrations in the ascites have a high risk of developing SBP. ${ }^{242-244}$ In a double-blind, randomized, controlled study in patients with an ascitic protein concentration $<1.5 \mathrm{~g} / \mathrm{dL}$, norfloxacin $(400 \mathrm{mg} /$ day for 6 months) reduced infections by Gram-negative bacteria, but did not lower the incidence and mortality of SBP. ${ }^{245}$ In another double-blind, placebo-controlled study in patients with an ascitic protein concentration $<1.5 \mathrm{~g} / \mathrm{dL}$, ciprofloxacin $(500 \mathrm{mg} /$ day for 12 months) reduced the incidence of SBP from $14 \%$ to $4 \%$ (albeit with limited statistical significance, $P=0.074)$, and increased the 1-year survival from $66 \%$ to $88 \%(P=0.04){ }^{246}$ Thus, the efficacy of prophylactic antibiotics in preventing SBP and reducing mortality is unclear for patients with an ascitic protein concentration $<1.5 \mathrm{~g} / \mathrm{dL}$. However, prophylactic administration of norfloxacin for 1 year in patients with an ascitic protein concentration $<1.5 \mathrm{~g} / \mathrm{dL}$ accompanied by hepatic dysfunction (Child-Pugh score $\geq 9$ and bilirubin $\geq 3 \mathrm{mg} / \mathrm{dL}$ ), renal insufficiency $(\mathrm{s} C \mathrm{C} \geq 1.2 \mathrm{mg} / \mathrm{dL}$ or blood urea nitrogen $\geq 25 \mathrm{mg} / \mathrm{dL}$ ), or hyponatremia ( $\mathrm{Na}<130 \mathrm{mmol} / \mathrm{L}$ ) reduced the cumulative incidence of SBP from $61 \%$ to $7 \%$, decreased the incidence of HRS from $41 \%$ to $28 \%$, and reduced mortality from $94 \%$ to $62 \%$ within 1 year. ${ }^{247}$ Therefore, prophylactic administration of norfloxacin (400 mg/day) may be helpful in patients with an ascitic protein concentration $<1.5 \mathrm{~g} / \mathrm{dL}$, especially when hepatic dysfunction, renal insufficiency, and hyponatremia are present. However, the long-term use of prophylactic antibiotics may increase the likelihood of infection by quinoloneresistant strains or multidrug-resistant strains. ${ }^{21,220}$

In a retrospective study using rifaximin as a primary prophylaxis in patients with no history of SBP, its use reduced the incidence of SBP (adjusted HR, 0.28; $P=0.007$ ). ${ }^{248} \mathrm{~A}$ prospective case-controlled study also showed that rifaximin reduces the incidence of SBP $(4.5 \%$ vs. $46 \%, P=0.027) .{ }^{249}$ A retrospective study of rifaximin for the treatment of hepatic encephalopathy in Korea showed that its use reduced the incidence of SBP $(P<0.001) .{ }^{250}$ However, there was no difference in the incidence of SBP between the rifaximin-treated group and the non-treated group ( $22 \%$ vs. $30 \%$ ) in another study. ${ }^{251}$ Therefore, the use of rifaximin as a primary prophylaxis to prevent SBP requires further studies.

\section{Secondary prophylaxis}

Patients recovered from SBP have a recurrence rate of SBP, about $70 \%$ within 1 year. ${ }^{252}$ After recovery from SBP, norfloxacin 
(400 mg/day) decreases the recurrence rate from $68 \%$ to $20 \%$, and decreases recurrence by Gram-negative bacteria from $60 \%$ to $3 \%{ }^{253}$ Norfloxacin at $400 \mathrm{mg} /$ day yields a lower tendency of recurrence rate than rufloxacin at $400 \mathrm{mg} /$ week (26\% vs. $36 \%$, $P=0.16)$, which was due to a lower rate of recurrence by the $E n$ terobacteriaceae with norfloxacin treatment (0\% vs. $22 \%$, $P=0.01) .{ }^{254}$ In a prospective study using trimethoprim-sulfamethoxazole (160-800 mg) and norfloxacin for secondary prevention, the recurrence rate of SBP did not differ between the trimethoprim-sulfamethoxazole group and the norfloxacin group $(10.0 \%$ vs. $9.1 \%, P=0.50) .{ }^{255}$ However, further studies are necessary as study sample are relatively small. In a randomized, controlled trial comparing rifaximin with norfloxacin, the 6 -month cumulative recurrence rate $(3.9 \%$ vs. $14.1 \%)$ and mortality rate $(13.7 \%$ vs. $24.4 \%)$ were lower for rifaximin $(1,200 \mathrm{mg} /$ day) than for norfloxacin $\left(400 \mathrm{mg} /\right.$ day). ${ }^{256}$

\section{[Recommendations]}

1. Third-generation cephalosporins, such as cefotaxime or ceftriaxone, are recommended as empirical antibiotics for community-acquired spontaneous bacterial peritonitis (A1).

2. In patients with hospital-acquired spontaneous bacterial peritonitis, history of prolonged use of prophylactic antibiotics, recent use of beta-lactam antibiotics, or recent hospitalization, the risk of infection by multidrug-resistant bacteria should be considered when choosing antibiotics (B1).

3. In patients with spontaneous bacterial peritonitis, the albumin infusion reduces the risk of hepatorenal syndrome (A1).

4. In patients with liver cirrhosis accompanied by gastrointestinal bleeding, intravenous ceftriaxone (1 $\mathrm{g} /$ day) is recommended (A1). Oral norfloxacin (400 mg twice, i.e. $800 \mathrm{mg} /$ day) can be considered if hepatic dysfunction is not severe (A2).

5. In patients with ascitic protein level of $<1.5 \mathrm{~g} / \mathrm{dL}$, norfloxacin (400 mg/day) can be considered for primary prevention of spontaneous bacterial peritonitis if severe hepatic dysfunction, renal insufficiency, or hyponatremia co-exist (A2).

6. Patients recovered from spontaneous bacterial peritonitis have a high risk of recurrence, and norfloxacin ( $400 \mathrm{mg} / \mathrm{day}$ ) can be considered to prevent recurrence of SBP (A2).

Rifaximin (1,100-1,200 mg/day) can be used as an alternative to norfloxacin as a secondary prophylactic agent (B1).

\section{ACUTE KIDNEY INJURY AND HEPATORENAL SYNDROME}

\section{Definition, diagnosis, and prevention}

Acute kidney injury (AKI) is common in patients with liver cir- rhosis, occurring in $13-20 \%$ of hospitalized patients with decompensated cirrhosis. ${ }^{257,258}$ It is significantly associated with a patient's prognosis. ${ }^{227,259,260}$ The development and progression of $A K I$ is an independent predictive factor for mortality in these patients. ${ }^{260,261}$ If AKI develops (even with later improvements), renal function progressively declines, and patients have a worse prognosis than those without a history of AKI. ${ }^{262}$ In patients without appropriate treatment, or without improvement after the initial treatment, AKI often progress to HRS. HRS is associated with significant morbidity and mortality. ${ }^{263}$ Although liver transplantation is considered the only definitive treatment for HRS, pre-transplant renal function can affect post-transplant morbidity and mortality. ${ }^{264}$ The three-year survival rate after liver transplantation is about $80 \%$ in patients without prior HRS, and is about $60 \%$ in patients with prior HRS. Patients with prior HRS before liver transplantation have a higher incidence of renal replacement treatment. ${ }^{265}$ Therefore, it is necessary to improve the renal function before transplantation.

AKI in patients with liver cirrhosis can be classified into two groups: functional injury and structural injury. In about $70 \%$ of cases with cirrhosis, AKI is a functional injury caused by pre-renal failure due to gastrointestinal hemorrhage, bacterial infection, hypovolemia by overuse of diuretics, LVP, diarrhea by overuse of non-absorbable disaccharide (lactulose or lactitol), or reduced renal blood flow by NSBBs-induced hypotension. ${ }^{266}$ The development of functional injury in patients with cirrhosis is caused by altered systemic hemodynamics. ${ }^{267}$ Liver cirrhosis and portal hypertension-induced splanchnic and systemic vasodilation lead to a reduction in the effective arterial volume. This activates the renin-angiotensin-aldosteron system and sympathetic nervous system, and induces renal injury. ${ }^{268}$ These changes induce sodium and water retention, promote the development of ascites and hyponatremia, and trigger renal impairment by reducing renal blood flow and renal arterial vasoconstriction, which can progress to HRS. ${ }^{226,269,270}$ The incidence of HRS is significantly increased in patients with left ventricular diastolic dysfunction, ${ }^{271}$ or relative adrenal insufficiency. ${ }^{272,273}$ In 70\% of cases, the functional renal disorder is a pre-renal azotemia which responds to intravascular volume replacement. In the other $30 \%$ of cases, the disorder is HRS, which is not responsive to intravascular volume replacement. ${ }^{257}$ About $30 \%$ of AKI in patients with cirrhosis is structural injury, as in case of hepatitis B- or hepatitis C-associated glomerulonephropathy or acute tubular necrosis. Acute tubular necrosis can be caused by gastrointestinal hemorrhage, overuse of diuretics, LVP-induced hypotension, toxins, antibiotics, non-steroidal 
The Korean Association for the Study of the Liver (KASL) Treatment guideline for ascites and related complications

anti-inflammatory drugs (NSAIDs), or computed tomography contrast agents. ${ }^{266,274}$ Post-renal AKI by urinary tract obstruction can lead to the development of AKI in these patients, but the incidence is very low $(<1 \%)^{275}$

\section{Diagnostic criteria}

Acute kidney injury: Traditionally, AKI in cirrhosis has been defined using $\mathrm{s} C r$ levels (>50\% increase in the $\mathrm{s} C \mathrm{C}$ level from baseline, or a final value $>1.5 \mathrm{mg} / \mathrm{dL}$ ). ${ }^{111,276}$ However, the $\mathrm{s} C \mathrm{r}$ level is a poor marker for renal function in patients with cirrhosis. These patients show a reduced production of $\mathrm{s} C \mathrm{r}$ from significant muscle wasting, ${ }^{277,278}$ and an increase in the renal tubular secretion of $s \mathrm{Cr}^{279}$ In addition, elevated bilirubin levels may interfere with $\mathrm{sCr}$ measurements. ${ }^{280}$ Therefore, sCr-based measurements could overestimate the true renal function, which in turn might delay the diagnosis and initiation of treatment for AKI in these patients. ${ }^{281}$ Additionally, the use of a fixed threshold of $\mathrm{sCr}(1.5$ $\mathrm{mg} / \mathrm{dL}$ ) may not represent dynamic changes in renal function, which are needed to distinguish between acute and chronic injury. $^{282}$

In 2004, the Acute Dialysis Quality Initiative (ADQI) group proposed a definition and classification system for AKI, known as the RIFLE (Risk, Injury, Failure, Loss of renal function, and End-stage renal disease) criteria. These criteria classify the degree of AKI into three stages according to changes in the $\mathrm{s} C r$ level and urine volume (Table 9). ${ }^{283}$ The RIFLE criteria do not use the strict $\mathrm{sCr}$ cut-off value of $1.5 \mathrm{mg} / \mathrm{dL}$ for the diagnosis of $\mathrm{AKl}$; rather, they define $\mathrm{AKI}$ as an increase in the $\mathrm{s} C \mathrm{r}$ level $\geq 1.5 \times$ the baseline level within 1 week. ${ }^{283}$ Several studies have suggested that the RIFLE criteria are useful for predicting in-hospital mortality in cirrhotic patients admitted to the ICU. ${ }^{284,285}$ The Acute Kidney Injury Network (AKIN), a collaborative network consisting of experts from $A D Q I$, nephrology societies, and intensive care medicine societies, proposed a new definition for $\mathrm{AKI}^{286}$ There were concerns about small increases in sCr levels which might not affect the RIFLE classification, but could be associated with adverse outcomes. ${ }^{287}$ The AKIN criteria broadened the definition of AKI to include an absolute increase in $\mathrm{sCr}$ of $\geq 0.3 \mathrm{mg} / \mathrm{dL}$ within 48 hours. ${ }^{286}$ The AKIN criteria have been useful for predicting the prognosis of patients with cirrhosis. ${ }^{260,288}$ In 2012, the Kidney Disease Improving Global Outcomes (KDIGO) Foundation proposed the following definition for AKI: an increase in $\mathrm{s} C r$ levels of $\geq 0.3 \mathrm{mg} / \mathrm{dL}$ within 48 hours, or $\geq 50 \%$ from baseline within 7 days, or a decrease in urine volume $<0.5 \mathrm{~mL} / \mathrm{kg} / \mathrm{h}$ within 6 hours. ${ }^{289}$ In a study involving 242 cirrhotic patients hospitalized in the intensive care unit, the KDIGO criteria were more useful in predicting patient prognosis than the RIFLE or AKIN criteria. ${ }^{290}$

Various studies have validated the usefulness of the RIFLE, AKIN, and KDIGO criteria. But because these criteria were not developed for patients with cirrhosis, it is not clear whether these criteria can be directly applied to cirrhotic patients. Both the RIFLE and AKIN criteria include a decrease in urine volume in the definition of AKI. This could be a problem in the diagnosis of AKI in patients with cirrhosis because urine volume may decrease without

Table 9. The diagnosis of acute kidney injury using serum creatinine levels in the RIFLE, AKIN, KDIGO, and ICA-AKI criteria

\begin{tabular}{|c|c|c|c|c|}
\hline & RIFLE $^{283}$ & $\mathrm{AKIN}^{286}$ & $\mathrm{KDIGO}^{289}$ & ICA-AKI $^{282}$ \\
\hline Definition & $\begin{array}{l}\text { Increase in } \mathrm{s} C r \text { to } \geq 1.5 \text { times } \\
\text { baseline within } 7 \text { days }\end{array}$ & $\begin{array}{c}\text { Increase in } \mathrm{s} C r \text { by } \geq 0.3 \mathrm{mg} / \mathrm{dL} \\
\text { within } 48 \text { hours or increase in } \\
\mathrm{s} C r \geq 1.5 \text { times baseline within } \\
48 \text { hours }\end{array}$ & $\begin{array}{c}\text { Increase in } \mathrm{s} C r \text { by } \geq 0.3 \mathrm{mg} / \mathrm{dL} \\
\text { within } 48 \text { hours or increase in } \\
\mathrm{s} C r \geq 1.5 \text { times baseline within } \\
7 \text { days }\end{array}$ & $\begin{array}{c}\text { Increase in } \mathrm{s} C r \text { by } \geq 0.3 \mathrm{mg} / \mathrm{dL} \\
\text { within } 48 \text { hours or increase in } \\
\mathrm{s} C r \geq 1.5 \text { times baseline within } \\
7 \text { days }\end{array}$ \\
\hline \multicolumn{5}{|l|}{ Staging } \\
\hline Stage 1 & $\begin{array}{l}\text { (Risk) sCr increase 1.5-1.9 } \\
\text { times baseline }\end{array}$ & $\begin{array}{c}\mathrm{s} C r \text { increase } 1.5-1.9 \text { times } \\
\text { baseline or } \mathrm{sCr} \text { increase } \geq 0.3 \\
\mathrm{mg} / \mathrm{dL}\end{array}$ & $\begin{array}{c}\mathrm{s} C r \text { increase } 1.5-1.9 \text { times } \\
\text { baseline or sCr increase } \geq 0.3 \\
\mathrm{mg} / \mathrm{dL}\end{array}$ & $\begin{array}{c}\mathrm{s} C \mathrm{r} \text { increase } \geq 0.3 \mathrm{mg} / \mathrm{dL} \\
\text { or sCr increase } 1.5-2 \text { times } \\
\text { baseline }\end{array}$ \\
\hline Stage 2 & $\begin{array}{l}\text { (Injury) sCr increase 2.0-2.9 } \\
\text { times baseline }\end{array}$ & $\begin{array}{c}\text { sCr increase } 2.0-2.9 \text { times } \\
\text { baseline }\end{array}$ & $\begin{array}{c}\text { sCr increase } 2.0-2.9 \text { times } \\
\text { baseline }\end{array}$ & $\begin{array}{c}\text { sCr increase }>2 \text { and } \leq 3 \text { times } \\
\text { baseline }\end{array}$ \\
\hline Stage 3 & $\begin{array}{l}\text { (Failure) } \mathrm{s} C r \text { increase } \geq 3 \text { times } \\
\text { baseline or sCr increase } \geq 4.0 \\
\mathrm{mg} / \mathrm{dL} \text { with an acute increase } \\
\text { of at least } 0.5 \mathrm{mg} / \mathrm{dL}\end{array}$ & $\begin{array}{c}\text { sCr increase } \geq 3 \text { times baseline } \\
\text { or sCr increase } \geq 4.0 \mathrm{mg} / \mathrm{dL} \\
\text { with an acute increase of at } \\
\text { least } 0.5 \mathrm{mg} / \mathrm{dL}\end{array}$ & $\begin{array}{l}\text { sCr increase } \geq 3 \text { times baseline } \\
\text { or sCr increase } \geq 4.0 \mathrm{mg} / \mathrm{dL}\end{array}$ & $\begin{array}{c}\text { sCr increase }>3 \text { times baseline } \\
\text { or } \mathrm{s} C \mathrm{r} \text { increase } \geq 4.0 \mathrm{mg} / \mathrm{dL} \\
\text { with an acute increase } \geq 0.3 \\
\mathrm{mg} / \mathrm{dL} \text { or initiation of renal } \\
\text { replacement therapy }\end{array}$ \\
\hline
\end{tabular}

RIFLE, Risk, Injury, Failure, Loss of renal function, and End-stage renal disease; AKIN, Acute Kidney Injury Network; KDIGO, Kidney Disease Improving Global Outcomes; ICA-AKI, International Club of Ascites-Acute Kidney Injury; sCr, serum creatinine. 
a decrease in renal function, and the use of diuretics may affect the urine volume without changing the renal function in these patients. ${ }^{291}$ Therefore, the International Club of Ascites (ICA) recently proposed the following definition of AKI: an increase in the $\mathrm{sCr}$ level of $\geq 0.3 \mathrm{mg} / \mathrm{dL}$ within 48 hours, or $\geq 50 \%$ from baseline within 7 days. Changes in urine volume are excluded from the definition. ${ }^{282}$ In this definition, the baseline $\mathrm{s} C \mathrm{C}$ level is defined as an $\mathrm{s} C r$ value obtained in the previous 3 months, when available. In patients without a prior $\mathrm{s} C \mathrm{C}$ level, the $\mathrm{s} C \mathrm{r}$ level on admission should be used as a baseline level. ${ }^{282}$ In patients without a prior sCr level, a baseline level could be calculated by the reverse application of the Modification of Diet in Renal Disease (MDRD) formula (using an arbitrarily defined normal value for the glomerular filtration rate [GFR] of $75 \mathrm{~mL} / \mathrm{min}$ ). ${ }^{289}$ This is not recommended because sCr-based methods to estimate GFR (such as the MDRD formula) are not accurate in patients with cirrhosis. ${ }^{292}$ Previous studies have shown that the efficacy of these methods for diagnosing AKI in cirrhosis patients is not precise. ${ }^{293}$ In one study involving 373 patients admitted for liver cirrhosis and bacterial infection, AKI (as defined by the ICA criteria) was a significant predictor of 30-day mortality. ${ }^{294}$

Hepatorenal syndrome: In advanced cirrhosis, aggravation of the effective hypovolemia by severe systemic and splanchnic vasodilatation leads to further potent activation of the renin-angiotensin and sympathetic nervous systems. Eventually, it causes a decrease in renal blood flow and potent renal vasoconstriction. In this condition, renal injury does not respond to the replacement of intravascular volume, and HRS develops. Although HRS in patients with cirrhosis is a reversible functional injury, structural injury in the glomerulus and/or renal tubule could be combined. ${ }^{295}$

Similar to AKI, there have been several changes in the diagnostic criteria of HRS. In 1996, the ICA proposed diagnostic criteria for HRS, ${ }^{111}$ and these were updated in 2007 (Supplementary Table 1, 2). ${ }^{263}$ The main differences in the 2007 updated definition were as follows: 1) estimation of the creatinine clearance using 24-hour urine collection was excluded because of complexity and inaccuracy; 2) HRS can be diagnosed in patients with bacterial infection; 3) intravenous albumin infusion, rather than normal saline, should be used for volume replacement; and 4) minor criteria in the previous (1996) definition were excluded because of low sensitivity and specificity. A fixed sCr threshold of $2.5 \mathrm{mg} / \mathrm{dL}$ remained in the updated definition, which might delay the initiation of vasoconstrictors and albumin treatment and lead to a lower treatment response. A subgroup analysis that showed a lower treatment response rate in patients with a higher baseline $\mathrm{s} C \mathrm{r}$ level supports this suggestion. ${ }^{296,297}$ In 2015, the ICA proposed a new HRS definition, excluding a fixed sCr threshold (Table 10). Using these criteria, HRS is defined as AKI in patients with cirrhotic ascites that is not responsive to two consecutive days of diuretic withdrawal or plasma volume expansion with albumin (1 $\mathrm{g} / \mathrm{kg}$ body weight). ${ }^{282}$ According to these criteria, vasoconstrictor and albumin treatment could be initiated at an earlier stage, before the $\mathrm{s} C \mathrm{r}$ level reaches $2.5 \mathrm{mg} / \mathrm{dL} .{ }^{282}$ Because the overuse of albumin could lead to pulmonary edema, caution is needed. ${ }^{298}$

The first guidelines for HRS were published in 1996. HRS was classified into two types according to the progression time. Type 1 HRS, rapidly progressive renal failure, was defined as a doubling of the $\mathrm{s} C \mathrm{r}$ level $(\geq 2.5 \mathrm{mg} / \mathrm{dL}$ ) within 2 weeks. Type 2 HRS was defined as a moderate and slowly progressive renal failure $(\mathrm{s} \mathrm{Cr}$ level of $1.5-2.5 \mathrm{mg} / \mathrm{dL}$ ), usually associated with refractory ascites..$^{111}$ In 2012, the ADQI group recommended that, in patients with type 2 HRS, those with an estimated glomerular filtration rate (eGFR) $<60 \mathrm{~mL} / \mathrm{min} / 1.73 \mathrm{~m}^{2}$ (calculated using the MDRD-6

Table 10. Diagnostic criteria for hepatorenal syndrome by the International Club of Ascites in $2015^{282}$

\section{Diagnostic criteria}

1) Diagnosis of cirrhosis and ascites

2) Diagnosis of AKI according to ICA-AKI criteria

3) No response after 2 consecutive days of diuretic withdrawal and plasma volume expansion with albumin (1 g/kg body weight)

4) Absence of shock

5) No current or recent use of nephrotoxic drugs (NSAIDs, aminoglycosides, iodinated contrast media, etc.)

6) No macroscopic signs of structural kidney injury, defined as:

- Absence of proteinuria (>500 mg/day)

- Absence of microhematuria (>50 RBCs per high-power field)

- Normal findings on renal ultrasonography

AKI, acute kidney injury; ICA-AKI, International Club of Ascites-Acute Kidney Injury; NSAIDs, non-steroidal anti-inflammatory drugs; RBCs, red blood cells. 
The Korean Association for the Study of the Liver (KASL) Treatment guideline for ascites and related complications

formula) for more than three months should be diagnosed with chronic kidney disease (CKD). The development of AKI in these patients should be classified as acute on CKD. ${ }^{299}$ Based on these recommendation, renal dysfunction in cirrhotic patients would be classified as AKI, type 1 HRS, or type 2 HRS in patients without underlying renal disease, and AKI or type 1 HRS in patients with CKD or type 2 HRS. $^{299}$ However, an sCr-based estimation of renal function is not accurate in cirrhotic patients, and its accuracy is still unknown in the differentiation of CKD and type 2 HRS in patients with cirrhotic ascites. In addition, the clinical efficacy of the ADQI classification of renal dysfunction is not clear. Updated (2015) diagnostic criteria for HRS by the ICA clarify that patients with cirrhotic ascites and AKI can be diagnosed with HRS if they meet the criteria, without type classification. ${ }^{282}$

In some cases of AKI, the differentiation of pre-renal azotemia, HRS, and acute tubular necrosis can be challenging. Several studies have suggested that biomarkers, such as neutrophil gelatinase-associated lipocalin (NGAL), interleukin-18 (IL-18), kidney injury molecule-1 (KIM-1), and liver-type fatty acid binding protein (L-FABP), could be helpful in the differentiation. ${ }^{300}$ However, further data are required to confirm the usefulness of these biomarkers.

\section{Prevention}

A main strategy for preventing renal injury in cirrhotic patients is preventing a decrease in plasma volume or vasodilation. To prevent a decrease in plasma volume, doses of diuretics and non-absorbable disaccharides should be cautiously titrated. After LVP, intravenous albumin infusion is more effective than normal saline or dextran for the prevention of AKI. ${ }^{301}$ In addition, avoidance of aminoglycosides or NSAIDs could be helpful for the prevention of acute tubular necrosis. ${ }^{302}$ In patients with SBP, intravenous albumin infusion with antibiotics could prevent the development of HRS. ${ }^{106,228}$ In patients with low ascitic protein $(<1.5 \mathrm{~g} / \mathrm{dL}$ ), with renal dysfunction ( $\mathrm{sCr} \geq 1.2 \mathrm{mg} / \mathrm{dL}$ or BUN $\geq 25 \mathrm{mg} / \mathrm{dL}$ ), or with serum $\mathrm{Na}<130 \mathrm{mEq} / \mathrm{L}$, treatment with oral norfloxacin reduces the incidence of HRS and increases the three-month survival rate. ${ }^{247}$ Pentoxifylline is more effective than corticosteroids for survival in patients with severe alcoholic hepatitis (Maddrey's discriminant factor $\geq 32$ ). A lower incidence of HRS in patients receiving pentoxifylline may point to a renal-protective effect. ${ }^{303}$ However, in a previous large-scale, double-blinded, randomized controlled trial to compare the efficacy of prednisolone and pentoxifylline in patients with severe alcoholic hepatitis, treatment with pentoxifylline did not affect the incidence of mortality or
AKI. ${ }^{304}$ In some retrospective studies, rifaximin decreased the incidence of AKI and HRS in patients with cirrhotic ascites. ${ }^{249,305}$ But in a double-blinded, randomized controlled trial to compare the efficacy of lactulose only and lactulose with rifaximin to treat hepatic encephalopathy, the combined treatment (lactulose with rifaximin) was more effective in improving hepatic encephalopathy and patient prognosis, although it did not affect the incidence of HRS. $^{306}$

\section{[Recommendations]}

1. In patients with liver cirrhosis, acute kidney injury is defined as an increase in serum creatinine of $\geq 0.3 \mathrm{mg} / \mathrm{dL}$ within 48 hours, or $\geq 1.5$ times the baseline within 7 days (B1).

2. In patients with liver cirrhosis and ascites, hepatorenal syndrome is defined as no response after 2 consecutive days of diuretic withdrawal and plasma volume expansion with albumin $(1 \mathrm{~g} / \mathrm{kg}$ body weight), in absence of other potential causes of renal injury (B1).

3. In patients with spontaneous bacterial peritonitis, intravenous albumin infusion prevents hepatorenal syndrome development in those with high risk factor for hepatorenal syndrome (A1).

\section{Treatment of acute kidney injury and hepatorenal syndrome in cirrhosis}

\section{General management}

The therapeutic approach for AKI that accompanies cirrhosis depends on the cause of $\mathrm{AKI}$, precipitating factors of renal damage, other organ dysfunction, and comorbid conditions. Management should be preceded by a process to verify these factors (Fig. 2). Functional impairment, which is not a renal parenchymal injury, can be reversed by elimination of the causative factors. It is necessary to first correct reversible triggering factors that may cause acute renal injury early in treatment. Proteinuria and hematuria must be identified to distinguish structural damage and the possibility of renal damage by nephrotoxic drugs or radiological contrast agents, which should be identified and discontinued. In addition, NSAIDs and vasodilators should be discontinued, and diuretics should be reduced or discontinued. In the first stage of $A K I$, if the plasma volume is inadequate, the patient should actively increase plasma volume by administering crystalloid fluid, albumin, and blood products. If a bacterial infection is suspected, antibiotics should be administered immediately. If $\mathrm{s} C \mathrm{r}$ is recovered to within a $0.3 \mathrm{mg} / \mathrm{dL}$ increase in baseline in response to these primary treatments, it is necessary to check sCr for 2 to 4 days intervals during hospitalization, and at 2-4 week intervals after dis- 


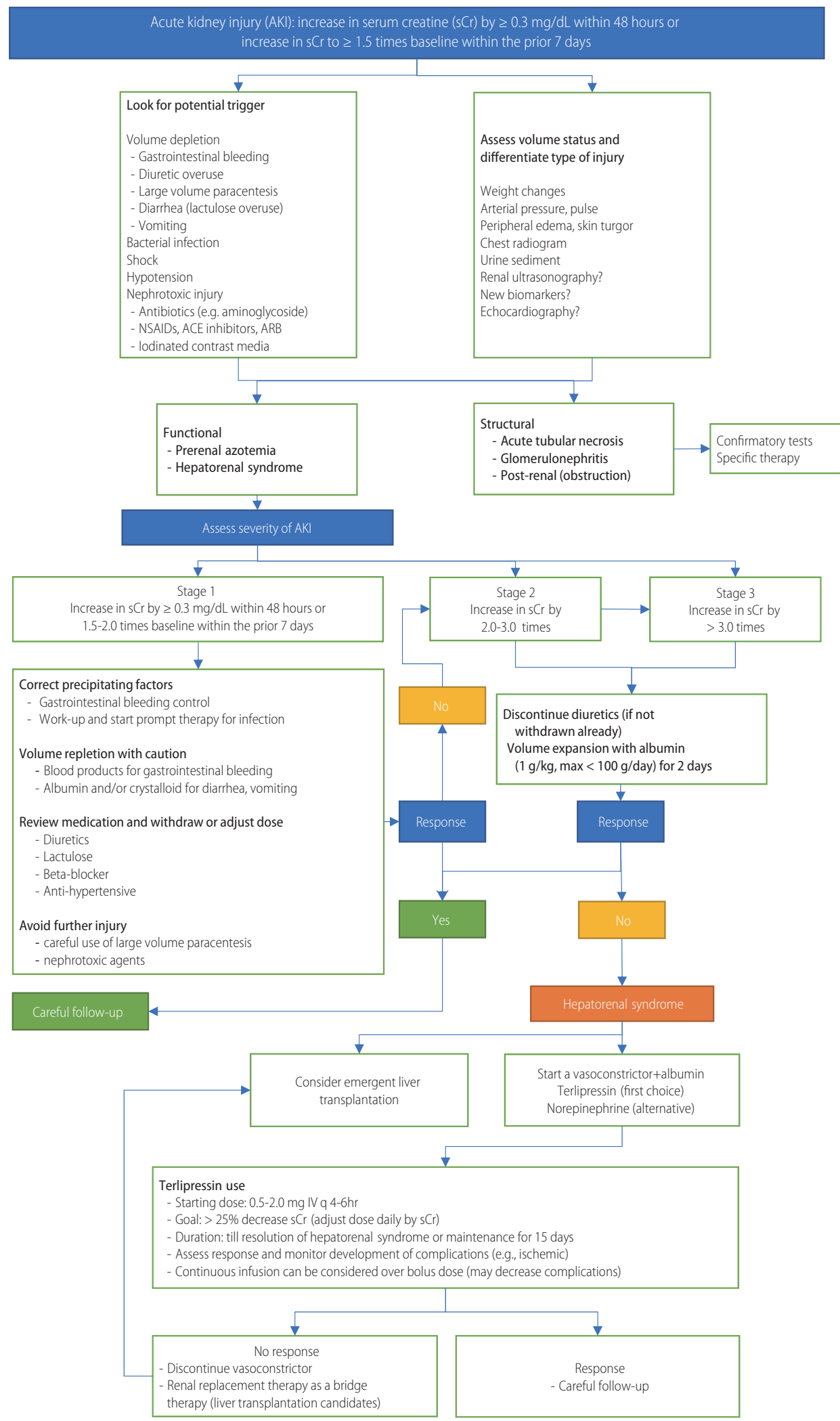

Figure 2. Treatment algorithm for acute kidney injury. NSAIDs, non-steroidal anti-inflammatory drugs; ACE, angiotensin converting enzyme; ARB, angiotension recepter blocker. 
The Korean Association for the Study of the Liver (KASL) Treatment guideline for ascites and related complications

charge for six months. ${ }^{262}$ If the renal impairment is exacerbated to AKI stage 2 or 3 in spite of the initial treatment, or if the patient presents with AKI stage 2 or 3 , diuretics should be discontinued. The patient should receive treatment for plasma volume expansion for 2 consecutive days together with $1 \mathrm{~g} / \mathrm{kg} /$ day (up to $100 \mathrm{~g} /$ day) of albumin intravascular supply. ${ }^{263,307}$ If there is no response to therapy and the patient complies with HRS, administration of a vasoconstrictor (such as terlipressin) with albumin should be considered. ${ }^{282} A$ therapeutic approach based on these criteria is expected to help identify the type of AKI and to diagnose and treat the HRS slightly earlier, but it is still necessary to establish evidence through large-scale prospective clinical studies. The ICA has defined AKI progression, regression, and therapeutic response as no, partial, and complete response to therapy as follow (Table 11).

\section{Pharmacological treatment}

Albumin: Albumin accounts for $60 \%$ of normal plasma proteins. It has a negative charge, which exerts oncotic pressure that attracts sodium and water. ${ }^{308}$ Therefore, administration of albumin may be a useful evaluation method for determining the relationship between AKI and insufficient plasma volume. In ICA, $1 \mathrm{~g}$ of albumin per $\mathrm{kg}$ of body weight (up to $100 \mathrm{~g}$ per day) is administered for 2 days, and it is used as an important index for judging the occurrence of HRS. ${ }^{282}$ In addition, albumin has a free cysteine moiety (cys34) that gives it antioxidant and scavenging properties. It is capable of absorbing and removing proinflammatory cytokines, bacterial products, and radical oxygen species. ${ }^{309}$ Administration of albumin improves renal blood flow in patients with AKI accompanied by acute decompensated aggravation of cirrhosis. This alleviates the secondary hyperactivity of the sympathetic nervous system. ${ }^{310}$ A combination therapy of antibiotics and albumin for SBP is known to improve renal blood flow and the survival rate compared with antibiotic monotherapy. ${ }^{106,228,229}$ In the case of cirrhotic patients with infectious diseases other than SBP, a com- bined treatment of antibiotics and albumin delayed the onset of AKI (compared with antibiotic monotherapy) in a randomized controlled trial of 193 patients. ${ }^{298}$ However, there was no difference in the cumulative incidence of kidney injury or mortality rate, with a higher incidence of pulmonary edema (8.3\%) among albumintreated group. Therefore, the albumin influsion should be cautiously used. ${ }^{298}$ Although albumin alone cannot be improve HRS, $^{311,312}$ albumin has anti-inflammatory and antioxidant effects that regulate immune responses and stabilize endothelial cells, helping the action of the vasoconstrictor. ${ }^{313}$

Vasoconstrictors: Although vasoconstriction is central to the treatment of HRS, data on the efficacy of treating AKI with vasoconstrictors before the onset of HRS are still lacking. ${ }^{314}$

\section{Terlipressin}

Terlipressin, a derivative of vasopressin, acts on V1 vasopressin receptors in the smooth muscle cells of the vascular wall to cause vasoconstriction. Terlipressin stabilizes the increased sympathetic nervous system and improves blood flow and perfusion to the kidney by moving the blood of the increased splanchnic circulation into other major organs through the constriction of the splanchnic vasculature in patients with liver cirrhosis.

In prospective randomized controlled trials, the combination of terlipressin and albumin showed improvement in renal function. Recovery of HRS was about $27-44 \%$, showing a significant effect compared with albumin monotherapy. ${ }^{312,315,316}$ However, in the above studies, the combination of terlipressin and albumin did not show an improvement in the survival rate compared with the control group. This was because many patients did not recover from HRS in the combination group. In the case of HRS associated with infection, sCr was reduced to less than $1.5 \mathrm{mg} / \mathrm{dL}$ in 12 of $18 \mathrm{pa}$ tients who received the combination of terlipressin and albumin for 9 days. The improvement of infection and mean blood pres-

Table 11. The 2015 International Club of Ascites definitions for change and response to treatment ${ }^{282}$

\begin{tabular}{ll}
\hline Progression of AKI & Progression of AKI to a higher stage and/or need for RRT \\
Regression of AKI & Regression of AKI to a lower stage \\
Response to treatment & \\
No response & No regression of AKI \\
Partial response & Regression of AKI stage with a reduction of $\mathrm{s} C \mathrm{r}$ to $\geq 0.3 \mathrm{mg} / \mathrm{dL}$ above the baseline value \\
Full response & Return of $\mathrm{s} C \mathrm{r}$ to a value within $0.3 \mathrm{mg} / \mathrm{dL}$ of the baseline value \\
\hline
\end{tabular}

$\mathrm{AKI}$, acute kidney injury; RRT, renal replacement therapy; sCr, serum creatinine. 
sure were independent factors of renal function recovery, suggesting that elimination of systemic inflammation and circulatory disturbances are important factors in the recovery of renal function. ${ }^{297}$ Although terlipressin is the best evidence-based treatment for HRS, it has not yet been approved for use in many countries, including the United States. Certain side effects of this drug (including abdominal pain and diarrhea) are reported to be as high as $30 \%$. Although they are relatively rare, serious side effects (including ischemia of the extremities, hyponatremia, and arrhythmia like bradycardia) may occur. ${ }^{317}$ There is a lack of evidence for the adequate dose and duration of therapy using terlipressin in the treatment of HRS. Generally, terlipressin is administered intravenously every 4-6 hours at $0.5-2.0 \mathrm{mg} / \mathrm{dose}$, and increase up to 2 $\mathrm{mg} /$ dose every 4 hours if the $\mathrm{s} C \mathrm{r}$ is not decreased by $25 \%$ after 3 days of drug administration. In patients with a therapeutic response, an increase in urinary output occurs within 12-24 hours of terlipressin administration, and an increase in the glomerular filtration rate appears slowly over several days. Maintenance therapy can be administered until the HRS is recovered, or up to 15 days. In a recent study comparing the administration of bolus doses and continuous infusion of terlipressin (to reduce ischemic side effects), the incidence of side effects was lower in continuous infusion group (62.1\% and $35.3 \%$, respectively), the total dose was also lower with continuous infusion group, while the response rate was similar (64.9\% and $76.5 \%$, respectively). Further study and consideration of drug administration methods are needed in the future. ${ }^{318}$ Predicting the terlipressin therapy response is clinically important. An increase in mean blood pressure after treatment with terlipressin is a good prognostic factor. Severe hyperbilirubinemia ( $>10 \mathrm{mg} / \mathrm{dL}$ ) and $\mathrm{s} C \mathrm{C}>5 \mathrm{mg} / \mathrm{dL}$ at baseline are poor prognostic factors. ${ }^{296,316,319}$ In a systematic review of randomized controlled trials including 739 patients, terlipressin was associated with a reduction in short-term mortality compared to placebo (OR, $0.65 ; 95 \% \mathrm{Cl}, 0.41-1.05$ ) and compared to midodrine and octreotide $(O R, 26.25 ; 95 \% \mathrm{Cl}, 3.07-224.21)$. After terlipressin treatment, $16 \%$ of patients (range, 5-20\%) had recurrence of HRS after discontinuation of medication, and $8 \%$ (range, $4-22 \%$ ) could not sustain the drug because of severe side effects. ${ }^{320}$

\section{Norepinephrine}

Systemic vasoconstrictors like norepinephrine and midodrine increase mean arterial pressure and improve renal perfusion pressure. In a randomized comparison of norepinephrine and terlipressin in HRS patients, norepinephrine showed similar effects and side effects to terlipressin. ${ }^{321,322}$ Combination therapy with norepinephrine and albumin was reported to be more effective than midodrine, octreotide, and albumin therapy. ${ }^{320,323}$ Therefore, in countries where terlipressin is not approved for use (including those in North America), norepinephrine is recommended..$^{148} \mathrm{~A}$ recent systematic review of the literature suggests that norepinephrine has been effective in restoring HRS compared to placebo (OR, 4.17; $95 \% \mathrm{Cl}, 1.37-12.50)$, however, randomized controlled trials reporting norepinephrine effects are limited by small sized studies, and the evidence level to suggest norepinephrine use are weak. The use of this drug often requires monitoring of the heart in the intensive care unit. It is not preferred in regions where terlipressin is available, such as Korea. Norepinephrine is continuously infused at 0.5-3.0 mg per hour, and the dose is adjusted to increase the mean arterial pressure to $10 \mathrm{mmHg}$ in the intensive care unit. ${ }^{324}$

\section{Midodrine and octreotide}

Midodrine raises mean arterial pressure through the alpha-adrenergic effect. The combination of octreotide and albumin (a nonspecific vasoconstrictor of visceral blood vessels) significantly improves renal function in $\mathrm{HRS}^{325-327}$ and some studies have shown significant survival improvement compared to non-treated groups. ${ }^{326,327}$ In North America, this combination therapy is recommended for use in patients with HRS. ${ }^{148}$ However, in a randomized controlled study, the improvement of renal function was lower than with terlipressin and albumin. ${ }^{328}$ In a recent systematic review of the literature, terlipressin therapy was superior to midodrine and octreotide combination therapy $(\mathrm{OR}, 10.0 ; 95 \% \mathrm{Cl}, 1.5$ 50.0). ${ }^{320}$ Therefore, in countries where terlipressin is available (such as Korea), combination therapy with midodrine and octreotide is not considered as the primary treatment for HRS. Typically, a midodrine dose of $7.5-12.5 \mathrm{mg}$ is given three times per day, with the goal of increasing mean arterial pressure by $15 \mathrm{mmHg}$. Octreotide is injected subcutaneously at a dose of $100-200 \mathrm{mg}$ three times per day. ${ }^{324}$

\section{Non-pharmacological treatment: Renal replacement therapy}

If cirrhotic patients present with uremic symptoms, excessive fluid, refractory hyperkalemia, or metabolic acidosis despite medication, renal replacement therapy needs to be considered. These patients often have difficulty with hemodialysis due to hemodynamic instability, lack of effective plasma volume, and risk of bleeding. Continuous renal replacement therapy can be consid- 
The Korean Association for the Study of the Liver (KASL) Treatment guideline for ascites and related complications

ered when conventional hemodialysis is not possible. In one study, a total of 102 patients with AKI awaiting liver transplantation were treated with renal replacement therapy, including continuous renal replacement therapy. Approximately $30 \%$ of patients receiving liver transplantation showed improvement, suggesting that renal replacement therapy in liver cirrhosis may be useful as a bridge treatment. ${ }^{329}$ However, since renal replacement therapy itself does not lead to the recovery of HRS, renal replacement therapy without liver transplantation is not helful in improving the survival, and may result in prolonging a poor clinical outcome. $^{299,330}$

\section{Transjugular intrahepatic portosystemic shunt}

In year 1998, TIPS was performed in seven patients with type 1 HRS, reported that six of the seven patients had renal function recovery. However, the mean survival time was 4.7 months, and four mortalities among the seven patients were within 90 days. ${ }^{331}$ Thus, safety and usefulness of TIPS is unclear. In early studies, TIPS was reported to reduce $\mathrm{s} C r$ and improve survival in patients with HRS. ${ }^{332,333}$ Prior treatment with vasoconstrictors prior to the application of TIPS was also repored to be helpful in improving renal function. ${ }^{325}$ TIPS was more effective in type 2 HRS than in type 1 HRS, as type 2 HRS shows relatively stable renal function. ${ }^{334}$ However, there are no randomized controlled trials comparing TIPS with medical treatment including vasoconstrictors. TIPS may increase the risk of hepatic encephalopathy, reduce systemic blood pressure through systemic arterial relaxation, and possibly lower the renal perfusion pressure. Most studies reporting the usefulness of TIPS are based on selected patients with relatively stable liver function, so caution is needed in the interpretation and application of the results of TIPS studies in HRS. ${ }^{335,336}$

\section{Molecular adsorbent recirculating systems (MARS)}

There are several kinds of extracorporeal therapies for liver disease, including molecular adsorbent recirculating systems (MARS), extracorporeal liver-assist devices, bio-artificial livers, bio-artificial liver support systems, and modular extracorporeal liver support systems. MARS is an albumin-assisted dialysis aid that helps maintain intestinal and systemic blood vessel relaxation by adsorbing and removing various cytokines and bacterial byproducts. MARS was designed to restore blood flow to the kidneys and improve renal function. In early studies, MARS caused a decrease in sCr levels. ${ }^{337,338}$ However, decrease in $\mathrm{sCr}$ was not due to an improvement in renal function, but due to elimination of $\mathrm{s} C \mathrm{r}$ by dialysis. ${ }^{339}$
Liver transplantation: The only treatment that can improve the long-term survival rate in patients with HRS is liver transplantation. A reduction in renal function before transplantation may affect survival and increase complications following transplantation. ${ }^{265,340}$ Recovery of renal function after liver transplantation is known to occur in about $50-75 \%$ of cases. ${ }^{341,342}$ The duration of renal impairment before liver transplantation is an important factor in predicting renal function after transplantation. Renal replacement therapy more than 14 days prior to transplantation is associated with nonreversal of renal function, and increases risk by $6 \%$ per each day increase in renal replacement therapy. ${ }^{342}$ This is likely related to structural changes of the kidney due to longterm ischemia. The liver and kidney dual transplantation is recommended when renal replacement therapy is given for more than 4 weeks before liver transplantation. ${ }^{299}$ The prognosis of patients recovering from HRS after liver transplantation is good. The 6-month to 1-year survival rate is over $90 \%,{ }^{342,343}$ and this is unrelated to the medication used for HRS before transplantation. If renal function is not restored after transplantation, the 1-year survival rate decreases to $60 \% .{ }^{342}$ Therefore, when a patient with HRS does not respond to medication, liver transplantation should be done as early as possible. There is no difference in the rate of renal function recovery between living-donor and cadaveric-donor liver transplantation. ${ }^{344,345}$

\section{[Recommendations]}

1. In liver cirrhosis patients with acute kidney injury or hepatorenal syndrome, diuretics should be reduced or discontinued (A1).

2. In liver cirrhosis patients with acute kidney injury, restroring effective blood volume by albumin infusion is helpful in restoring renal function (A1).

3. The combination treatment of terlipressin and albumin is recommended for the improvement of renal function in hepatorenal syndrome (A1).

4. Where terlipressin is not available, the combination treatment of norepinephrine and albumin is recommended for the improvement of renal function in hepatorenal syndrome (A2).

5. The combination treatment of midodrine, octreotide, and albumin may also be considered in hepatorenal syndrome (B2).

6. The best treatment for hepatorenal syndrome is liver transplantation (A1).

\section{OTHER COMPLICATIONS OF CIRRHOSIS}

\section{Hepatic hydrothorax}

Hepatic hydrothorax $(\mathrm{HH})$ is a complication of portal hyperten- 
sion, characterized by a transudative pleural effusion in the absence of underlying cardiac or pulmonary disease. Its prevalence has been estimated to be $5-10 \%$ in cirrhosis patients. ${ }^{346}$

\section{Pathophysiology}

The direct passage of fluid from the peritoneal to the pleural cavity through diaphragmatic defects is the accepted mechanism explaining most cases of $\mathrm{HH} .{ }^{347}$ Most diaphragmatic defects are $<1 \mathrm{~cm}$ in size and are predominantly located on the right hemidiaphragm. ${ }^{348}$ Malnutrition in cirrhosis seems to make thinning of the diaphragmatic muscle and formation of these defects. Additionary, negative intrathoracic pressure is thought to lead to the oneway directional flow of ascitic fluid from the abdominal cavity. ${ }^{349}$

\section{Clinical manifestation}

Most patients have right-sided effusions, but a few patients present with left-sided or bilateral effusions. In one study, $\mathrm{HH}$ was right-sided in $70 \%$ of cases, left-sided in $18 \%$, and bilateral in $12 \%$. ${ }^{346}$ When there is left-sided $\mathrm{HH}$, possibility of tuberculosis, cancer, and pancreatic disease should be considered. ${ }^{350}$ The pleural cavity is a restricted space, and smaller volumes of fluid ( $\sim 500$ $\mathrm{mL}$ ) in the peritoneal space can make symptoms frequently. ${ }^{349} \mathrm{~Pa}$ tients in whom pleural effusion is minimal may be asymptomatic, or they may have pulmonary symptoms of dyspnea, cough, chest discomfort, hypoxemia, or respiratory failure (usually associated with large pleural effusions).

\section{Diagnosis}

Chest radiography is used to diagnose the presence of pleural effusion, and thoracentesis is needed for the initial diagnosis of HH. Thoracentesis is performed to identify the cause of pleural effusion, to make sure the presence of infection, and to provide the relief of symptom. Thoracentesis can be performed without infusion of platelets or fresh frozen plasma. ${ }^{351}$ Pleural fluid analysis should include protein, albumin, LDH, cell count, Gram stain, and culture examination. The nature of $\mathrm{HH}$ is transudate, and the diagnosis of uncomplicated HH is as follows: 1) a serum to pleural fluid albumin gradient (SPAG) $>1.1$; 2) pleural fluid total protein $<2.5 \mathrm{~g} / \mathrm{dL}$, or pleural fluid/serum total protein ratio $<0.5 ; 3$ ) pleural fluid/serum LDH ratio $<0.6$; and 4) PMN $<250$ cells/ $\mathrm{mm}^{3}{ }^{3.52}$ Spontaneous bacterial pleuritis (SBPL) is a infection of $\mathrm{HH}$ and requires prompt antibiotic therapy. When SBPL is suspected, diagnostic thoracentesis is essential. SBPL is diagnosed when PMN $>250$ cells $/ \mathrm{mm}^{3}$ with positive pleural fluid culture, or when PMN $>500$ cells $/ \mathrm{mm}^{3}$ with negative pleural fluid culture (without any evidence of pneumonia on chest $X$-ray). ${ }^{353}$ Symptoms of SBPL differ from fever and pleuritic chest pain to deteriorating encephalopathy or worsening of renal function. The microorganisms involved in SBPL are similar to those involved in SBP. ${ }^{354,355}$ SBPL develops in $10-16 \%$ of patients with cirrhosis and $\mathrm{HH}$, and is more common in patients with low total protein $(<1.5 \mathrm{~g} / \mathrm{dL})$, low pleural fluid C3 complement levels, and more higher Child-Pugh score. ${ }^{354,355}$ Over $50 \%$ of patients with ascites and SBPL do not develop concomitant SBP. In such patients who is suspected with infection but paracentesis is negative, thoracentesis is essential. ${ }^{353}$

\section{Treatment}

The development of $\mathrm{HH}$ represents progression to decompensated cirrhosis and should warrant prompt consideration for liver transplantation. ${ }^{356}$ Medical management of $\mathrm{HH}$ is similar to the management of ascites. Restriction of sodium intake with the administration of diuretics is effective in controlling $\mathrm{HH}$, and therapeutic paracentesis is performed in cases of symptomatic dyspnea. Limiting pleural fluid removal to $1-2 \mathrm{~L}$ is recommended to decrease the risk of re-expansion pulmonary edema, although recent data suggest that larger volumes can be safely removed if no symptoms develop during the procedure, and end-expiratory pleural pressure remains below $20 \mathrm{cmH}_{2} \mathrm{O}^{357}$ However, repeated thoracentesis is associated with an increased risk of infection, bleeding, and protein loss. ${ }^{351}$ The standard of care for refractory $\mathrm{HH}$ is TIPS, with response rates of $70-80 \%{ }^{358-362}$ However, severe liver dysfunction, poorly controlled hepatic encephalopathy, rightsided heart failure, pulmonary hypertension, and complete portal vein thrombosis are contraindications for TIPS in HH. Risk factors for increased mortality in patients receiving TIPS for $\mathrm{HH}$ include elevated baseline $\mathrm{SCr}$, a MELD score $>15$, and a poor response to TIPS. ${ }^{349}$

Video-assisted thoracoscopy with pleurodesis is a potential treatment alternative for patients with refractory $\mathrm{HH}$ who are not eligible for TIPS, or who have failed to respond to TIPS ${ }^{363,364}$ However, video-assisted thoracoscopy appears to be inferior to TIPS and can have complications including fistula, empyema, and death. Therefore, it should only be considered in cases that are uncontrollable with medical treatment and TIPS. ${ }^{349}$ Chest tube insertion should be cautious in HH and SBPL due to serious complications including empyema, hemothorax, pneumothorax, and HRS. ${ }^{36,366}$ Since chest tube insertion is associated with high adverse events, and as most cases of SBPL respond to antibiotic therapy alone, a chest tube should not be placed in patients with SBPL unless they meet specific criteria (e.g., frank pus or pH 
The Korean Association for the Study of the Liver (KASL) Treatment guideline for ascites and related complications

< 7.2). ${ }^{353,367}$ Indwelling pleural catheter insertion can provide symptomatic relief until TIPS or transplantation, and can be performed. However, further studies are required to see the effectiveness of indwelling pleural catheters. ${ }^{367-370}$

\section{[Recommendations]}

1. The development of hepatic hydrothorax should prompt consideration for liver transplantation. First-line therapy consists of dietary sodium restriction and diuretics (B1).

2. Transjugular intrahepatic portal-systemic shunt can be considered for refractory hepatic hydrothorax (B2).

3. Spontaneous bacterial pleuritis is diagnosed when polymorphonuclear leukocyte $>250$ cells $/ \mathrm{mm}^{3}$ with positive pleural fluid culture, or when polymorphonuclear leukocyte $>$ 500 cells $/ \mathrm{mm}^{3}$ with negative pleural fluid culture without any evidence of pneumonia. Spontaneous bacterial pleuritis can be treated with appropriate antibiotics alone in most cases (B1).

\section{Abdominal hernia in patients with cirrhotic ascites}

Abdominal hernia (including umbilical, inguinal, and femoral hernia) is common in cirrhotic patients with ascites. Particularly, umbilical hernia is observed in up to $20 \%$ of these patients. ${ }^{371}$ Abdominal hernia can be prevented by lowering intra-abdominal pressure with effective ascites control. For the prevention of umbilical hernia, an abdominal support belt may be helpful. Manual support is recommended to prevent abdominal hernia in situations of increased abdominal pressure, such as coughing or straining.

If large-volume of ascites is evacuated rapidly (e.g. due to LVPs, peritoneovenous shunt, or TIPS), the large intestine or omentum may be trapped in the hernia ring, and incarceration may occur. Trapped intestine can turn necrotic or perforate if manual reduction fails, and emergency surgery should be considered in this situation. Thus, patients with hernia should acknowledge the risk of developing incarceration.

Patients scheduled for liver transplantation may require hernia repair during or after transplantation. Patients who are not on a waiting list for liver transplantation require a careful decision for surgery. Strangulated hernia (which does not respond to manual reduction) needs emergency surgery, even in patients with decompensated liver function. ${ }^{372}$ For patients with preserved liver function, surgical reduction can be considered (even for nonstrangulated hernia) to improve quality of life. ${ }^{373,374}$

If ascites exists before surgical repair, recurrence of hernia is very frequent (up to $73 \%$ ), so ascites control is very important. ${ }^{375}$
To control ascites before surgery, a multidisciplinary approach may be necessary, such as TIPS in addition to diuretic treatment. ${ }^{376}$ To prevent the recurrence of hernia after surgery, all patients are advised to restrict their daily sodium intake to $<2 \mathrm{~g}$ (5 $\mathrm{g}$ of salt), and to minimize the use of sodium-rich intravenous fluid therapy.

\section{[Recommendations]}

1. Controlling ascites is important to reduce intra-abdominal pressure. This can prevent the occurrence of an abdominal hernia, or slow the worsening of a hernia (B1).

2. Strangulated hernia is an indication for emergent surgical repair (B1).

\section{CONSIDERATIONS FOR DRUG USE IN CIR- RHOTIC PATIENTS}

The liver plays a central role in the absorption, distribution, and elimination kinetics of most drugs and many active or inactive drug metabolites. Impairment of liver function may have complex effects on drug clearance, biotransformation, and a drug's pharmacokinetics. These changes can lead to alterations in various parameters affecting the efficacy or safety of drugs. Sometimes alterations increase levels of the bioavailable drug, causing normal drug doses to have toxic effects. Therefore, patients with hepatic dysfunction may be more sensitive to the effects, both desired and adverse, of several drugs. The main problem with drug use in patients with hepatic dysfunction is that physicians cannot define with precision the degree of impairment of liver function relevant to elimination of a particular drug in a given patient. Unfortunately, there is currently no single equivalent of the clearance creatinine test (as for renal disease) routinely available to clinicians to accurately determine what extent hepatic dysfunction will have on a drug's pharmacokinetics. Moreover, there is no clear test to predict hepatic function with respect to the elimination capacity of specific drugs, and no general rules are available for modifying drug dosage in patients with hepatic dysfunction. It is important to have a solid understanding of changes to a drug's pharmacokinetic properties, in combination with an assessment of a patient's hepatic function in cirrhotic patients. ${ }^{377}$

\section{Effects of cirrhosis on drug metabolism}

The liver plays a major role in drug metabolism. Metabolism is 
dependent on the metabolic capacity of the liver and hepatic blood flow. A number of significant pharmacokinetic changes are known to occur in cirrhotic patients. These often raise several concerns in using medications safely. ${ }^{378,379}$ Hepatic clearance of drugs depends on the activity of drug-metabolizing enzymes, and clearance capacity is often reduced in cirrhotic patients. Cirrhosis may lead to the formation of portosystemic shunts, which are new blood vessels that divert blood from the abdominal viscera to the heart (bypassing the liver). As a result, a substantial fraction of the blood, which would normally reach the portal vein, flows through these shunts. This process decreases rates of drug metabolism. It also affects absorption, distribution, bioavailability, elimination, and cytochrome P450 metabolism due to hypoalbuminemia, portal hypertensive gastropathy, ascites, edema, and substantial renal blood flow reduction. In cirrhotic patients, the clinician should consider pharmacokinetic changes, the severity of liver disease, compromised metabolic pathways, and the administration route in choosing the type, dose, and administration interval of drugs. It is also important to consider changes in altered receptor sensitivity (i.e. pharmacodynamics, including tissue responsiveness to the pharmacological action). The pharmacodynamic responses to various drugs, and the frequency and pattern of adverse effects, are altered in cirrhotic patients. Clinically, the most important medications are sedatives (e.g. benzodiazepines), diuretics, and vasoconstrictors. ${ }^{378,380}$ Cirrhotic patients usually have resistance or a diminished response to loop diuretics because of pharmacodynamic alterations. The natriuretic potency of furosemide is markedly reduced in decompensated patients with ascites. $^{381}$

\section{Effects of transjugular intrahepatic portal-systemic shunt and portosystemic shunting on drug metabolism}

TIPS and other surgical shunts (e.g. the Denver shunt) are performed to manage complications from portal hypertension. Patients who have undergone TIPS appear to develop changes in drug metabolism. For drugs with a high hepatic extraction, portosystemic shunting (both endogenous and iatrogenic) may reduce first-pass metabolism. This can increase oral bioavailability and decrease drug clearance in the liver. ${ }^{377,382}$ Thus, if such drugs are administered orally to cirrhotic patients, the initial dose should be reduced according to the ratio of their hepatic extraction. Examples include beta-adrenergic blockers, calcium channel antagonists, cisapride and other prokinetic agents, antipsychotics, anti- anxiety and sedative agents, antiparkinson drugs, antidepressants, sumatriptan, certain statins (e.g. fluvastatin and lovastatin), and morphine. Cirrhotic patients with artificial portosystemic shunting are frequently found to have baseline QTc interval prolongation, likely reflecting an altered ventricular repolarization due to the portosystemic shunting of splanchnic-derived cardioactive substances into the systemic circulation. ${ }^{383}$ Clinicians should avoid prescribing any medications known to prolong QTC in cirrhotic patients who have undergone TIPS (e.g., patients who are being prescribed a fluoroquinolone for SBP treatment or prophylaxis), as it can lead to potentially fatal ventricular arrhythmias. ${ }^{377}$

\section{Analgesics}

In 2012, the prescription pattern of analgesics for cirrhotic patients registered with the Health Insurance Review Assessment Service was reported. Approximately $40.5 \%$ of 125,505 patients claimed reimbursement for at least one prescription for analgesics. This study showed that many cirrhotic patients are exposed to analgesics. ${ }^{384}$

\section{Acetaminophen}

Acetaminophen is a widely used nonprescription analgesic and antipyretic medication for mild-to-moderate pain and fever. Although acetaminophen rarely induces hepatotoxicity by an idiosyncratic mechanism, it is an intrinsic hepatotoxin with a narrow safety margin. ${ }^{385}$ This means there is little difference between the maximum daily dose and a potentially harmful dose. acetaminophen toxicity can result from either an acute overdose or from chronic overuse. The recommended dose of acetaminophen in adults is 650 to 1,000 mg every 4 to 6 hours, not to exceed 4,000 $\mathrm{mg}$ in a 24-hour period. Single doses of more than $150 \mathrm{mg} / \mathrm{kg}$ (or $7.5 \mathrm{~g}$ ) in adults are considered potentially toxic, although the minimal dose associated with liver injury can range anywhere from 4 to $10 \mathrm{~g} .^{386}$ The probability of an individual patient without pre-existing liver disease or concomitant alcohol consumption developing clinically important hepatotoxicity when acetaminophen dosing is limited to less than $4 \mathrm{~g} /$ day is exceedingly rare. The American Liver Foundation recommends patients not exceed $3 \mathrm{~g}$ of acetaminophen daily for any prolonged period of time, and suggests a maximum daily dose of 2-3 $\mathrm{g}$ for cirrhotic patients. ${ }^{382,387}$ Generally, low-dose therapy is acceptable in most patients with chronic liver disease/cirrhosis. But chronic use should be avoided, and cirrhotic patients with ascites should be cautious of acetaminophen use. 
The Korean Association for the Study of the Liver (KASL) Treatment guideline for ascites and related complications

\section{Non-steroidal anti-inflammatory drugs}

NSAIDs are associated with an increased risk of variceal/ulcer hemorrhage, impaired renal function, and the development of diuretic-resistant ascites in cirrhotic patients. ${ }^{388-390}$ Thus, NSAIDs should generally be used with caution in cirrhotic patients. Another concern related to the use of NSAIDs in cirrhotic patients with ascites is that they diminish the natriuretic effects of diuretics, leading to impaired free water clearance and the worsening of ascites and edema. Use of NSAIDs should be considered when evaluating patients with apparent diuretic-resistant ascites. Most NSAIDs are highly protein-bound, usually to albumin, thereby increasing the free component of NSAID in the serum. ${ }^{391}$ Some NSAIDs (e.g. diclofenac) have a significant hepatotoxic potential. ${ }^{377}$

Selective COX-2 inhibitors are effective analgesics that are associated with a decreased incidence of gastrointestinal and renal toxicity. However, they have been associated with an increased incidence of adverse cardiovascular events. At present, available studies on the safety and efficacy of COX-2 selective inhibitors in cirrhotic patients are limited. One pilot study in humans included 28 patients with cirrhosis and ascites who were randomly assigned to receive celecoxib, naproxen, or placebo. ${ }^{390} \mathrm{~A}$ significant reduction in the GFR, renal plasma flow, and urinary prostaglandin E2 excretion was observed in the group receiving naproxen but not celecoxib. Suppression of the diuretic and natriuretic response to furosemide was also observed in the group receiving naproxen but not celecoxib. Furthermore, naproxen, but not celecoxib, significantly inhibited platelet aggregation. The study evaluated only short-term treatment and involved only a small number of patients. Clearly, further studies are needed to address the use of COX-2 inhibitors in cirrhotic patients with ascites.

\section{Cardiovascular drugs}

NSBBs such as propranolol and nadolol have been shown to effectively reduce the risk of variceal bleeding and re-bleeding due to a reduction of portal pressure. This effect is mediated by several mechanisms acting on the hemodynamic alterations present in cirrhotic patients (e.g. a decrease in cardiac output via $\beta 1$ receptors, and a splanchnic vasoconstriction through $\beta 2$ receptors). ${ }^{392}$ NSBBs typically have a high rate of first-pass extraction by the liver, and lower bioavailability. In cirrhotic patients, impairment of hepatic blood flow can decrease the metabolism of high-extraction drugs, leading to significantly higher drug exposure. Therefore, careful dose monitoring is needed. ${ }^{37,393}$ Recently, a growing body of evidence has shown that NSBBs can be harmful in end- stage liver cirrhosis. In 2010, a study by Sersté et al. demonstrated reduced survival in patients with refractory ascites who were treated with propranolol. ${ }^{120}$ This study initiated debate among hepatologists on the appropriate use of NSBBs in patients with refractory ascites. Nearly half of the patients included in the study by Serste et al..$^{119}$ received the high propranolol dose of $160 \mathrm{mg}$. In a consecutive cross-over study, propranolol treatment was found to be associated with increased risk for paracentesis-induced circulatory dysfunction in cirrhotic patients with refractory ascites. NSBBs can cause exacerbations in systemic hemodynamics due to a reduction of cardiac output and systemic hypotension, resulting in renal insufficiency. ${ }^{394}$ But more recent studies investigating the effects of NSBB treatment in cirrhotic patients with ascites have reported contrary results. ${ }^{395,396}$ According to the concept of risk-benefit stratification, careful monitoring of blood pressure and renal function should be performed to identify scenarios in which the NSBB dose should be reduced, or treatment discontinued, in patients with refractory ascites or SBP.

Generally, angiotensin-converting enzyme inhibitors and angiotensin receptor blockers (ARBs) appear to be relatively well tolerated in cirrhosis. ${ }^{397,398}$ However, they should be avoided (even in low doses) in cirrhotic patients with ascites since they can induce arterial hypotension and renal failure. ${ }^{399,400}$

\section{Statins}

Statins, which are lipid-lowering agents, undergo first-pass hepatic metabolism and are associated with elevations in liver enzymes. Given that cirrhotic patients are at risk of decreased hepatic clearance, there is concern that this patient population may be at higher risk for complications from statin therapy. However, emerging data from prospective studies suggest that statin therapy appears to be safe and effective in patients with chronic liver disease and compensated cirrhosis. ${ }^{401,402} \mathrm{~A}$ large-scale populationbased study and meta-analysis have demonstrated a beneficial effect of statins on the risk of hepatic decompensation and mortality in patients with compensated cirrhosis. ${ }^{403,404} \mathrm{It}$ is important that clinicians understand the potential benefits, side effects, and challenges of using statin therapy in patients with cirrhosis. This requires regular monitoring of liver function. Besides their lipidlowering effects, statins also improve endothelial function by increasing the synthesis of nitric oxide, restoring the function of endothelial cells, and increasing the number of endothelial progenitor cells by decreasing the activation of inflammatory cells. In vitro and pre-clinical studies have also suggested a favorable impact of statins on hepatic inflammation, fibrosis, and can- 
cer. ${ }^{405,406}$ However, more clinical studies will be necessary to assess the benefits of statin use in cirrhosis, and to evaluate the best statin for different cirrhosis contexts (such as fibrosis or portal hypertension). ${ }^{407}$ The pharmacokinetics of statins in advanced cirrhotic patients with ascites have not been reported, and use in this setting has been discouraged. ${ }^{408}$

\section{Proton pump inhibitors}

There has been growing concern about the possible overuse and long-term side effects of proton pump inhibitors (PPIs). Several studies have suggested that PPIs are associated with increased risk for SBP, Clostridium difficile infection, and other serious infections in cirrhotic patients. ${ }^{409-413} \mathrm{PPI}$ use alters the gut microbiota. For example, hypochlorhydria induced by PPI use may lead to small bowel bacterial overgrowth and bacterial translocation. This might subsequently be important in the development of minimal or overt hepatic encephalopathy. ${ }^{409,414}$ From drug trials of satavaptan for ascites control, the confounder-adjusted HR of epatic encephalopathy for current PPI use versus non-use was $1.36(95 \% \mathrm{Cl}, 1.01-1.84)$. The adjusted HR of SBP for current PPI use versus non-use was 1.72 $(95 \% \mathrm{Cl}, 1.10-2.69)$. It is essential that clinicians are aware of the potential deleterious effects of long-term PPI use in cirrhotic patients, and that PPIs are used with caution. ${ }^{415}$

\section{[Recommendations]}

1. In cirrhotic patients, especially those with ascites, the use of drugs may cause altered pharmacokinetics/pharmacodynamics, and changes in susceptibility to side effects. Therefore, clinical efficacy and safety of drugs should be assessed frequently (A1).

2. In cirrhotic patients, acetaminophen use should not exceed 2-3 g/day (A1).

3. In cirrhotic patients with ascites, non-steroidal anti-inflammatory drugs can exacerbate ascites, edema, and renal function. Therefore, the use of non-steroidal anti-inflammatory drugs requires attention (B1).

4. In cirrhotic patients with refractory ascites or spontaneous bacterial peritonitis, non-selective ß-blockers should be used with caution. Careful monitoring of blood pressure and renal function is necessary (B1).

5. In cirrhotic patients with ascites, angiotensin-converting enzyme inhibitors and angiotensin II antagonists can induce arterial hypotension and renal failure, so their use requires attention (B1).

6. In cirrhotic patients, proton pump inhibitors can increase the incidence of spontaneous bacterial peritonitis and hepatic encephalopathy. Careful attention should be given to their longterm use (B1).

\section{Conflicts of Interest}

Potential conflicts of interest are as follows:

Yong-Han Paik: Consulted Bayer; received honoraria from BMS, Gilead, Bayer, MSD, and Chongkundang; received grants from Yuhan and Dong-A ST.

Yeon Seok Seo: Received honoraria from Gilead, Dong-A ST, IIdong, Hanmi, MSD, and Yuhan.

Moon Young Kim: Received grants from Alfa Wassermann, Samjin, and Yuhan; received honoraria from BMS, Gilead, and Dong-A ST; consulted Gilead.

Jun Yong Park: Received honoraria from BMS, Gilead, Yuhan, Dong-A ST, Hanmi, Celtrion, and CJ; received grants from Hanmi, Abbvie, Gilead, and Norvatis.

Ki Tae Suk: Nothing to disclose.

Do Seon Song: Received honoraria from BMS and Celtrion; consulted Samil.

Dong Hyun Sinn: Received honoraria from Gilead, Yuhan, DongA ST, and Celtrion; received a grant from Dong-A ST; consulted Abbvie and Bayer.

Jeong-Hoon Lee: Nothing to disclose.

Soung Won Jeong: Received honoraria from BMS and Hanmi; received grants from BMS, Samil, and Hanmi.

Young Kul Jung: Received honoraria from BMS, Dong-A ST, and Daewoog; received grants from Ferring, Sillajen, Dong-A ST, Daewoong, Chongkundang, Ildong, and BMS.

\section{SUPPLEMENTARY MATERIALS}

Supplementary materials are available at Clinical and Molecular Hepatology website (http://www.e-cmh.org).

\section{REFERENCES}

1. Ginés $P$, Quintero $E$, Arroyo $V$, Terés J, Bruguera $M$, Rimola $A$, et al. Compensated cirrhosis: natural history and prognostic factors. Hepatology 1987;7:122-128.

2. D'Amico G, Garcia-Tsao G, Pagliaro L. Natural history and prognostic indicators of survival in cirrhosis: a systematic review of 118 studies. J Hepatol 2006;44:217-231.

3. Guyatt GH, Oxman AD, Vist GE, Kunz R, Falck-Ytter Y, Alonso-Coello $P$, et al. GRADE: an emerging consensus on rating quality of evidence and strength of recommendations. BMJ 2008;336:924-926. 
The Korean Association for the Study of the Liver (KASL)

Treatment guideline for ascites and related complications

4. Runyon BA, Montano AA, Akriviadis EA, Antillon MR, Irving MA, McHutchison JG. The serum-ascites albumin gradient is superior to the exudate-transudate concept in the differential diagnosis of ascites. Ann Intern Med 1992;117:215-220.

5. Shaikh MA, Khan J, Almani S, Dur-e-Yakta, Shaikh D. Frequency of causes of ascites in patients admitted at medical unit of a tertiary medical care facility. J Ayub Med Coll Abbottabad 2010;22:88-92.

6. Runyon BA. Ascites. In: Schiff L, Schiff ER, eds. Diseases of the Liver. 7th ed. Philadelphia: Lippincott, 1993:990-1015.

7. Hwangbo Y, Jung JH, Shim J, Kim BH, Jung SH, Lee CK, et al. Etiologic and laboratory analyses of ascites in patients who underwent diagnostic paracentesis. Korean J Hepatol 2007;13:185-195.

8. Cattau EL Jr, Benjamin SB, Knuff TE, Castell DO. The accuracy of the physical examination in the diagnosis of suspected ascites. JAMA 1982;247:1164-1166.

9. Kuiper JJ, de Man RA, van Buuren HR. Review article: management of ascites and associated complications in patients with cirrhosis. Aliment Pharmacol Ther 2007;26 Suppl 2:183-193.

10. Sheer TA, Joo E, Runyon BA. Usefulness of serum N-terminalProBNP in distinguishing ascites due to cirrhosis from ascites due to heart failure. J Clin Gastroenterol 2010;44:e23-e26.

11. Runyon BA. Care of patients with ascites. N Engl J Med 1994;330: 337-342.

12. Borzio M, Salerno F, Piantoni L, Cazzaniga M, Angeli P, Bissoli F, et al. Bacterial infection in patients with advanced cirrhosis: a multicentre prospective study. Dig Liver Dis 2001;33:41-48.

13. European Association for the Study of the Liver. EASL clinical practice guidelines on the management of ascites, spontaneous bacterial peritonitis, and hepatorenal syndrome in cirrhosis. J Hepatol 2010;53:397-417.

14. Sakai H, Sheer TA, Mendler MH, Runyon BA. Choosing the location for non-image guided abdominal paracentesis. Liver Int 2005:25:984-986

15. Webster ST, Brown KL, Lucey MR, Nostrant TT. Hemorrhagic complications of large volume abdominal paracentesis. Am J Gastroenterol 1996;91:366-368.

16. Runyon BA. Paracentesis of ascitic fluid. A safe procedure. Arch Intern Med 1986;146:2259-2261.

17. Pache I, Bilodeau M. Severe haemorrhage following abdominal paracentesis for ascites in patients with liver disease. Aliment Pharmacol Ther 2005;21:525-529.

18. Liebowitz HR. Hazards of abdominal paracentesis in the cirrhotic patient. N Y State J Med 1962;62:2223-2229.

19. Serbin RA. Fatal hemorrhage from paracentesis; a case of Cruveilhier Baumgarten syndrome. Gastroenterology 1956;30:127-129.
20. Thomson A, Cain P, Kerlin P, Strong R. Serious hemorrhage complicating diagnostic abdominal paracentesis. J Clin Gastroenterol 1998;26:306-308.

21. Arnold C, Haag K, Blum HE, Rössle M. Acute hemoperitoneum after large-volume paracentesis. Gastroenterology 1997;113:978982.

22. Qureshi WA, Harshfield D, Shah H, Netchvolodoff C, Banerjee B. An unusual complication of paracentesis. Am J Gastroenterol 1992;87:1209-1211.

23. Park YJ, Lee SY, Kim SH, Kim IH, Kim SW, Lee SO. Transcatheter coil embolization of the inferior epigastric artery in a huge abdominal wall hematoma caused by paracentesis in a patient with liver cirrhosis. Korean J Hepatol 2011;17:233-237.

24. Kang JW, Kim YD, Hong JS, Kwon JH, Seo HW, Kim SH, et al. A case of lateral abdominal wall hematoma treated with transcatheter arterial embolization. Korean J Gastroenterol 2012;59:185188.

25. Martinet O, Reis ED, Mosimann F. Delayed hemoperitoneum following large-volume paracentesis in a patient with cirrhosis and ascites. Dig Dis Sci 2000;45:357-358.

26. McGibbon A, Chen GI, Peltekian KM, van Zanten SV. An evidence-based manual for abdominal paracentesis. Dig Dis Sci 2007;52:3307-3315.

27. Grabau CM, Crago SF, Hoff LK, Simon JA, Melton CA, Ott BJ, et al. Performance standards for therapeutic abdominal paracentesis. Hepatology 2004;40:484-488.

28. Mannucci PM. Abnormal hemostasis tests and bleeding in chronic liver disease: are they related? No. J Thromb Haemost 2006;4:721723.

29. Caldwell SH, Hoffman M, Lisman T, Macik BG, Northup PG, Reddy $K R$, et al. Coagulation disorders and hemostasis in liver disease: pathophysiology and critical assessment of current management. Hepatology 2006;44:1039-1046.

30. Jeffries MA, Stern MA, Gunaratnam NT, Fontana RJ. Unsuspected infection is infrequent in asymptomatic outpatients with refractory ascites undergoing therapeutic paracentesis. Am J Gastroenterol 1999;94:2972-2976.

31. Evans LT, Kim WR, Poterucha JJ, Kamath PS. Spontaneous bacterial peritonitis in asymptomatic outpatients with cirrhotic ascites. Hepatology 2003;37:897-901.

32. Runyon BA, Hoefs JC, Morgan TR. Ascitic fluid analysis in malignancy-related ascites. Hepatology 1988;8:1104-1109.

33. Ahadi M, Tehranian S, Memar B, Vossoughinia H, Salari M, Eskandari $E$, et al. Diagnostic value of carcinoembryonic antigen in malignancy-related ascites: systematic review and meta-analysis. 
Acta Gastroenterol Belg 2014;77:418-424.

34. Sathar MA, Simjee AE, Coovadia YM, Soni PN, Moola SA, Insam B, et al. Ascitic fluid gamma interferon concentrations and adenosine deaminase activity in tuberculous peritonitis. Gut 1995;36:419421.

35. Saleh MA, Hammad E, Ramadan MM, Abd El-Rahman A, Enein AF. Use of adenosine deaminase measurements and QuantiFERON in the rapid diagnosis of tuberculous peritonitis. J Med Microbiol 2012;61(Pt 4):514-519.

36. Portillo-Gómez L, Morris SL, Panduro A. Rapid and efficient detection of extra-pulmonary Mycobacterium tuberculosis by PCR analysis. Int J Tuberc Lung Dis 2000;4:361-370.

37. Inadomi JM, Kapur S, Kinkhabwala M, Cello JP. The laparoscopic evaluation of ascites. Gastrointest Endosc Clin N Am 2001;11:7991.

38. Menzies RI, Fitzgerald JM, Mulpeter K. Laparoscopic diagnosis of ascites in Lesotho. Br Med J (Clin Res Ed) 1985;291:473-475.

39. Singh MM, Bhargava AN, Jain KP. Tuberculous peritonitis. An evaluation of pathogenetic mechanisms, diagnostic procedures and therapeutic measures. N Engl J Med 1969;281:1091-1094.

40. Voigt MD, Kalvaria I, Trey C, Berman P, Lombard C, Kirsch RE. Diagnostic value of ascites adenosine deaminase in tuberculous peritonitis. Lancet 1989;1:751-754.

41. Bhargava DK, Gupta M, Nijhawan S, Dasarathy S, Kushwaha AK. Adenosine deaminase (ADA) in peritoneal tuberculosis: diagnostic value in ascitic fluid and serum. Tubercle 1990;71:121-126.

42. Ribera E, Martínez Vásquez JM, Ocaña I, Ruiz I, Jimínez JG, Encabo $G$, et al. Diagnostic value of ascites gamma interferon levels in tuberculous peritonitis. Comparison with adenosine deaminase activity. Tubercle 1991;72:193-197.

43. Dwivedi M, Misra SP, Misra V, Kumar R. Value of adenosine deaminase estimation in the diagnosis of tuberculous ascites. Am J Gastroenterol 1990;85:1123-1125.

44. Hillebrand DJ, Runyon BA, Yasmineh WG, Rynders GP. Ascitic fluid adenosine deaminase insensitivity in detecting tuberculous peritonitis in the United States. Hepatology 1996;24:1408-1412.

45. Lee JS, Kim KA, Lee WJ, Jeon YB, Lee JW, Kim YS, et al. Diagnostic value of ascitic fluid adenosine deaminase activity for diagnosis of tuberculous peritonitis. Korean J Gastroenterol 2003;41:126-132.

46. Liao YJ, Wu CY, Lee SW, Lee CL, Yang SS, Chang CS, et al. Adenosine deaminase activity in tuberculous peritonitis among patients with underlying liver cirrhosis. World J Gastroenterol 2012;18:5260-5265.

47. Cappell MS, Shetty V. A multicenter, case-controlled study of the clinical presentation and etiology of ascites and of the safety and clinical efficacy of diagnostic abdominal paracentesis in HIV seropositive patients. Am J Gastroenterol 1994;89:2172-2177.

48. Akriviadis EA, Runyon BA. Utility of an algorithm in differentiating spontaneous from secondary bacterial peritonitis. Gastroenterology 1990;98:127-133.

49. Wu SS, Lin OS, Chen YY, Hwang KL, Soon MS, Keeffe EB. Ascitic fluid carcinoembryonic antigen and alkaline phosphatase levels for the differentiation of primary from secondary bacterial peritonitis with intestinal perforation. J Hepatol 2001;34:215-221.

50. Ridinger HA, Kavitt RT, Green JK. Urinary ascites and renal failure from unrecognized bladder rupture. Am J Med 2012;125:e1-e2.

51. Woo JJ, Koh YY, Kim HJ, Chung JW, Chang KS, Hong SP. N-terminal pro B-type natriuretic peptide and the evaluation of cardiac dysfunction and severity of disease in cirrhotic patients. Yonsei Med J 2008;49:625-631.

52. Runyon BA. Malignancy-related ascites and ascitic fluid "humoral tests of malignancy". J Clin Gastroenterol 1994;18:94-98.

53. Zuckerman E, Lanir A, Sabo E, Rosenvald-Zuckerman T, Matter I, Yeshurun $D$, et al. Cancer antigen 125: a sensitive marker of ascites in patients with liver cirrhosis. Am J Gastroenterol 1999;94:16131618.

54. Garg H, Sarin SK, Kumar M, Garg V, Sharma BC, Kumar A. Tenofovir improves the outcome in patients with spontaneous reactivation of hepatitis B presenting as acute-on-chronic liver failure. Hepatology 2011;53:774-780.

55. Runyon BA; AASLD Practice Guidelines Committee. Management of adult patients with ascites due to cirrhosis: an update. Hepatology 2009;49:2087-2107.

56. Veldt BJ, Lainé F, Guillygomarc'h A, Lauvin L, Boudjema K, Messner $\mathrm{M}$, et al. Indication of liver transplantation in severe alcoholic liver cirrhosis: quantitative evaluation and optimal timing. J Hepatol 2002;36:93-98.

57. Yamini D, Lee SH, Avanesyan A, Walter M, Runyon B. Utilization of baclofen in maintenance of alcohol abstinence in patients with alcohol dependence and alcoholic hepatitis with or without cirrhosis. Alcohol Alcohol 2014;49:453-456.

58. Addolorato G, Leggio L, Ferrulli A, Cardone S, Vonghia L, Mirijello $A$, et al. Effectiveness and safety of baclofen for maintenance of alcohol abstinence in alcohol-dependent patients with liver cirrhosis: randomised, double-blind controlled study. Lancet 2007;370:19151922.

59. Moon W, Choi MS, Moon YM, Paik SW, Lee JH, Koh KC, et al. Efficacy and safety of adefovir dipivoxil in patients with decompensated liver cirrhosis with Lamivudine resistance compared to patients with compensated liver disease. Korean J Hepatol 2005;11:125-134. 
The Korean Association for the Study of the Liver (KASL)

Treatment guideline for ascites and related complications

60. Shim JH, Lee HC, Kim KM, Lim YS, Chung YH, Lee YS, et al. Efficacy of entecavir in treatment-naïve patients with hepatitis $B$ virusrelated decompensated cirrhosis. J Hepatol 2010;52:176-182.

61. Yao FY, Bass NM. Lamivudine treatment in patients with severely decompensated cirrhosis due to replicating hepatitis B infection. J Hepatol 2000;33:301-307.

62. Manolakopoulos S, Triantos C, Theodoropoulos J, Vlachogiannakos J, Kougioumtzan A, Papatheodoridis G, et al. Antiviral therapy reduces portal pressure in patients with cirrhosis due to $\mathrm{HBeAg}$ negative chronic hepatitis $B$ and significant portal hypertension. J Hepatol 2009;51:468-474.

63. Curry MP, O'Leary JG, Bzowej N, Muir AJ, Korenblat KM, Fenkel $J M$, et al. Sofosbuvir and velpatasvir for HCV in patients with decompensated cirrhosis. N Engl J Med 2015;373:2618-2628.

64. Afdhal N, Everson G, Calleja JL, McCaughan G, Symonds WT, Denning J, et al. Sofosbuvir and ribavirin for the treatment chronic $\mathrm{HCV}$ with cirrhosis and portal hypertension with and without decompensation: early virologic response and safety. J Hepatol 2014;60:S28.

65. Kim TY, Kim MY, Sohn JH, Kim SM, Ryu JA, Lim S, et al. Sarcopenia as a useful predictor for long-term mortality in cirrhotic patients with ascites. J Korean Med Sci 2014;29:1253-1259.

66. Plauth M, Cabré E, Campillo B, Kondrup J, Marchesini G, Schütz T, et al. ESPEN guidelines on Parenteral Nutrition: hepatology. Clin Nutr 2009;28:436-444.

67. Plauth M, Cabré E, Riggio O, Assis-Camilo M, Pirlich M, Kondrup J, et al. ESPEN guidelines on Enteral Nutrition: liver disease. Clin Nutr 2006;25:285-294.

68. Lochs H, Plauth M. Liver cirrhosis: rationale and modalities for nutritional support--the European Society of Parenteral and Enteral Nutrition consensus and beyond. Curr Opin Clin Nutr Metab Care 1999;2:345-349.

69. Swart GR, Zillikens MC, van Vuure JK, van den Berg JW. Effect of a late evening meal on nitrogen balance in patients with cirrhosis of the liver. BMJ 1989;299:1202-1203.

70. Zillikens MC, van den Berg JW, Wattimena JL, Rietveld T, Swart GR. Nocturnal oral glucose supplementation. The effects on protein metabolism in cirrhotic patients and in healthy controls. J Hepatol 1993;17:377-383.

71. Chang WK, Chao YC, Tang HS, Lang HF, Hsu CT. Effects of extracarbohydrate supplementation in the late evening on energy expenditure and substrate oxidation in patients with liver cirrhosis. JPEN J Parenter Enteral Nutr 1997;21:96-99.

72. Plank LD, Gane EJ, Peng S, Muthu C, Mathur S, Gillanders L, et al. Nocturnal nutritional supplementation improves total body protein status of patients with liver cirrhosis: a randomized 12-month trial. Hepatology 2008;48:557-566.

73. Sorrentino P, Castaldo G, Tarantino L, Bracigliano A, Perrella A, Perrella 0 , et al. Preservation of nutritional-status in patients with refractory ascites due to hepatic cirrhosis who are undergoing repeated paracentesis. J Gastroenterol Hepatol 2012;27:813-822.

74. Stickel F, Hoehn B, Schuppan D, Seitz HK. Review article: nutritional therapy in alcoholic liver disease. Aliment Pharmacol Ther 2003;18:357-373.

75. DiCecco SR, Francisco-Ziller N. Nutrition in alcoholic liver disease. Nutr Clin Pract 2006;21:245-254.

76. Grungreiff K, Reinhold D, Wedemeyer $H$. The role of zinc in liver cirrhosis. Ann Hepatol 2016;15:7-16.

77. Fialla $A D$, Israelsen $M$, Hamberg 0 , Krag A, Gluud LL. Nutritional therapy in cirrhosis or alcoholic hepatitis: a systematic review and meta-analysis. Liver Int 2015;35:2072-2078.

78. Shiozawa S, Usui T, Kuhara K, Tsuchiya A, Miyauchi T, Kono T, et al. Impact of branched-chain amino acid-enriched nutrient on liver cirrhosis with hepatocellular carcinoma undergoing transcatheter arterial chemoembolization in Barcelona Clinic Liver Cancer Stage B: a prospective study. J Nippon Med Sch 2016;83:248-256.

79. Wong F. Management of ascites in cirrhosis. J Gastroenterol Hepatol 2012;27:11-20.

80. Moore KP, Aithal GP. Guidelines on the management of ascites in cirrhosis. Gut 2006;55 Suppl 6:vi1- vi12.

81. Suk KT, Baik SK, Yoon JH, Cheong JY, Paik YH, Lee CH, et al. Revision and update on clinical practice guideline for liver cirrhosis. Korean J Hepatol 2012;18:1-21.

82. Reynolds TB. Ascites. Clin Liver Dis 2000;4:151-168, vii.

83. Santos J, Planas R, Pardo A, Durández R, Cabré E, Morillas RM, et al. Spironolactone alone or in combination with furosemide in the treatment of moderate ascites in nonazotemic cirrhosis. A randomized comparative study of efficacy and safety. J Hepatol 2003;39:187-192.

84. Angeli P, Dalla Pria M, De Bei E, Albino G, Caregaro L, Merkel C, et al. Randomized clinical study of the efficacy of amiloride and potassium canrenoate in nonazotemic cirrhotic patients with ascites. Hepatology 1994;19:72-79.

85. Gentilini P, Laffi G, La Villa G, Carloni V, Foschi M, Romanelli RG, et al. Torasemide in the treatment of patients with cirrhosis and ascites. Cardiovasc Drugs Ther 1993;7 Suppl 1:81-85.

86. Bernardi M. Optimum use of diuretics in managing ascites in patients with cirrhosis. Gut 2010;59:10-11.

87. Angeli P, Fasolato S, Mazza E, Okolicsanyi L, Maresio G, Velo E, et al. Combined versus sequential diuretic treatment of ascites in non- 
azotaemic patients with cirrhosis: results of an open randomised clinical trial. Gut 2010;59:98-104.

88. Korean Association for the Study of the Liver. Treatment guideline of complications of liver cirrhosis. Korean J Hepatol 2005;11(Suppl 4):S115-S138.

89. Pockros PJ, Reynolds TB. Rapid diuresis in patients with ascites from chronic liver disease: the importance of peripheral edema. Gastroenterology 1986;90:1827-1833.

90. Dougher CE, Rifkin DE, Anderson CA, Smits G, Persky MS, Block $G A$, et al. Spot urine sodium measurements do not accurately estimate dietary sodium intake in chronic kidney disease. Am J Clin Nutr 2016;104:298-305.

91. Stiehm AJ, Mendler MH, Runyon BA. Detection of diureticresistace or diuretic-sensitivity by the spot urine $\mathrm{Na}+/ \mathrm{K}+$ ratio in 729 specimens from cirrhotics with ascites: approximately $90 \%$ accuracy as compared to 24-hour urine $\mathrm{Na}+$ excretion. Hepatology 2002;36:222A.

92. Park JE, Lee CH, Kim BS, Shin IH. Diagnostic usefulness of the random urine $\mathrm{Na} / \mathrm{K}$ ratio in cirrhotic patients with ascites: a pilot study. Korean J Hepatol 2010;16:66-74.

93. Marchesini G, Dioguardi FS, Bianchi GP, Zoli M, Bellati G, Roffi L, et al. Long-term oral branched-chain amino acid treatment in chronic hepatic encephalopathy. A randomized double-blind caseincontrolled trial. The Italian Multicenter Study Group. J Hepatol 1990;11:92-101.

94. Fukui H, Saito H, Ueno Y, Uto H, Obara K, Sakaida I, et al. Evidence-based clinical practice guidelines for liver cirrhosis 2015. J Gastroenterol 2016;51:629-650.

95. Hirsch S, Bunout D, de la Maza P, Iturriaga H, Petermann M, Icazar $G$, et al. Controlled trial on nutrition supplementation in outpatients with symptomatic alcoholic cirrhosis. JPEN J Parenter Enteral Nutr 1993;17:119-124.

96. Yatsuhashi H, Ohnishi Y, Nakayama S, Iwase H, Nakamura T, Imawari M. Anti-hypoalbuminemic effect of branched-chain amino acid granules in patients with liver cirrhosis is independent of dietary energy and protein intake. Hepatol Res 2011;41:1027-1035.

97. Kawamura E, Habu D, Morikawa H, Enomoto M, Kawabe J, Tamori $A$, et al. A randomized pilot trial of oral branched-chain amino acids in early cirrhosis: validation using prognostic markers for preliver transplant status. Liver Transpl 2009;15:790-797.

98. Kitajima Y, Takahashi H, Akiyama T, Murayama K, Iwane S, Kuwashiro T, et al. Supplementation with branched-chain amino acids ameliorates hypoalbuminemia, prevents sarcopenia, and reduces fat accumulation in the skeletal muscles of patients with liver cirrhosis. J Gastroenterol 2018;53:427-437.
99. Ruiz-Margáin A, Macías-Rodríguez RU, Ríos-Torres SL, RománCalleja BM, Méndez-Guerrero O, Rodríguez-Córdova P, et al. Effect of a high-protein, high-fiber diet plus supplementation with branched-chain amino acids on the nutritional status of patients with cirrhosis. Rev Gastroenterol Mex 2018;83:9-15.

100. Kikuchi Y, Hiroshima Y, Matsuo K, Kawaguchi D, Murakami T, Yabushita $Y$, et al. A randomized clinical trial of preoperative administration of branched-chain amino acids to prevent postoperative ascites in patients with liver resection for hepatocellular carcinoma. Ann Surg Oncol 2016;23:3727-3735.

101. Park JG, Tak WY, Park SY, Kweon YO, Jang SY, Lee YR, et al. Effects of branched-chain amino acids (BCAAs) on the progression of advanced liver disease: a Korean nationwide, multicenter, retrospective, observational, cohort study. Medicine (Baltimore) 2017;96:e6580.

102. Takaguchi K, Moriwaki H, Doyama H, lida M, Yagura M, Shimada N, et al. Effects of branched-chain amino acid granules on serum albumin level and prognosis are dependent on treatment adherence in patients with liver cirrhosis. Hepatol Res 2013;43:459-466.

103. Lee JS. Albumin for end-stage liver disease. Korean J Intern Med 2012;27:13-19.

104. Gentilini P, Casini-Raggi V, Di Fiore G, Romanelli RG, Buzzelli G, Pinzani $M$, et al. Albumin improves the response to diuretics in patients with cirrhosis and ascites: results of a randomized, controlled trial. J Hepatol 1999;30:639-645.

105. Bernardi M, Caraceni P, Navickis RJ, Wilkes MM. Albumin infusion in patients undergoing large-volume paracentesis: a meta-analysis of randomized trials. Hepatology 2012;55:1172-1181.

106. Sort P, Navasa M, Arroyo V, Aldeguer X, Planas R, Ruiz-del-Arbol $L$, et al. Effect of intravenous albumin on renal impairment and mortality in patients with cirrhosis and spontaneous bacterial peritonitis. N Engl J Med 1999;341:403-409.

107. Romanelli RG, La Villa G, Barletta G, Vizzutti F, Lanini F, Arena $U$, et al. Long-term albumin infusion improves survival in patients with cirrhosis and ascites: an unblinded randomized trial. World J Gastroenterol 2006;12:1403-1407.

108. Italian Association for the Study of the Liver (AISF); Italian Society of Transfusion Medicine and Immunohaematology (SIMTI). AISFSIMTI position paper: the appropriate use of albumin in patients with liver cirrhosis. Dig Liver Dis 2016;48:4-15.

109. Titó L1, Ginès P, Arroyo V, Planas R, Panés J, Rimola A, et al. Total paracentesis associated with intravenous albumin management of patients with cirrhosis and ascites. Gastroenterology 1990;98:146151.

110. Hong SP, Eun YG, Kim HJ, Kim BH, Chang YW, Lee Jl, et al. Effects 
The Korean Association for the Study of the Liver (KASL)

Treatment guideline for ascites and related complications

of large volume paracentesis. Korean J Med 1991;40:147-152.

111. Arroyo V, Ginès P, Gerbes AL, Dudley FJ, Gentilini P, Laffi G, et al. Definition and diagnostic criteria of refractory ascites and hepatorenal syndrome in cirrhosis. International Ascites Club. Hepatology 1996;23:164-176.

112. Moore KP, Wong F, Gines P, Bernardi M, Ochs A, Salerno F, et al. The management of ascites in cirrhosis: report on the consensus conference of the International Ascites Club. Hepatology 2003;38:258-266.

113. Choi CH, Ahn SH, Kim DY, Lee SK, Park JY, Chon CY, et al. Long-term clinical outcome of large volume paracentesis with intravenous albumin in patients with spontaneous bacterial peritonitis: a randomized prospective study. J Gastroenterol Hepatol 2005;20:1215-1222.

114. Shim E, Ryu HJ, Hwang J, Kim SY, Chung EJ. Dietary sodium intake in young Korean adults and its relationship with eating frequency and taste preference. Nutr Res Pract 2013;7:192-198.

115. Ginès $A$, Fernández-Esparrach $G$, Monescillo $A$, Vila $C$, Domènech $\mathrm{E}$, Abecasis $\mathrm{R}$, et al. Randomized trial comparing albumin, dextran 70, and polygeline in cirrhotic patients with ascites treated by paracentesis. Gastroenterology 1996;111:1002-1010.

116. Moreau R, Valla DC, Durand-Zaleski I, Bronowicki JP, Durand F, Chaput JC, et al. Comparison of outcome in patients with cirrhosis and ascites following treatment with albumin or a synthetic colloid. Liver Int 2006;26:46-54.

117. Singh V, Dheerendra PC, Singh B, Nain CK, Chawla D, Sharma N, et al. Midodrine versus albumin in the prevention of paracentesisinduced circulatory dysfunction in cirrhotics: a randomized pilot study. Am J Gastroenterol 2008;103:1399-1405.

118. Lata J, Marecek Z, Fejfar T, Zdenek P, Brůha R, Safka V, et al. The efficacy of terlipressin in comparison with albumin in the prevention of circulatory changes after the paracentesis of tense ascites--a randomized multicentric study. Hepatogastroenterology 2007;54:1930-1933.

119. Sersté T, Francoz C, Durand F, Rautou PE, Melot C, Valla D, et al. Beta-blockers cause paracentesis-induced circulatory dysfunction in patients with cirrhosis and refractory ascites: a cross-over study. J Hepatol 2011;55:794-799.

120. Sersté T, Melot C, Francoz C, Durand F, Rautou PE, Valla D, et al. Deleterious effects of beta-blockers on survival in patients with cirrhosis and refractory ascites. Hepatology 2010;52:1017-1022.

121. Llach J, Ginès P, Arroyo V, Rimola A, Titó L, Badalamenti S, et al. Prognostic value of arterial pressure, endogenous vasoactive systems, and renal function in cirrhotic patients admitted to the hospital for the treatment of ascites. Gastroenterology 1988;94:482-487.
122. Singh V, Singh A, Singh B, Vijayvergiya R, Sharma N, Ghai A, et al. Midodrine and clonidine in patients with cirrhosis and refractory or recurrent ascites: a randomized pilot study. Am J Gastroenterol 2013;108:560-567.

123. Singh V, Dhungana SP, Singh B, Vijayverghia R, Nain CK, Sharma N, et al. Midodrine in patients with cirrhosis and refractory or recurrent ascites: a randomized pilot study. J Hepatol 2012;56:348-354.

124. Yang YY, Lin HC, Lee WP, Chu CJ, Lin MW, Lee FY, et al. Association of the $\mathrm{G}$-protein and a2-adrenergic receptor gene and plasma norepinephrine level with clonidine improvement of the effects of diuretics in patients with cirrhosis with refractory ascites: a randomised clinical trial. Gut 2010;59:1545-1553.

125. Wong F, Watson H, Gerbes A, Vilstrup H, Badalamenti S, Bernardi $M$, et al. Satavaptan for the management of ascites in cirrhosis: efficacy and safety across the spectrum of ascites severity. Gut 2012;61:108-116.

126. Rössle M, Ochs A, Gülberg V, Siegerstetter V, Holl J, Deibert $P$, et al. A comparison of paracentesis and transjugular intrahepatic portosystemic shunting in patients with ascites. N Engl J Med 2000;342:1701-1707.

127. Salerno F, Cammà C, Enea M, Rössle M, Wong F. Transjugular intrahepatic portosystemic shunt for refractory ascites: a meta-analysis of individual patient data. Gastroenterology 2007;133:825-834.

128. Ginès P, Uriz J, Calahorra B, Garcia-Tsao G, Kamath PS, Del Arbol $L R$, et al. Transjugular intrahepatic portosystemic shunting versus paracentesis plus albumin for refractory ascites in cirrhosis. Gastroenterology 2002;123:1839-1847.

129. Sanyal AJ, Genning C, Reddy KR, Wong F, Kowdley KV, Benner K, et al. The North American study for the treatment of refractory ascites. Gastroenterology 2003;124:634-641.

130. Miraglia R, Maruzzelli L, Tuzzolino F, Petridis I, D'Amico M, Luca A. Transjugular intrahepatic portosystemic shunts in patients with cirrhosis with refractory ascites: comparison of clinical outcomes by using 8-and 10-mm PTFE-covered Stents. Radiology 2017;284:281288.

131. Bai M, Qi XS, Yang ZP, Yang M, Fan DM, Han GH. TIPS improves liver transplantation-free survival in cirrhotic patients with refractory ascites: an updated meta-analysis. World J Gastroenterol 2014;20:2704-2714.

132. Bureau C, Thabut D, Oberti F, Dharancy S, Carbonell N, Bouvier A, et al. Transjugular intrahepatic portosystemic shunts with covered stents increase transplant-free survival of patients with cirrhosis and recurrent ascites. Gastroenterology 2017;152:157-163.

133. Berry K, Lerrigo R, Liou IW, Ioannou GN. Association between transjugular intrahepatic portosystemic shunt and survival in pa- 
tients with cirrhosis. Clin Gastroenterol Hepatol 2016;14:118-123.

134. Hosokawa I, Adam R, Allard MA, Pittau G, Vibert E, Cherqui D, et al. Outcomes of surgical shunts and transjugular intrahepatic portasystemic stent shunts for complicated portal hypertension. $\mathrm{Br}$ J Surg 2017;104:443-451.

135. Rabie R, Cazzaniga M, Salerno F, Wong F. The effect of cirrhotic cardiomyopathy on the post-TIPS outcome of patients treated for complications of portal hypertension. Hepatology 2006;44:444A.

136. Azoulay D, Castaing D, Dennison A, Martino W, Eyraud D, Bismuth $H$. Transjugular intrahepatic portosystemic shunt worsens the hyperdynamic circulatory state of the cirrhotic patient: preliminary report of a prospective study. Hepatology 1994;19:129-132.

137. Michl P. Transjugular intrahepatic portosystemic shunt for cirrhosis and ascites: effects in patients with organic or functional renal failure. Scand J Gastroenterol 2000;35:654-658.

138. Seo JH, Kim SU, Park JY, Kim DY, Han KH, Chon CY, et al. Predictors of refractory ascites development in patients with hepatitis $B$ virus-related cirrhosis hospitalized to control ascitic decompensation. Yonsei Med J 2013;54:145-153.

139. Heuman DM, Abou-Assi SG, Habib A, Williams LM, Stravitz RT, Sanyal AJ, et al. Persistent ascites and low serum sodium identify patients with cirrhosis and low MELD scores who are at high risk for early death. Hepatology 2004;40:802-810.

140. Durand F, Valla D. Assessment of prognosis of cirrhosis. Semin Liver Dis 2008;28:110-122.

141. Luca A, Angermayr B, Bertolini G, Koenig F, Vizzini G, Ploner M, et al. An integrated MELD model including serum sodium and age improves the prediction of early mortality in patients with cirrhosis. Liver Transpl 2007;13:1174-1180.

142. Trotter J, Pieramici E, Everson GT. Chronic albumin infusions to achieve diuresis in patients with ascites who are not candidates for transjugular intrahepatic portosystemic shunt (TIPS). Dig Dis Sci 2005:50:1356-1360.

143. Lenaerts A, Codden T, Henry JP, Legros F, Ligny G. Comparative pilot study of repeated large volume paracentesis vs the combination on clonidine-spironolactone in the treatment of cirrhosis-associated refractory ascites. Gastroenterol Clin Biol 2005;29:1137-1142.

144. Ginès $P$, Arroyo V, Vargas V, Planas R, Casafont F, Panés J, et al. Paracentesis with intravenous infusion of albumin as compared with peritoneovenous shunting in cirrhosis with refractory ascites. N Engl J Med 1991;325:829-835.

145. Bureau C, Adebayo D, Chalret de Rieu M, Elkrief L, Valla D, PeckRadosavljevic $M$, et al. Alfapump(R) system vs. large volume paracentesis for refractory ascites: a multicenter randomized controlled study. J Hepatol 2017;67:940-949.
146. Zaak D, Paquet KJ, Kuhn R. Prospective study comparing human albumin vs. reinfusion of ultrafiltrate-ascitic fluid after total paracentesis in cirrhotic patients with tense ascites. Z Gastroenterol 2001;39:5-10.

147. Graziotto A, Rossaro L, Inturri P, Salvagnini M. Reinfusion of concentrated ascitic fluid versus total paracentesis. A randomized prospective trial. Dig Dis Sci 1997;42:1708-1714.

148. Runyon BA; AASLD. Introduction to the revised American Association for the Study of Liver Diseases Practice Guideline management of adult patients with ascites due to cirrhosis 2012. Hepatology 2013;57:1651-1653.

149. Kim JH, Lee JS, Lee SH, Bae WK, Kim NH, Kim KA, et al. The association between the serum sodium level and the severity of complications in liver cirrhosis. Korean J Intern Med 2009;24:106-112.

150. Angeli P, Wong F, Watson H, Ginès P; CAPPS Investigators. Hyponatremia in cirrhosis: results of a patient population survey. Hepatology 2006;44:1535-1542.

151. Ge PS, Runyon BA. Treatment of patients with cirrhosis. N Engl J Med 2016;375:2104-2105.

152. Abelmann WH. Hyperdynamic circulation in cirrhosis: a historical perspective. Hepatology 1994;20:1356-1358.

153. Kim MY, Baik SK. Hyperdynamic circulation in patients with liver cirrhosis and portal hypertension. Korean J Gastroenterol 2009;54:143-148

154. Battista S, Bar F, Mengozzi G, Zanon E, Grosso M, Molino G. Hyperdynamic circulation in patients with cirrhosis: direct measurement of nitric oxide levels in hepatic and portal veins. J Hepatol 1997;26:75-80.

155. Arkenau HT, Stichtenoth DO, Frolich JC, Manns MP, Böker KH. Elevated nitric oxide levels in patients with chronic liver disease and cirrhosis correlate with disease stage and parameters of hyperdynamic circulation. Z Gastroenterol 2002:40:907-913.

156. Hébert RL, Jacobson HR, Breyer MD. PGE2 inhibits AVP-induced water flow in cortical collecting ducts by protein kinase $\mathrm{C}$ activation. Am J Physiol 1990;259(2 Pt 2):F318-F325.

157. Bichet D, Szatalowicz V, Chaimovitz C, Schrier RW. Role of vasopressin in abnormal water excretion in cirrhotic patients. Ann Intern Med 1982;96:413-417.

158. Adrogué HJ, Madias NE. Hyponatremia. N Engl J Med 2000;342:1581-1589.

159. Gerbes AL, Gülberg V, Ginès P, Decaux G, Gross P, Gandjini $H$, et al. Therapy of hyponatremia in cirrhosis with a vasopressin receptor antagonist: a randomized double-blind multicenter trial. Gastroenterology 2003;124:933-939.

160. Wong F, Blei AT, Blendis LM, Thuluvath PJ. A vasopressin receptor 
The Korean Association for the Study of the Liver (KASL)

Treatment guideline for ascites and related complications

antagonist (VPA-985) improves serum sodium concentration in patients with hyponatremia: a multicenter, randomized, placebocontrolled trial. Hepatology 2003;37:182-191.

161. McCormick PA, Mistry P, Kaye G, Burroughs AK, McIntyre N. Intravenous albumin infusion is an effective therapy for hyponatraemia in cirrhotic patients with ascites. Gut 1990;31:204-207.

162. Martinez-Castelao A. Conivaptan (Yamanouchi). Curr Opin Investig Drugs 2002;3:89-95.

163. Wada K, Tahara A, Arai Y, Aoki M, Tomura Y, Tsukada J, et al. Effect of the vasopressin receptor antagonist conivaptan in rats with heart failure following myocardial infarction. Eur J Pharmacol 2002;450:169-177.

164. Fernández-Varo G, Ros J, Cejudo-Martín P, Cano C, Arroyo V, Rivera F, et al. Effect of the V1a/V2-AVP receptor antagonist, Conivaptan, on renal water metabolism and systemic hemodynamics in rats with cirrhosis and ascites. J Hepatol 2003;38:755-761.

165. Hline SS, Pham PT, Pham PT, Aung MH, Pham PM, Pham PC. Conivaptan: a step forward in the treatment of hyponatremia? Ther Clin Risk Manag 2008;4:315-326.

166. Dominguez M, Perez JA, Patel CB. Efficacy of $3 \%$ saline vs. conivaptan in achieving hyponatremia treatment goals. Methodist Debakey Cardiovasc J 2013;9:49-53.

167. Ghali JK, Koren MJ, Taylor JR, Brooks-Asplund E, Fan K, Long WA, et al. Efficacy and safety of oral conivaptan: a V1A/V2 vasopressin receptor antagonist, assessed in a randomized, placebo-controlled trial in patients with euvolemic or hypervolemic hyponatremia. J Clin Endocrinol Metab 2006;91:2145-2152.

168. Marbury T, Fox J, Kaelin B, Pavliv L. Pharmacokinetics of conivaptan use in patients with severe hepatic impairment. Drug Des Devel Ther 2017;11:373-382.

169. Soupart A, Gross P, Legros JJ, Alföldi S, Annane D, Heshmati HM, et al. Successful long-term treatment of hyponatremia in syndrome of inappropriate antidiuretic hormone secretion with satavaptan (SR121463B), an orally active nonpeptide vasopressin V2-receptor antagonist. Clin J Am Soc Nephrol 2006;1:1154-1160.

170. Ginès $P$, Wong $F$, Watson $H$, Milutinovic $S$, del Arbol LR, Olteanu $D$, et al. Effects of satavaptan, a selective vasopressin $V(2)$ receptor antagonist, on ascites and serum sodium in cirrhosis with hyponatremia: a randomized trial. Hepatology 2008;48:204-213.

171. Wong F, Gines $P$, Watson $H$, Horsmans $Y$, Angeli $P$, Gow $P$, et al. Effects of a selective vasopressin V2 receptor antagonist, satavaptan, on ascites recurrence after paracentesis in patients with cirrhosis. J Hepatol 2010;53:283-290.

172. Konstam MA, Gheorghiade M, Burnett JC Jr, Grinfeld L, Maggioni AP, Swedberg K, et al. Effects of oral tolvaptan in patients hospital- ized for worsening heart failure: the EVEREST Outcome Trial. JAMA 2007:297:1319-1331.

173. Cárdenas A, Ginès $P$, Marotta $P$, Czerwiec F, Oyuang J, Guevara $M$, et al. Tolvaptan, an oral vasopressin antagonist, in the treatment of hyponatremia in cirrhosis. J Hepatol 2012;56:571-578.

174. Berl T, Quittnat-Pelletier F, Verbalis JG, Schrier RW, Bichet DG, Ouyang J, et al. Oral tolvaptan is safe and effective in chronic hyponatremia. J Am Soc Nephrol 2010;21:705-712.

175. Torres VE, Chapman AB, Devuyst O, Gansevoort RT, Grantham JJ, Higashihara $E$, et al. Tolvaptan in patients with autosomal dominant polycystic kidney disease. N Engl J Med 2012;367:2407-2418.

176. Watkins PB, Lewis JH, Kaplowitz N, Alpers DH, Blais JD, Smotzer DM, et al. Clinical pattern of tolvaptan-associated liver injury in subjects with autosomal dominant polycystic kidney disease: analysis of clinical trials database. Drug Saf 2015;38:1103-1113.

177. United States Food and Drug Administration (FDA). Guidance for industry; Drug-induced liver injury: premarketing clinical evaluation. FDA web site, <http://www.fda.gov/downloads/Drugs/GuidanceComplianceRegulatoryInformation/Guidances/UCM174090. pdf $>$. Accessed 3 Nov 2017.

178. European Medicines Agency (EMA). Assessment report. EMA web site, <http://www.ema.europa.eu/docs/en_GB/document_ library/EPAR_-_Public_assessment_report/human/002788/ WC500187923.pdf>. Accessed 3 Nov 2017.

179. Pharmaceuticals and Medical Devices Agency (Pmda). Report on the Deliberation Results. Pmda web site, <http://www.pmda.go.jp/ files/000208511.pdf>. Accessed 3 Nov 2017.

180. Biggins SW, Rodriguez HJ, Bacchetti P, Bass NM, Roberts JP, Terrault NA. Serum sodium predicts mortality in patients listed for liver transplantation. Hepatology 2005;41:32-39.

181. Guevara M, Baccaro ME, Ríos J, Martín-Llahí M, Uriz J, Ruiz de Arbol $L$, et al. Risk factors for hepatic encephalopathy in patients with cirrhosis and refractory ascites: relevance of serum sodium concentration. Liver Int 2010;30:1137-1142.

182. Pereira G, Guevara M, Fagundes C, Solá E, Rodríguez E, Fernández $J$, et al. Renal failure and hyponatremia in patients with cirrhosis and skin and soft tissue infection. A retrospective study. J Hepatol 2012;56:1040-1046.

183. Kim WR, Biggins SW, Kremers WK, Wiesner RH, Kamath PS, Benson JT, et al. Hyponatremia and mortality among patients on the liver-transplant waiting list. N Engl J Med 2008;359:1018-1026.

184. Yun BC, Kim WR, Benson JT, Biggins SW, Therneau TM, Kremers WK, et al. Impact of pretransplant hyponatremia on outcome following liver transplantation. Hepatology 2009:49:1610-1615.

185. Caly WR, Strauss E. A prospective study of bacterial infections in 
patients with cirrhosis. J Hepatol 1993;18:353-358.

186. Tandon P, Garcia-Tsao G. Bacterial infections, sepsis, and multiorgan failure in cirrhosis. Semin Liver Dis 2008;28:26-42.

187. Rimola A, García-Tsao G, Navasa M, Piddock LJ, Planas R, Bernard $\mathrm{B}$, et al. Diagnosis, treatment and prophylaxis of spontaneous bacterial peritonitis: a consensus document. International Ascites Club. J Hepatol 2000;32:142-153.

188. Runyon BA, Canawati HN, Akriviadis EA. Optimization of ascitic fluid culture technique. Gastroenterology 1988;95:1351-1355.

189. Kim SU, Kim DY, Lee CK, Park JY, Kim SH, Kim HM, et al. Ascitic fluid infection in patients with hepatitis $B$ virus-related liver cirrhosis: culture-negative neutrocytic ascites versus spontaneous bacterial peritonitis. J Gastroenterol Hepatol 2010;25:122-128.

190. Pelletier G, Lesur G, Ink O, Hagege H, Attali P, Buffet C, et al. Asymptomatic bacterascites: is it spontaneous bacterial peritonitis? Hepatology 1991;14:112-115.

191. Runyon BA. Monomicrobial nonneutrocytic bacterascites: a variant of spontaneous bacterial peritonitis. Hepatology 1990;12(4 Pt 1):710-715.

192. Rerknimitr R, Limmathurotsakul D, Bhokaisawan N, Kongkam P, Treeprasertsuk S, Kullavanijaya P. A comparison of diagnostic efficacies among different reagent strips and automated cell count in spontaneous bacterial peritonitis. J Gastroenterol Hepatol 2010;25:946-950.

193. Nousbaum JB, Cadranel JF, Nahon P, Khac EN, Moreau R, Thévenot T, et al. Diagnostic accuracy of the Multistix 8 SG reagent strip in diagnosis of spontaneous bacterial peritonitis. Hepatology 2007;45:1275-1281.

194. Farmer AD, Cook MJ, Bruckner Holt CE, Syn WK, Lewis MJ. Leucocyte esterase reagent strips for the diagnosis of spontaneous bacterial peritonitis: a systematic review by Koulaouzidis et al. Eur J Gastroenterol Hepatol 2009;21:1102.

195. Soriano G, Castellote J, Alvarez C, Girbau A, Gordillo J, Baliellas $C$, et al. Secondary bacterial peritonitis in cirrhosis: a retrospective study of clinical and analytical characteristics, diagnosis and management. J Hepatol 2010;52:39-44.

196. Runyon BA, Hoefs JC. Ascitic fluid analysis in the differentiation of spontaneous bacterial peritonitis from gastrointestinal tract perforation into ascitic fluid. Hepatology 1984;4:447-450.

197. Teh SH, Nagorney DM, Stevens SR, Offord KP, Therneau TM, Plevak DJ, et al. Risk factors for mortality after surgery in patients with cirrhosis. Gastroenterology 2007;132:1261-1269.

198. Park MK, Lee JH, Byun YH, Lee Hle, Gwak GY, Choi MS, et al. Changes in the profiles of causative agents and antibiotic resistance rate for spontaneous bacterial peritonitis: an analysis of cultured microorganisms in recent 12 years. Korean J Hepatol 2007;13:370-377.

199. Kim JH, Jeon YD, Jung IY, Ahn MY, Ahn HW, Ahn JY, et al. Predictive factors of spontaneous bacterial peritonitis caused by grampositive bacteria in patients with cirrhosis. Medicine (Baltimore) 2016;95:e3489.

200. Cheong HS, Kang Cl, Lee JA, Moon SY, Joung MK, Chung DR, et al. Clinical significance and outcome of nosocomial acquisition of spontaneous bacterial peritonitis in patients with liver cirrhosis. Clin Infect Dis 2009;48:1230-1236.

201. Heo J, Seo YS, Yim HJ, Hahn T, Park SH, Ahn SH, et al. Clinical features and prognosis of spontaneous bacterial peritonitis in korean patients with liver cirrhosis: a multicenter retrospective study. Gut Liver 2009;3:197-204.

202. Tsung PC, Ryu SH, Cha IH, Cho HW, Kim JN, Kim YS, et al. Predictive factors that influence the survival rates in liver cirrhosis patients with spontaneous bacterial peritonitis. Clin Mol Hepatol 2013;19:131-139.

203. Runyon BA, Akriviadis EA, Sattler FR, Cohen J. Ascitic fluid and serum cefotaxime and desacetyl cefotaxime levels in patients treated for bacterial peritonitis. Dig Dis Sci 1991;36:1782-1786.

204. Felisart J, Rimola A, Arroyo V, Perez-Ayuso RM, Quintero E, Gines P, et al. Cefotaxime is more effective than is ampicillin-tobramycin in cirrhotics with severe infections. Hepatology 1985;5:457-462.

205. Ricart E, Soriano G, Novella MT, Ortiz J, Sàbat M, Kolle L, et al. Amoxicillin-clavulanic acid versus cefotaxime in the therapy of bacterial infections in cirrhotic patients. J Hepatol 2000;32:596-602.

206. Tuncer I, Topcu N, Durmus A, Turkdogan MK. Oral ciprofloxacin versus intravenous cefotaxime and ceftriaxone in the treatment of spontaneous bacterial peritonitis. Hepatogastroenterology 2003;50:1426-1430.

207. Yim HJ, Suh SJ, Jung YK, Kim MY, Baik SK, Kim HS, et al. Comparison of efficacy of cefotaxime, ceftriaxone, and ciprofloxacin for the treatment of spontaneous bacterial peritonitis in patients with liver cirrhosis: a randomized controlled trial. J Hepatol 2017;66:S374S375.

208. França A, Giordano HM, Sevá-Pereira T, Soares EC. Five days of ceftriaxone to treat spontaneous bacterial peritonitis in cirrhotic patients. J Gastroenterol 2002;37:119-122.

209. Gómez-Jiménez J, Ribera E, Gasser I, Artaza MA, Del Valle O, Pahissa $A$, et al. Randomized trial comparing ceftriaxone with cefonicid for treatment of spontaneous bacterial peritonitis in cirrhotic patients. Antimicrob Agents Chemother 1993;37:1587-1592.

210. Baskol M, Gursoy S, Baskol G, Ozbakir O, Guven K, Yucesoy M. Five days of ceftriaxone to treat culture negative neutrocytic ascites 
The Korean Association for the Study of the Liver (KASL)

Treatment guideline for ascites and related complications

in cirrhotic patients. J Clin Gastroenterol 2003;37:403-405.

211. Terg R, Cobas S, Fassio E, Landeira G, Ríos B, Vasen W, et al. Oral ciprofloxacin after a short course of intravenous ciprofloxacin in the treatment of spontaneous bacterial peritonitis: results of a multicenter, randomized study. J Hepatol 2000;33:564-569.

212. Navasa M, Follo A, Llovet JM, Clemente G, Vargas V, Rimola A, et al. Randomized, comparative study of oral ofloxacin versus intravenous cefotaxime in spontaneous bacterial peritonitis. Gastroenterology 1996;111:1011-1017.

213. Kim J, Kang Cl, Joo EJ, Ha YE, Cho SY, Gwak GY, et al. Risk factor of community-onset spontaneous bacterial peritonitis caused by fluoroquinolone-resistant Escherichia coli in patients with cirrhosis. Liver Int 2014;34:695-699.

214. Fernández J, Navasa M, Gómez J, Colmenero J, Vila J, Arroyo V, et al. Bacterial infections in cirrhosis: epidemiological changes with invasive procedures and norfloxacin prophylaxis. Hepatology 2002;35:140-148.

215. Song JY, Jung SJ, Park CW, Sohn JW, Kim WJ, Kim MJ, et al. Prognostic significance of infection acquisition sites in spontaneous bacterial peritonitis: nosocomial versus community acquired. J Korean Med Sci 2006;21:666-671.

216. Song KH, Jeon JH, Park WB, Park SW, Kim HB, Oh MD, et al. Clinical outcomes of spontaneous bacterial peritonitis due to extendedspectrum beta-lactamase-producing Escherichia coli and Klebsiella species: a retrospective matched case-control study. BMC Infect Dis 2009;9:41.

217. Kim MJ, Song KH, Kim NH, Choe PG, Park WB, Bang JH, et al. Clinical outcomes of spontaneous bacterial peritonitis due to extended-spectrum beta-lactamase-producing Escherichia coli or Klebsiella pneumoniae: a retrospective cohort study. Hepatol Int 2014;8:582-587.

218. Park YH, Lee HC, Song HG, Jung S, Ryu SH, Shin JW, et al. Recent increase in antibiotic-resistant microorganisms in patients with spontaneous bacterial peritonitis adversely affects the clinical outcome in Korea. J Gastroenterol Hepatol 2003;18:927-933.

219. Piano S, Fasolato S, Salinas F, Romano A, Tonon M, Morando F, et al. The empirical antibiotic treatment of nosocomial spontaneous bacterial peritonitis: results of a randomized, controlled clinical trial. Hepatology 2016;63:1299-1309.

220. Fernández J, Acevedo J, Castro M, Garcia O, de Lope CR, Roca D, et al. Prevalence and risk factors of infections by multiresistant bacteria in cirrhosis: a prospective study. Hepatology 2012;55:15511561.

221. Ariza X, Castellote J, Lora-Tamayo J, Girbau A, Salord S, Rota R, et al. Risk factors for resistance to ceftriaxone and its impact on mortality in community, healthcare and nosocomial spontaneous bacterial peritonitis. J Hepatol 2012;56:825-832.

222. Fernández J, Tandon P, Mensa J, Garcia-Tsao G. Antibiotic prophylaxis in cirrhosis: good and bad. Hepatology 2016;63:2019-2031.

223. Jalan R, Fernandez J, Wiest R, Schnabl B, Moreau R, Angeli P, et al. Bacterial infections in cirrhosis: a position statement based on the EASL Special Conference 2013. J Hepatol 2014;60:1310-1324.

224. Wiest R, Krag A, Gerbes A. Spontaneous bacterial peritonitis: recent guidelines and beyond. Gut 2012;61:297-310.

225. Follo A, Llovet JM, Navasa M, Planas R, Forns X, Francitorra A, et al. Renal impairment after spontaneous bacterial peritonitis in cirrhosis: incidence, clinical course, predictive factors and prognosis. Hepatology 1994;20:1495-1501.

226. Ruiz-del-Arbol L, Urman J, Fernández J, González M, Navasa M, Monescillo A, et al. Systemic, renal, and hepatic hemodynamic derangement in cirrhotic patients with spontaneous bacterial peritonitis. Hepatology 2003;38:1210-1218.

227. Tandon P, Garcia-Tsao G. Renal dysfunction is the most important independent predictor of mortality in cirrhotic patients with spontaneous bacterial peritonitis. Clin Gastroenterol Hepatol 2011;9:260-265.

228. Sigal SH, Stanca CM, Fernandez J, Arroyo V, Navasa M. Restricted use of albumin for spontaneous bacterial peritonitis. Gut 2007;56:597-599.

229. de Araujo A, de Barros Lopes A, Rossi G, da Silva GV, Ananias P, Ness $S$, et al. Low-dose albumin in the treatment of spontaneous bacterial peritonitis: should we change the standard treatment? Gut 2012;61:1371-1372.

230. Pérez-Paramo M, Muñoz J, Albillos A, Freile I, Portero F, Santos $M$, et al. Effect of propranolol on the factors promoting bacterial translocation in cirrhotic rats with ascites. Hepatology 2000;31:4348.

231. Senzolo M, Cholongitas E, Burra P, Leandro G, Thalheimer U, Patch $D$, et al. $\beta$-blockers protect against spontaneous bacterial peritonitis in cirrhotic patients: a meta-analysis. Liver Int 2009;29:11891193.

232. Mandorfer M, Bota S, Schwabl P, Bucsics T, Pfisterer N, Kruzik M, et al. Nonselective $\beta$ blockers increase risk for hepatorenal syndrome and death in patients with cirrhosis and spontaneous bacterial peritonitis. Gastroenterology 2014;146:1680-1690.e1.

233. Madsen BS, Nielsen KF, Fialla AD, Krag A. Keep the sick from harm in spontaneous bacterial peritonitis: dose of beta blockers matters. J Hepatol 2016;64:1455-1456.

234. Runyon BA, Van Epps DE. Diuresis of cirrhotic ascites increases its opsonic activity and may help prevent spontaneous bacterial peri- 
tonitis. Hepatology 1986;6:396-399.

235. Runyon BA, Antillon MR, McHutchison JG. Diuresis increases ascitic fluid opsonic activity in patients who survive spontaneous bacterial peritonitis. J Hepatol 1992;14:249-252.

236. Bernard B, Grangé JD, Khac EN, Amiot X, Opolon P, Poynard T. Antibiotic prophylaxis for the prevention of bacterial infections in cirrhotic patients with gastrointestinal bleeding: a meta-analysis. Hepatology 1999;29:1655-1661.

237. Goulis J, Armonis A, Patch D, Sabin C, Greenslade L, Burroughs AK. Bacterial infection is independently associated with failure to control bleeding in cirrhotic patients with gastrointestinal hemorrhage. Hepatology 1998;27:1207-1212.

238. Vivas S, Rodriguez M, Palacio MA, Linares $A$, Alonso JL, Rodrigo L. Presence of bacterial infection in bleeding cirrhotic patients is independently associated with early mortality and failure to control bleeding. Dig Dis Sci 2001;46:2752-2757.

239. Chavez-Tapia NC, Barrientos-Gutierrez T, Tellez-Avila F, SoaresWeiser K, Mendez-Sanchez N, Gluud C, et al. Meta-analysis: antibiotic prophylaxis for cirrhotic patients with upper gastrointestinal bleeding - an updated Cochrane review. Aliment Pharmacol Ther 2011;34:509-518.

240. Soriano G, Guarner C, Tomás A, Villanueva C, Torras X, González D, et al. Norfloxacin prevents bacterial infection in cirrhotics with gastrointestinal hemorrhage. Gastroenterology 1992;103:1267-1272.

241. Fernández J, Ruiz del Arbol L, Gómez C, Durandez R, Serradilla R, Guarner $C$, et al. Norfloxacin vs ceftriaxone in the prophylaxis of infections in patients with advanced cirrhosis and hemorrhage. Gastroenterology 2006;131:1049-1056; quiz 1285.

242. Llach J, Rimola $A$, Navasa $M$, Ginès $P$, Salmerón JM, Ginès $A$, et al. Incidence and predictive factors of first episode of spontaneous bacterial peritonitis in cirrhosis with ascites: relevance of ascitic fluid protein concentration. Hepatology 1992;16:724-727.

243. Andreu M, Sola R, Sitges-Serra A, Alia C, Gallen M, Vila MC, et al. Risk factors for spontaneous bacterial peritonitis in cirrhotic patients with ascites. Gastroenterology 1993;104:1133-1138.

244. Guarner C, Solà R, Soriano G, Andreu M, Novella MT, Vila MC, et al. Risk of a first community-acquired spontaneous bacterial peritonitis in cirrhotics with low ascitic fluid protein levels. Gastroenterology 1999;117:414-419.

245. Grangé JD, Roulot D, Pelletier G, Pariente EA, Denis J, Ink O, et al. Norfloxacin primary prophylaxis of bacterial infections in cirrhotic patients with ascites: a double-blind randomized trial. J Hepatol 1998;29:430-436.

246. Terg R, Fassio E, Guevara M, Cartier M, Longo C, Lucero R, et al. Ciprofloxacin in primary prophylaxis of spontaneous bacterial peritonitis: a randomized, placebo-controlled study. J Hepatol 2008:48:774-779.

247. Fernández J, Navasa M, Planas R, Montoliu S, Monfort D, Soriano $G$, et al. Primary prophylaxis of spontaneous bacterial peritonitis delays hepatorenal syndrome and improves survival in cirrhosis. Gastroenterology 2007;133:818-824.

248. Hanouneh MA, Hanouneh IA, Hashash JG, Law R, Esfeh JM, Lopez $R$, et al. The role of rifaximin in the primary prophylaxis of spontaneous bacterial peritonitis in patients with liver cirrhosis. J Clin Gastroenterol 2012;46:709-715.

249. Vlachogiannakos J, Viazis N, Vasianopoulou P, Vafiadis I, Karamanolis DG, Ladas SD. Long-term administration of rifaximin improves the prognosis of patients with decompensated alcoholic cirrhosis. J Gastroenterol Hepatol 2013;28:450-455.

250. Kang SH, Lee YB, Lee JH, Nam JY, Chang Y, Cho H, et al. Rifaximin treatment is associated with reduced risk of cirrhotic complications and prolonged overall survival in patients experiencing hepatic encephalopathy. Aliment Pharmacol Ther 2017;46:845-855.

251. Lutz P, Parcina M, Bekeredjian-Ding I, Nischalke HD, Nattermann J, Sauerbruch $T$, et al. Impact of rifaximin on the frequency and characteristics of spontaneous bacterial peritonitis in patients with liver cirrhosis and ascites. PLoS One 2014;9:e93909.

252. Titó L, Rimola A, Ginès P, Llach J, Arroyo V, Rodés J. Recurrence of spontaneous bacterial peritonitis in cirrhosis: frequency and predictive factors. Hepatology 1988;8:27-31.

253. Ginés P, Rimola A, Planas R, Vargas V, Marco F, Almela M, et al. Norfloxacin prevents spontaneous bacterial peritonitis recurrence in cirrhosis: results of a double-blind, placebo-controlled trial. Hepatology 1990;12(4 Pt 1):716-724

254. Bauer TM, Follo A, Navasa M, Vila J, Planas R, Clemente G, et al. Daily norfloxacin is more effective than weekly rufloxacin in prevention of spontaneous bacterial peritonitis recurrence. Dig Dis Sci 2002;47:1356-1361

255. Lontos S, Shelton E, Angus PW, Vaughan R, Roberts SK, Gordon A, et al. A randomized controlled study of trimethoprim-sulfamethoxazole versus norfloxacin for the prevention of infection in cirrhotic patients. J Dig Dis 2014;15:260-267.

256. Elfert A, Abo Ali L, Soliman S, Ibrahim S, Abd-Elsalam S. Randomized-controlled trial of rifaximin versus norfloxacin for secondary prophylaxis of spontaneous bacterial peritonitis. Eur J Gastroenterol Hepatol 2016;28:1450-1454.

257. Garcia-Tsao G, Parikh CR, Viola A. Acute kidney injury in cirrhosis. Hepatology 2008;48:2064-2077.

258. Choi YJ, Kim JH, Koo JK, Lee Cl, Lee JY, Yang JH, et al. Prevalence of renal dysfunction in patients with cirrhosis according to ADQI- 
The Korean Association for the Study of the Liver (KASL)

Treatment guideline for ascites and related complications

IAC working party proposal. Clin Mol Hepatol 2014;20:185-191.

259. Cárdenas $A$, Ginès $P$, Uriz J, Bessa X, Salmerón JM, Mas $A$, et al. Renal failure after upper gastrointestinal bleeding in cirrhosis: incidence, clinical course, predictive factors, and short-term prognosis. Hepatology 2001;34(4 Pt 1):671-676.

260. Belcher JM, Garcia-Tsao G, Sanyal AJ, Bhogal H, Lim JK, Ansari N, et al. Association of AKI with mortality and complications in hospitalized patients with cirrhosis. Hepatology 2013;57:753-762.

261. Bucsics T, Mandorfer M, Schwabl P, Bota S, Sieghart W, Ferlitsch A, et al. Impact of acute kidney injury on prognosis of patients with liver cirrhosis and ascites: a retrospective cohort study. J Gastroenterol Hepatol 2015;30:1657-1665.

262. Tsien CD, Rabie R, Wong F. Acute kidney injury in decompensated cirrhosis. Gut 2013;62:131-137.

263. Salerno F, Gerbes A, Ginès $P$, Wong F, Arroyo V. Diagnosis, prevention and treatment of hepatorenal syndrome in cirrhosis. Gut 2007:56:1310-1318.

264. Tan HK, Marguez M, Wong F, Renner EL. Pretransplant type 2 hepatorenal syndrome is associated with persistently impaired renal function after liver transplantation. Transplantation 2015;99:14411446.

265. Gonwa TA, Klintmalm GB, Levy M, Jennings LS, Goldstein RM, Husberg BS. Impact of pretransplant renal function on survival after liver transplantation. Transplantation 1995;59:361-365.

266. Warner NS, Cuthbert JA, Bhore R, Rockey DC. Acute kidney injury and chronic kidney disease in hospitalized patients with cirrhosis. J Investig Med 2011;59:1244-1251.

267. Wong F. Recent advances in our understanding of hepatorenal syndrome. Nat Rev Gastroenterol Hepatol 2012;9:382-391.

268. Schrier RW, Arroyo V, Bernardi M, Epstein M, Henriksen JH, Rodés J. Peripheral arterial vasodilation hypothesis: a proposal for the initiation of renal sodium and water retention in cirrhosis. Hepatology 1988;8:1151-1157.

269. Ruiz-del-Arbol L, Monescillo A, Arocena C, Valer P, Ginès P, Moreira $V$, et al. Circulatory function and hepatorenal syndrome in cirrhosis. Hepatology 2005;42:439-447.

270. Arroyo V, Colmenero J. Ascites and hepatorenal syndrome in cirrhosis: pathophysiological basis of therapy and current management. J Hepatol 2003;38 Suppl 1:S69-S89.

271. Ruíz-del-Árbol L, Achécar L, Serradilla R, Rodríguez-Gandía MÁ, Rivero $M$, Garrido $E$, et al. Diastolic dysfunction is a predictor of poor outcomes in patients with cirrhosis, portal hypertension, and a normal creatinine. Hepatology 2013;58:1732-1741.

272. Acevedo J, Fernández J, Prado V, Silva A, Castro M, Pavesi M, et al. Relative adrenal insufficiency in decompensated cirrhosis: relation- ship to short-term risk of severe sepsis, hepatorenal syndrome, and death. Hepatology 2013;58:1757-1765.

273. Kim G, Huh JH, Lee KJ, Kim MY, Shim KY, Baik SK. Relative adrenal insufficiency in patients with cirrhosis: a systematic review and meta-analysis. Dig Dis Sci 2017;62:1067-1079.

274. Schrier RW, Shchekochikhin D, Ginès P. Renal failure in cirrhosis: prerenal azotemia, hepatorenal syndrome and acute tubular necrosis. Nephrol Dial Transplant 2012;27:2625-2628.

275. Low G, Alexander GJ, Lomas DJ. Renal impairment in cirrhosis unrelated to hepatorenal syndrome. Can J Gastroenterol Hepatol 2015;29:253-257.

276. Wong F. Acute kidney injury in liver cirrhosis: new definition and application. Clin Mol Hepatol 2016;22:415-422.

277. Orlando R, Floreani M, Padrini R, Palatini P. Evaluation of measured and calculated creatinine clearances as glomerular filtration markers in different stages of liver cirrhosis. Clin Nephrol 1999;51:341347.

278. Sherman DS, Fish DN, Teitelbaum I. Assessing renal function in cirrhotic patients: problems and pitfalls. Am J Kidney Dis 2003:41:269-278.

279. Caregaro L, Menon F, Angeli P, Amodio P, Merkel C, Bortoluzzi A, et al. Limitations of serum creatinine level and creatinine clearance as filtration markers in cirrhosis. Arch Intern Med 1994;154:201205.

280. Spencer K. Analytical reviews in clinical biochemistry: the estimation of creatinine. Ann Clin Biochem 1986;23 (Pt 1):1-25.

281. Kim DJ, Kang HS, Choi HS, Cho HJ, Kim ES, Keum B, et al. Serum cystatin $C$ level is a useful marker for the evaluation of renal function in patients with cirrhotic ascites and normal serum creatinine levels. Korean J Hepatol 2011;17:130-138.

282. Angeli $P$, Gines $P$, Wong $F$, Bernardi $M$, Boyer TD, Gerbes $A$, et al. Diagnosis and management of acute kidney injury in patients with cirrhosis: revised consensus recommendations of the International Club of Ascites. Gut 2015;64:531-537.

283. Bellomo R, Ronco C, Kellum JA, Mehta RL, Palevsky P; Acute Dialysis Quality Initiative workgroup. Acute renal failure - definition, outcome measures, animal models, fluid therapy and information technology needs: the Second International Consensus Conference of the Acute Dialysis Quality Initiative (ADQI) Group. Crit Care 2004:8:R204-R212.

284. Jenq CC, Tsai MH, Tian YC, Lin CY, Yang C, Liu NJ, et al. RIFLE classification can predict short-term prognosis in critically ill cirrhotic patients. Intensive Care Med 2007;33:1921-1930.

285. Cholongitas E, Calvaruso V, Senzolo M, Patch D, Shaw S, O'Beirne J, et al. RIFLE classification as predictive factor of mortality in pa- 
tients with cirrhosis admitted to intensive care unit. J Gastroenterol Hepatol 2009;24:1639-1647.

286. Mehta RL, Kellum JA, Shah SV, Molitoris BA, Ronco C, Warnock $D G$, et al. Acute Kidney Injury Network: report of an initiative to improve outcomes in acute kidney injury. Crit Care 2007;11:R31.

287. Lassnigg A, Schmidlin D, Mouhieddine M, Bachmann LM, Druml W, Bauer $\mathrm{P}$, et al. Minimal changes of serum creatinine predict prognosis in patients after cardiothoracic surgery: a prospective cohort study. J Am Soc Nephrol 2004;15:1597-1605.

288. Tu KH, Jenq CC, Tsai MH, Hsu HH, Chang MY, Tian YC, et al. Outcome scoring systems for short-term prognosis in critically ill cirrhotic patients. Shock 2011;36:445-450.

289. Radhakrishnan J, Cattran DC. The KDIGO practice guideline on glomerulonephritis: reading between the (guide)lines--application to the individual patient. Kidney Int 2012;82:840-856.

290. Pan HC, Chien YS, Jenq CC, Tsai MH, Fan PC, Chang CH, et al. Acute kidney injury classification for critically III cirrhotic patients: a comparison of the KDIGO, AKIN, and RIFLE classifications. Sci Rep 2016;6:23022.

291. Angeli P, Gatta A, Caregaro L, Menon F, Sacerdoti D, Merkel C, et al. Tubular site of renal sodium retention in ascitic liver cirrhosis evaluated by lithium clearance. Eur J Clin Invest 1990;20:111-117.

292. Francoz C, Prié D, Abdelrazek W, Moreau R, Mandot A, Belghiti $J$, et al. Inaccuracies of creatinine and creatinine-based equations in candidates for liver transplantation with low creatinine: impact on the model for end-stage liver disease score. Liver Transpl 2010;16:1169-1177.

293. Rosi S, Piano S, Frigo AC, Morando F, Fasolato S, Cavallin M, et al. New ICA criteria for the diagnosis of acute kidney injury in cirrhotic patients: can we use an imputed value of serum creatinine? Liver Int 2015;35:2108-2114.

294. Wong F, O'Leary JG, Reddy KR, Patton H, Kamath PS, Fallon MB, et al. New consensus definition of acute kidney injury accurately predicts 30-day mortality in patients with cirrhosis and infection. Gastroenterology 2013;145:1280-1288.e1.

295. Trawalé JM, Paradis V, Rautou PE, Francoz C, Escolano S, Sallée $M$, et al. The spectrum of renal lesions in patients with cirrhosis: a clinicopathological study. Liver Int 2010;30:725-732.

296. Boyer TD, Sanyal AJ, Garcia-Tsao G, Blei A, Carl D, Bexon AS, et al. Predictors of response to terlipressin plus albumin in hepatorenal syndrome (HRS) type 1: relationship of serum creatinine to hemodynamics. J Hepatol 2011;55:315-321.

297. Rodríguez E, Elia C, Solà E, Barreto R, Graupera I, Andrealli A, et al. Terlipressin and albumin for type-1 hepatorenal syndrome associated with sepsis. J Hepatol 2014;60:955-961.
298. Thévenot T, Bureau C, Oberti F, Anty R, Louvet A, Plessier A, et al. Effect of albumin in cirrhotic patients with infection other than spontaneous bacterial peritonitis. A randomized trial. J Hepatol 2015;62:822-830.

299. Nadim MK, Kellum JA, Davenport A, Wong F, Davis C, Pannu N, et al. Hepatorenal syndrome: the 8th International Consensus Conference of the Acute Dialysis Quality Initiative (ADQI) Group. Crit Care 2012;16:R23.

300. Belcher JM, Sanyal AJ, Peixoto AJ, Perazella MA, Lim J, ThiessenPhilbrook $\mathrm{H}$, et al. Kidney biomarkers and differential diagnosis of patients with cirrhosis and acute kidney injury. Hepatology 2014;60:622-632.

301. Sola-Vera J, Miñana J, Ricart E, Planella M, González B, Torras X, et al. Randomized trial comparing albumin and saline in the prevention of paracentesis-induced circulatory dysfunction in cirrhotic patients with ascites. Hepatology 2003;37:1147-1153.

302. Elia C, Graupera I, Barreto R, Solà E, Moreira R, Huelin P, et al. Severe acute kidney injury associated with non-steroidal antiinflammatory drugs in cirrhosis: a case-control study. J Hepatol 2015;63:593-600

303. Akriviadis E, Botla R, Briggs W, Han S, Reynolds T, Shakil O. Pentoxifylline improves short-term survival in severe acute alcoholic hepatitis: a double-blind, placebo-controlled trial. Gastroenterology 2000;119:1637-1648.

304. Thursz MR, Richardson P, Allison M, Austin A, Bowers M, Day CP, et al. Prednisolone or pentoxifylline for alcoholic hepatitis. N Engl J Med 2015;372:1619-1628.

305. Dong T, Aronsohn A, Gautham Reddy K, Te HS. Rifaximin decreases the incidence and severity of acute kidney injury and hepatorenal syndrome in cirrhosis. Dig Dis Sci 2016;61:3621-3626.

306. Sharma BC, Sharma P, Lunia MK, Srivastava S, Goyal R, Sarin SK. A randomized, double-blind, controlled trial comparing rifaximin plus lactulose with lactulose alone in treatment of overt hepatic encephalopathy. Am J Gastroenterol 2013;108:1458-1463.

307. Salerno F, Navickis RJ, Wilkes MM. Albumin treatment regimen for type 1 hepatorenal syndrome: a dose-response meta-analysis. BMC Gastroenterol 2015;15:167.

308. Wong F. Drug insight: the role of albumin in the management of chronic liver disease. Nat Clin Pract Gastroenterol Hepatol 2007:4:43-51.

309. Garcia-Martinez R, Caraceni P, Bernardi M, Gines P, Arroyo V, Jalan R. Albumin: pathophysiologic basis of its role in the treatment of cirrhosis and its complications. Hepatology 2013;58:1836-1846.

310. Garcia-Martinez R, Noiret L, Sen S, Mookerjee R, Jalan R. Albumin infusion improves renal blood flow autoregulation in patients with 
The Korean Association for the Study of the Liver (KASL)

Treatment guideline for ascites and related complications

acute decompensation of cirrhosis and acute kidney injury. Liver Int 2015;35:335-343.

311. Neri S, Pulvirenti D, Malaguarnera M, Cosimo BM, Bertino G, Ignaccolo $L$, et al. Terlipressin and albumin in patients with cirrhosis and type I hepatorenal syndrome. Dig Dis Sci 2008;53:830-835.

312. Martín-Llahí M, Pépin MN, Guevara M, Díaz F, Torre A, Monescillo $A$, et al. Terlipressin and albumin vs albumin in patients with cirrhosis and hepatorenal syndrome: a randomized study. Gastroenterology 2008;134:1352-1359.

313. Ortega $R$, Ginès $P$, Uriz J, Cárdenas $A$, Calahorra $B$, De Las Heras $D$, et al. Terlipressin therapy with and without albumin for patients with hepatorenal syndrome: results of a prospective, nonrandomized study. Hepatology 2002;36(4 Pt 1):941-948.

314. Rodriguez E, Henrique Pereira G, Solà E, Elia C, Barreto R, Pose E, et al. Treatment of type 2 hepatorenal syndrome in patients awaiting transplantation: effects on kidney function and transplantation outcomes. Liver Transpl 2015;21:1347-1354.

315. Sanyal AJ, Boyer T, Garcia-Tsao G, Regenstein F, Rossaro L, Appenrodt $B$, et al. A randomized, prospective, double-blind, placebocontrolled trial of terlipressin for type 1 hepatorenal syndrome. Gastroenterology 2008;134:1360-1368.

316. Sanyal AJ, Boyer TD, Frederick RT, Wong F, Rossaro L, Araya V, et al. Reversal of hepatorenal syndrome type 1 with terlipressin plus albumin vs. placebo plus albumin in a pooled analysis of the OT0401 and REVERSE randomised clinical studies. Aliment Pharmacol Ther 2017;45:1390-1402.

317. Egerod Israelsen M, Gluud LL, Krag A. Acute kidney injury and hepatorenal syndrome in cirrhosis. J Gastroenterol Hepatol 2015;30:236-243.

318. Cavallin M, Piano S, Romano A, Fasolato S, Frigo AC, Benetti G, et al. Terlipressin given by continuous intravenous infusion versus intravenous boluses in the treatment of hepatorenal syndrome: a randomized controlled study. Hepatology 2016;63:983-992.

319. Nazar A, Pereira GH, Guevara M, Martín-Llahi M, Pepin MN, Marinelli $\mathrm{M}$, et al. Predictors of response to therapy with terlipressin and albumin in patients with cirrhosis and type 1 hepatorenal syndrome. Hepatology 2010;51:219-226.

320. Facciorusso A, Chandar AK, Murad MH, Prokop LJ, Muscatiello N, Kamath PS, et al. Comparative efficacy of pharmacological strategies for management of type 1 hepatorenal syndrome: a systematic review and network meta-analysis. Lancet Gastroenterol Hepatol 2017;2:94-102.

321. Sharma P, Kumar A, Shrama BC, Sarin SK. An open label, pilot, randomized controlled trial of noradrenaline versus terlipressin in the treatment of type 1 hepatorenal syndrome and predictors of response. Am J Gastroenterol 2008;103:1689-1697.

322. Singh V, Ghosh S, Singh B, Kumar P, Sharma N, Bhalla A, et al. Noradrenaline vs. terlipressin in the treatment of hepatorenal syndrome: a randomized study. J Hepatol 2012;56:1293-1298.

323. Nassar Junior AP, Farias AQ, D' Albuquerque LA, Carrilho FJ, Malbouisson $L M$. Terlipressin versus norepinephrine in the treatment of hepatorenal syndrome: a systematic review and meta-analysis. PLoS One 2014;9:e107466.

324. Nadim MK, Durand F, Kellum JA, Levitsky J, O'Leary JG, Karvellas CJ, et al. Corrigendum to "Management of the critically ill patients with cirrhosis: a multidisciplinary perspective". J Hepatol 2016 May 27. pii: S0168-8278(16)30185-4. doi: 10.1016/j.jhep.2016.05.001. [Epub ahead of print].

325. Wong F, Pantea L, Sniderman K. Midodrine, octreotide, albumin, and TIPS in selected patients with cirrhosis and type 1 hepatorenal syndrome. Hepatology 2004;40:55-64.

326. Esrailian E, Pantangco ER, Kyulo NL, Hu KQ, Runyon BA. Octreotide/midodrine therapy significantly improves renal function and 30-day survival in patients with type 1 hepatorenal syndrome. Dig Dis Sci 2007; 52:742-748.

327. Skagen C, Einstein M, Lucey MR, Said A. Combination treatment with octreotide, midodrine, and albumin improves survival in patients with type 1 and type 2 hepatorenal syndrome. J Clin Gastroenterol 2009;43:680-685.

328. Cavallin M, Kamath PS, Merli M, Fasolato S, Toniutto P, Salerno $F$, et al. Terlipressin plus albumin versus midodrine and octreotide plus albumin in the treatment of hepatorenal syndrome: a randomized trial. Hepatology 2015;62:567-574.

329. Wong LP, Blackley MP, Andreoni KA, Chin H, Falk RJ, Klemmer PJ. Survival of liver transplant candidates with acute renal failure receiving renal replacement therapy. Kidney Int 2005;68:362-370.

330. Zhang Z, Maddukuri G, Jaipaul N, Cai CX. Role of renal replacement therapy in patients with type 1 hepatorenal syndrome receiving combination treatment of vasoconstrictor plus albumin. J Crit Care 2015;30:969-974.

331. Guevara $M$, Ginès $P$, Bandi JC, Gilabert $R$, Sort $P$, Jiménez $W$, et al. Transjugular intrahepatic portosystemic shunt in hepatorenal syndrome: effects on renal function and vasoactive systems. Hepatology 1998;28:416-422.

332. Rössle M, Gerbes AL. TIPS for the treatment of refractory ascites, hepatorenal syndrome and hepatic hydrothorax: a critical update. Gut 2010;59:988-1000.

333. Brensing KA, Textor J, Perz J, Schiedermaier P, Raab P, Strunk H, et al. Long term outcome after transjugular intrahepatic portosystemic stent-shunt in non-transplant cirrhotics with hepatorenal 
syndrome: a phase II study. Gut 2000;47:288-295.

334. Senzolo M, Cholongitas E, Tibballs J, Burroughs A, Patch D. Transjugular intrahepatic portosystemic shunt in the management of ascites and hepatorenal syndrome. Eur J Gastroenterol Hepatol 2006;18:1143-1150.

335. Wong F, Sniderman K, Liu P, Allidina Y, Sherman M, Blendis L. Transjugular intrahepatic portosystemic stent shunt: effects on hemodynamics and sodium homeostasis in cirrhosis and refractory ascites. Ann Intern Med 1995;122:816-822.

336. Trebicka J. Emergency TIPS in a child-pugh B patient: when does the window of opportunity open and close? J Hepatol 2017;66:442-450.

337. Jalan R, Sen S, Steiner C, Kapoor D, Alisa A, Williams R. Extracorporeal liver support with molecular adsorbents recirculating system in patients with severe acute alcoholic hepatitis. J Hepatol 2003;38:24-31.

338. Mitzner SR, Stange J, Klammt S, Risler T, Erley CM, Bader BD, et al. Improvement of hepatorenal syndrome with extracorporeal albumin dialysis MARS: results of a prospective, randomized, controlled clinical trial. Liver Transpl 2000;6:277-286.

339. Wong F, Raina N, Richardson R. Molecular adsorbent recirculating system is ineffective in the management of type 1 hepatorenal syndrome in patients with cirrhosis with ascites who have failed vasoconstrictor treatment. Gut 2010;59:381-386.

340. Nair S, Verma S, Thuluvath PJ. Pretransplant renal function predicts survival in patients undergoing orthotopic liver transplantation. Hepatology 2002;35:1179-1185.

341. Marik PE, Wood K, Starzl TE. The course of type 1 hepato-renal syndrome post liver transplantation. Nephrol Dial Transplant 2006;21:478-482.

342. Wong F, Leung W, Al Beshir M, Marquez M, Renner EL. Outcomes of patients with cirrhosis and hepatorenal syndrome type 1 treated with liver transplantation. Liver Transpl 2015;21:300-307.

343. Boyer TD, Sanyal AJ, Garcia-Tsao G, Regenstein F, Rossaro L, Appenrodt $B$, et al. Impact of liver transplantation on the survival of patients treated for hepatorenal syndrome type 1. Liver Transpl 2011;17:1328-1332.

344. Goldaracena N, Marquez M, Selzner N, Spetzler VN, Cattral MS, Greig PD, et al. Living vs. deceased donor liver transplantation provides comparable recovery of renal function in patients with hepatorenal syndrome: a matched case-control study. Am J Transplant 2014;14:2788-2795.

345. Lee JP, Kwon HY, Park JI, Yi NJ, Suh KS, Lee HW, et al. Clinical outcomes of patients with hepatorenal syndrome after living donor liver transplantation. Liver Transpl 2012;18:1237-1244.
346. Malagari K, Nikita A, Alexopoulou E, Brountzos E, Papathanasiou M, Mitromaras J, et al. Cirrhosis-related intrathoracic disease. Imaging features in 1038 patients. Hepatogastroenterology 2005;52:558-562.

347. Strauss RM, Boyer TD. Hepatic hydrothorax. Semin Liver Dis 1997;17:227-232.

348. Huang PM, Chang YL, Yang CY, Lee YC. The morphology of diaphragmatic defects in hepatic hydrothorax: thoracoscopic finding. J Thorac Cardiovasc Surg 2005;130:141-145.

349. Machicao VI, Balakrishnan M, Fallon MB. Pulmonary complications in chronic liver disease. Hepatology 2014;59:1627-1637.

350. Mirouze D, Juttner HU, Reynolds TB. Left pleural effusion in patients with chronic liver disease and ascites. Prospective study of 22 cases. Dig Dis Sci 1981;26:984-988.

351. Xiol X, Castellote J, Cortes-Beut R, Delgado M, Guardiola J, Sesé E. Usefulness and complications of thoracentesis in cirrhotic patients. Am J Med 2001;111:67-69.

352. Gurung P, Goldblatt M, Huggins JT, Doelken P, Nietert PJ, Sahn SA. Pleural fluid analysis and radiographic, sonographic, and echocardiographic characteristics of hepatic hydrothorax. Chest 2011;140:448-453.

353. Xiol X, Castellvi JM, Guardiola J, Sesé E, Castellote J, Perelló A, et al. Spontaneous bacterial empyema in cirrhotic patients: a prospective study. Hepatology 1996;23:719-723.

354. Chen TA, Lo GH, Lai KH. Risk factors for spontaneous bacterial empyema in cirrhotic patients with hydrothorax. J Chin Med Assoc 2003:66:579-586.

355. Sese E, Xiol X, Castellote J, Rodríguez-Fariñas E, Tremosa G. Low complement levels and opsonic activity in hepatic hydrothorax: its relationship with spontaneous bacterial empyema. J Clin Gastroenterol 2003;36:75-77.

356. Xiol X, Tremosa G, Castellote J, Gornals J, Lama C, Lopez C, et al. Liver transplantation in patients with hepatic hydrothorax. Transpl Int 2005;18:672-675.

357. Feller-Kopman D, Berkowitz D, Boiselle P, Ernst A. Large-volume thoracentesis and the risk of reexpansion pulmonary edema. Ann Thorac Surg 2007;84:1656-1661.

358. Siegerstetter $V$, Deibert P, Ochs A, Olschewski M, Blum HE, Rössle $M$. Treatment of refractory hepatic hydrothorax with transjugular intrahepatic portosystemic shunt: long-term results in 40 patients. Eur J Gastroenterol Hepatol 2001;13:529-534.

359. Gordon FD, Anastopoulos HT, Crenshaw W, Gilchrist B, McEniff N, Falchuk KR, et al. The successful treatment of symptomatic, refractory hepatic hydrothorax with transjugular intrahepatic portosystemic shunt. Hepatology 1997;25:1366-1369. 
The Korean Association for the Study of the Liver (KASL)

Treatment guideline for ascites and related complications

360. Dhanasekaran R, West JK, Gonzales PC, Subramanian R, Parekh S, Spivey JR, et al. Transjugular intrahepatic portosystemic shunt for symptomatic refractory hepatic hydrothorax in patients with cirrhosis. Am J Gastroenterol 2010;105:635-641.

361. Spencer EB, Cohen DT, Darcy MD. Safety and efficacy of transjugular intrahepatic portosystemic shunt creation for the treatment of hepatic hydrothorax. J Vasc Interv Radiol 2002;13:385-390.

362. Chalasani N, Clark WS, Martin LG, Kamean J, Khan MA, Patel NH, et al. Determinants of mortality in patients with advanced cirrhosis after transjugular intrahepatic portosystemic shunting. Gastroenterology 2000;118:138-144.

363. Milanez de Campos JR, Filho LO, de Campos Werebe E, Sette H Jr, Fernandez A, Filomeno LT, et al. Thoracoscopy and talc poudrage in the management of hepatic hydrothorax. Chest 2000;118:13-17.

364. Ferrante D, Arguedas MR, Cerfolio RJ, Collins BG, van Leeuwen DJ. Video-assisted thoracoscopic surgery with talc pleurodesis in the management of symptomatic hepatic hydrothorax. Am J Gastroenterol 2002;97:3172-3175.

365. Runyon BA, Greenblatt M, Ming RH. Hepatic hydrothorax is a relative contraindication to chest tube insertion. Am J Gastroenterol 1986;81:566-567.

366. Orman ES, Lok AS. Outcomes of patients with chest tube insertion for hepatic hydrothorax. Hepatol Int 2009;3:582-586.

367. Singh A, Bajwa A, Shujaat A. Evidence-based review of the management of hepatic hydrothorax. Respiration 2013;86:155-173.

368. Baker EM, Melander S. Management of recurrent pleural effusions with a tunneled catheter. Heart Lung 2010;39:314-318.

369. Chalhoub M, Harris K, Castellano M, Maroun R, Bourjeily G. The use of the pleurX catheter in the management of non-malignant pleural effusions. Chron Respir Dis 2011;8:185-191.

370. Herlihy JP, Loyalka P, Gnananandh J, Gregoric ID, Dahlberg CG, Kar $B$, et al. PleurX catheter for the management of refractory pleural effusions in congestive heart failure. Tex Heart Inst J 2009;36:3843.

371. Belghiti J, Durand F. Abdominal wall hernias in the setting of cirrhosis. Semin Liver Dis 1997;17:219-226.

372. Odom SR, Gupta A, Talmor D, Novack V, Sagy I, Evenson AR. Emergency hernia repair in cirrhotic patients with ascites. J Trauma Acute Care Surg 2013;75:404-409.

373. Yu BC, Chung M, Lee $G$. The repair of umbilical hernia in cirrhotic patients: 18 consecutive case series in a single institute. Ann Surg Treat Res 2015;89:87-91.

374. Hur YH, Kim JC, Kim DY, Kim SK, Park CY. Inguinal hernia repair in patients with liver cirrhosis accompanied by ascites. J Korean Surg Soc 2011;80:420-425.
375. Runyon BA, Juler GL. Natural history of repaired umbilical hernias in patients with and without ascites. Am J Gastroenterol 1985;80:38-39.

376. Telem DA, Schiano T, Divino CM. Complicated hernia presentation in patients with advanced cirrhosis and refractory ascites: management and outcome. Surgery 2010;148:538-543.

377. Lewis JH, Stine JG. Review article: prescribing medications in patients with cirrhosis - a practical guide. Aliment Pharmacol Ther 2013:37:1132-1156.

378. Verbeeck RK. Pharmacokinetics and dosage adjustment in patients with hepatic dysfunction. Eur J Clin Pharmacol 2008;64:1147-1161.

379. Elbekai RH, Korashy HM, El-Kadi AO. The effect of liver cirrhosis on the regulation and expression of drug metabolizing enzymes. Curr Drug Metab 2004;5:157-167.

380. Krähenbühl S, Reichen J. Pharmacokinetics and pharmacodynamics in cirrhosis. Medicine 2002;30:24-27.

381. Villeneuve JP, Verbeeck RK, Wilkinson GR, Branch RA. Furosemide kinetics and dynamics in patients with cirrhosis. Clin Pharmacol Ther 1986;40:14-20.

382. Chalasani N, Gorski JC, Patel NH, Hall SD, Galinsky RE. Hepatic and intestinal cytochrome P450 3A activity in cirrhosis: effects of transjugular intrahepatic portosystemic shunts. Hepatology 2001;34:1103-1108.

383. Vuppalanchi R, Juluri R, Ghabril M, Kim S, Thong N, Gorski JC, et al. Drug-induced QT prolongation in cirrhotic patients with transjugular intrahepatic portosystemic shunt. J Clin Gastroenterol 2011;45:638-642

384. Hong YM, Yoon KT, Heo J, Woo HY, Lim W, An DS, et al. The prescription pattern of acetaminophen and non-steroidal antiinflammatory drugs in patients with liver cirrhosis. J Korean Med Sci 2016;31:1604-1610.

385. Ahn BM. Acetaminophen-induced acute hepatic failure. J Korean Med Assoc 2006:49:846-883.

386. Manyike PT, Kharasch ED, Kalhorn TF, Slattery JT. Contribution of CYP2E1 and CYP3A to acetaminophen reactive metabolite formation. Clin Pharmacol Ther 2000;67:275-282.

387. Chandok N, Watt KD. Pain management in the cirrhotic patient: the clinical challenge. Mayo Clin Proc 2010;85:451-458.

388. De Lédinghen V, Heresbach D, Fourdan O, Bernard P, Liebaert-Bories MP, Nousbaum JB, et al. Anti-inflammatory drugs and variceal bleeding: a case-control study. Gut 1999;44:270-273.

389. Bosilkovska M, Walder B, Besson M, Daali Y, Desmeules J. Analgesics in patients with hepatic impairment: pharmacology and clinical implications. Drugs 2012;72:1645-1669.

390. Clària J, Kent JD, López-Parra M, Escolar G, Ruiz-Del-Arbol L, 
Ginès $P$, et al. Effects of celecoxib and naproxen on renal function in nonazotemic patients with cirrhosis and ascites. Hepatology 2005;41:579-587.

391. Williams RL, Upton RA, Cello JP, Jones RM, Blitstein M, Kelly J, et al. Naproxen disposition in patients with alcoholic cirrhosis. Eur J Clin Pharmacol 1984;27:291-296.

392. Hayes PC, Davis JM, Lewis JA, Bouchier IA. Meta-analysis of value of propranolol in prevention of variceal haemorrhage. Lancet 1990;336:153-156.

393. Homeida M, Jackson L, Roberts CJ. Decreased first-pass metabolism of labetalol in chronic liver disease. Br Med J 1978;2:10481050.

394. Ge PS, Runyon BA. The changing role of beta-blocker therapy in patients with cirrhosis. J Hepatol 2014;60:643-653.

395. Leithead JA, Rajoriya N, Tehami N, Hodson J, Gunson BK, Tripathi $D$, et al. Non-selective $\beta$-blockers are associated with improved survival in patients with ascites listed for liver transplantation. Gut 2015;64:1111-1119.

396. Mookerjee RP, Pavesi M, Thomsen KL, Mehta G, Macnaughtan J, Bendtsen $F$, et al. Treatment with non-selective beta-blockers is associated with reduced severity of systemic inflammation and improved survival of patients with acute-on-chronic liver failure. J Hepatol 2016;64:574-582.

397. Franz CC, Egger S, Born C, Rätz Bravo AE, Krähenbühl S. Potential drug-drug interactions and adverse drug reactions in patients with liver cirrhosis. Eur J Clin Pharmacol 2012;68:179-188.

398. Lucena MI, Andrade RJ, Tognoni G, Hidalgo R, Sanchez de la Cuesta F; Spanish Collaborative Study Group on Therapeutic Management of Liver Diseases. Drug use for non-hepatic associated conditions in patients with liver cirrhosis. Eur J Clin Pharmacol 2003;59:71-76.

399. Gentilini P, Romanelli RG, La Villa G, Maggiore Q, Pesciullesi E, Cappelli G, et al. Effects of low-dose captopril on renal hemodynamics and function in patients with cirrhosis of the liver. Gastroenterology 1993;104:588-594.

400. Pariente EA, Bataille C, Bercoff E, Lebrec D. Acute effects of captopril on systemic and renal hemodynamics and on renal function in cirrhotic patients with ascites. Gastroenterology 1985;88(5 Pt 1):1255-1259.

401. Lewis JH, Mortensen ME, Zweig S, Fusco MJ, Medoff JR, Belder $R$, et al. Efficacy and safety of high-dose pravastatin in hypercholesterolemic patients with well-compensated chronic liver disease: results of a prospective, randomized, double-blind, placebocontrolled, multicenter trial. Hepatology 2007;46:1453-1463.

402. Athyros VG, Tziomalos K, Gossios TD, Griva T, Anagnostis P, Kar-

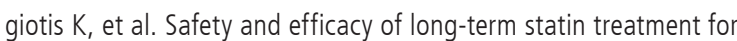
cardiovascular events in patients with coronary heart disease and abnormal liver tests in the Greek Atorvastatin and Coronary Heart Disease Evaluation (GREACE) Study: a post-hoc analysis. Lancet 2010;376:1916-1922.

403. Chang FM, Wang YP, Lang HC, Tsai CF, Hou MC, Lee FY, et al. Statins decrease the risk of decompensation in hepatitis $B$ virusand hepatitis C virus-related cirrhosis: a population-based study. Hepatology 2017;66:896-907.

404. Kim RG, Loomba R, Prokop LJ, Singh S. Statin use and risk of cirrhosis and related complications in patients with chronic liver diseases: a systematic review and meta-analysis. Clin Gastroenterol Hepatol 2017;15:1521-1530.e8.

405. Simon TG, King LY, Zheng $H$, Chung RT. Statin use is associated with a reduced risk of fibrosis progression in chronic hepatitis $C$. J Hepatol 2015;62:18-23.

406. Tsan YT, Lee CH, Wang JD, Chen PC. Statins and the risk of hepatocellular carcinoma in patients with hepatitis B virus infection. J Clin Oncol 2012;30:623-630.

407. Abraldes JG, Villanueva C, Aracil C, Turnes J, Hernandez-Guerra $\mathrm{M}$, Genesca J, et al. Addition of simvastatin to standard therapy for the prevention of variceal rebleeding does not reduce rebleeding but increases survival in patients with cirrhosis. Gastroenterology 2016;150:1160-1170.e3.

408. Drug Information Handbook. 26th ed. Hudson: Wolters Kluwer Clinical Drug Information, Inc., 2017.

409. Dam G, Vilstrup H, Watson H, Jepsen P. Proton pump inhibitors as a risk factor for hepatic encephalopathy and spontaneous bacterial peritonitis in patients with cirrhosis with ascites. Hepatology 2016;64:1265-1272.

410. Xu HB, Wang HD, Li CH, Ye S, Dong MS, Xia QJ, et al. Proton pump inhibitor use and risk of spontaneous bacterial peritonitis in cirrhotic patients: a systematic review and meta-analysis. Genet Mol Res 2015;14:7490-7501.

411. Goel GA, Deshpande A, Lopez R, Hall GS, van Duin D, Carey WD. Increased rate of spontaneous bacterial peritonitis among cirrhotic patients receiving pharmacologic acid suppression. Clin Gastroenterol Hepatol 2012;10:422-427.

412. Deshpande A, Pant C, Pasupuleti V, Rolston DD, Jain A, Deshpande $N$, et al. Association between proton pump inhibitor therapy and Clostridium difficile infection in a meta-analysis. Clin Gastroenterol Hepatol 2012;10:225-233

413. Bajaj JS, Ratliff SM, Heuman DM, Lapane KL. Proton pump inhibitors are associated with a high rate of serious infections in veterans with decompensated cirrhosis. Aliment Pharmacol Ther 
The Korean Association for the Study of the Liver (KASL)

Treatment guideline for ascites and related complications

2012;36:866-874.

414. Tsai CF, Chen MH, Wang YP, Chu CJ, Huang YH, Lin HC, et al. Proton pump inhibitors increase risk for hepatic encephalopathy in patients with cirrhosis in a population study. Gastroenterology
2017;152:134-141.

415. Vaezi MF, Yang YX, Howden CW. Complications of proton pump inhibitor therapy. Gastroenterology 2017;153:35-48. 